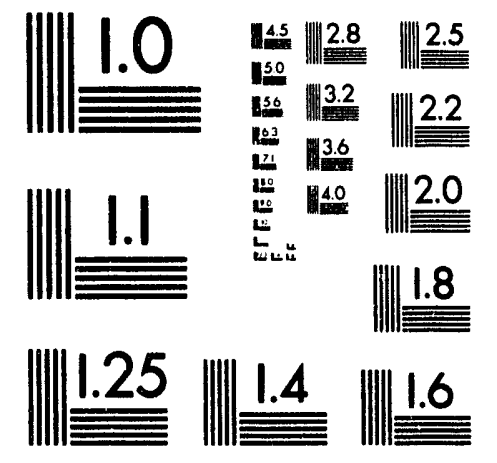



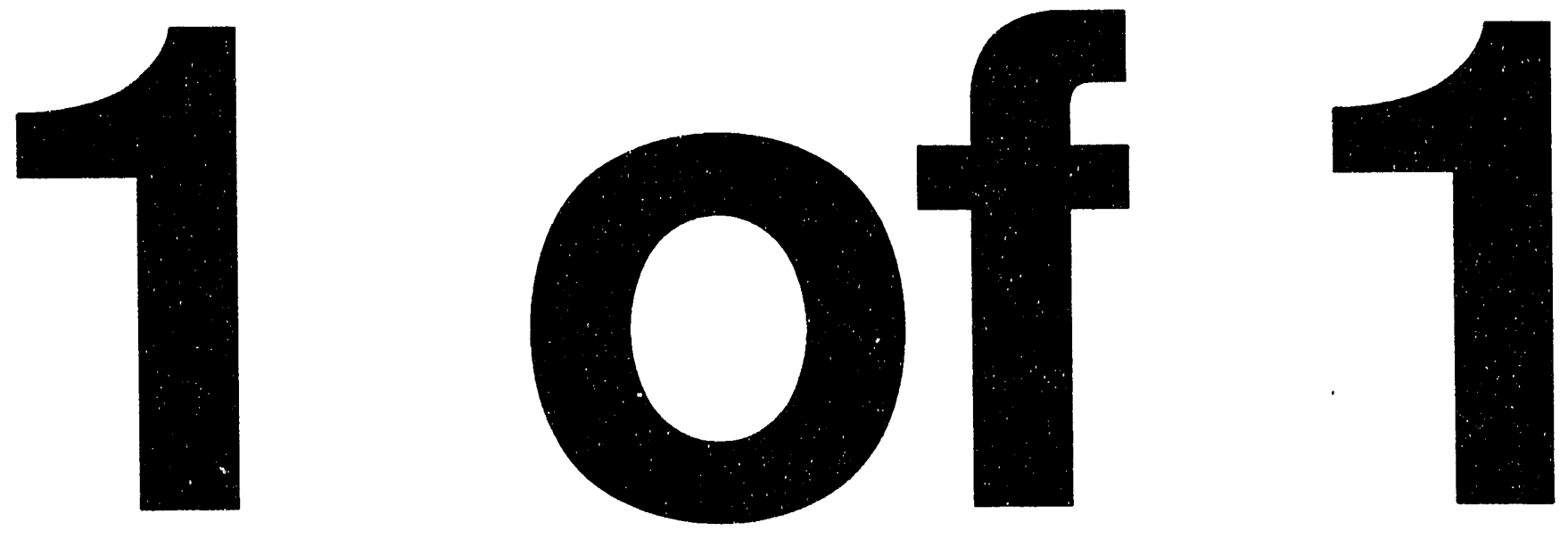


\section{Energy Analysis Program 1992 Annual Report}

Mark D. Levine, Program Leader

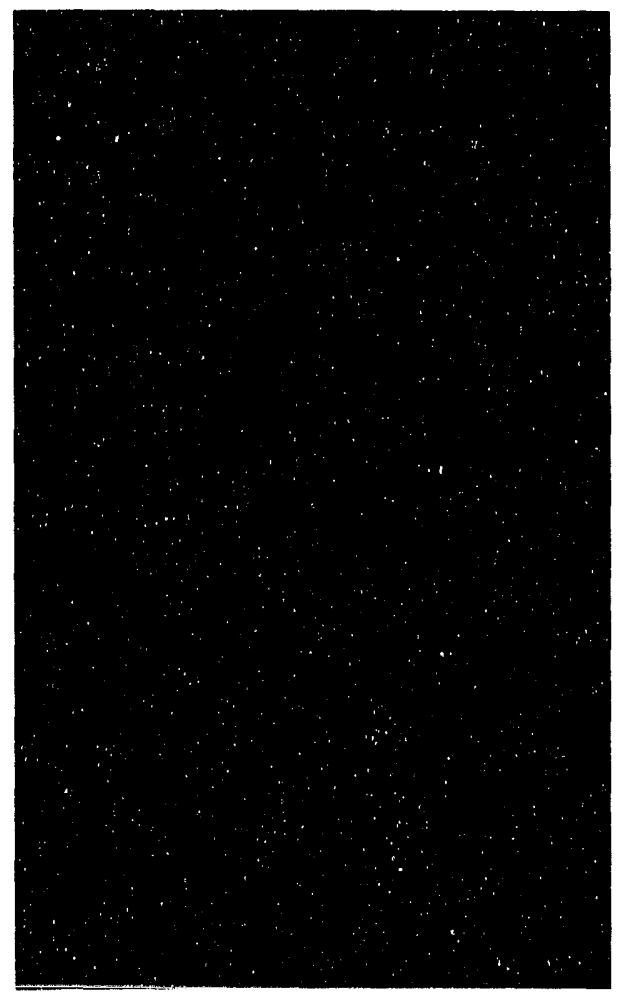

Energy \& Environment Division

Lawrence Berkeley Laboratory

University of California

Berkeley, California 94720

(510) 486-5001

Report No. LBL-33441 


\section{Contents}

Introduction

\section{Building Energy Analysis}

Load Shapes and End-Use Intensities for Commercial Buildings in Northern and Central California ........... 1

Guidelines for Using Energy Management and Control Systems to Monitor Building Performance ............ 1

Opportunities for Energy-Efficiency Improvements in HUD-Assisted Housing .......................................... 2

Peak Power and Cooling Energy Savings from Trees and White Surfaces in Sacramento, California ........... 3

Alternative to Compressive Cooling in the California Transition Climate Zones .......................................4

Residential Heating and Cooling Loads Component Analysis ........................................................ 5

\section{Building Energy Data}

Multiyear Energy Performance of New, Low-Energy Commercial Buildings

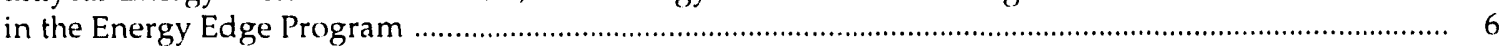

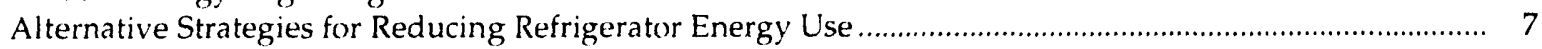

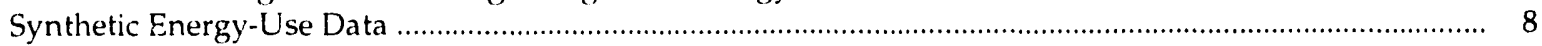

Fifty Million Retrofits Later: Progress and Prospects for Residential Energy Conservation ........................ 9

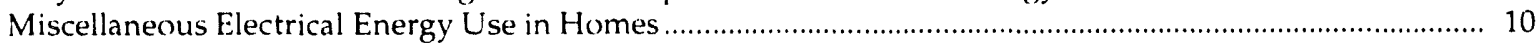

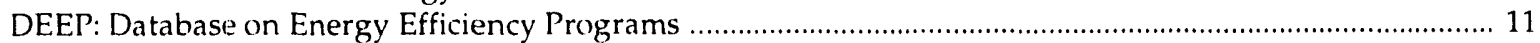

\section{End-Use Forecasting}

The Potential for Efficiency Improvements in Residential and Commercial Buildings ................................ 12

An Assessment of Future Energy Use and Carbon Emissions in U.S. Residences .................................... 13

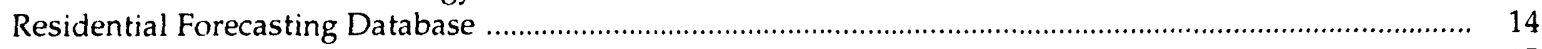

Comparison of Residential End-Use Forecasting Models ..............................................................

\section{Energy Conservation Policy}

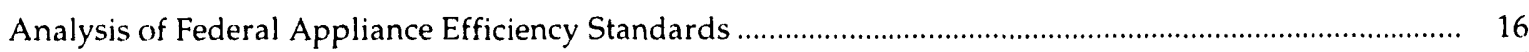

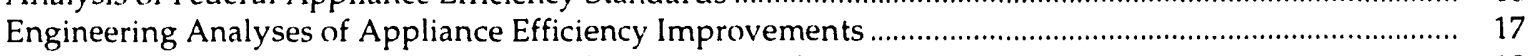

Assessing the Impacts os Appliance Standards on Manufacturers .......................................................... 18

Analysis of Federal Policy Options for Improving U.S. Lighting Energy Efficiency:

Commercial and Residential Buildings

\section{Utility Planning and Policy}

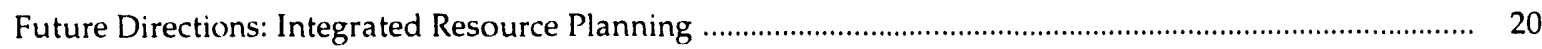

Transmission Planning in the Era of Integrated Resource Planning: A Survey of Recent Cases ................ 21

Evolution of DSM Bidding: A More Constructive Role for Energy Service Companies .............................. 22

Analysis of Residential End-Use Metered Data to Improve Electricity Demand Forecasts ......................... 23

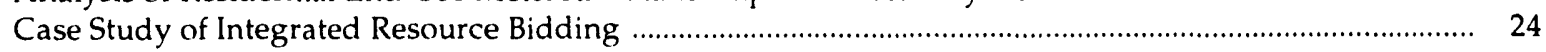

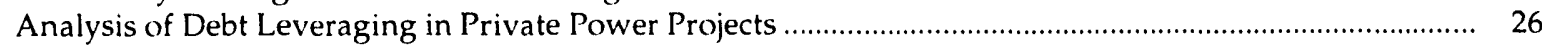

Global Energy/Environmental Issues

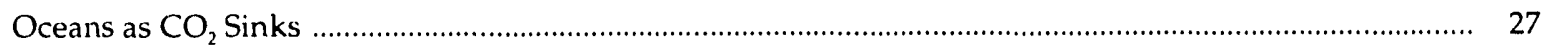

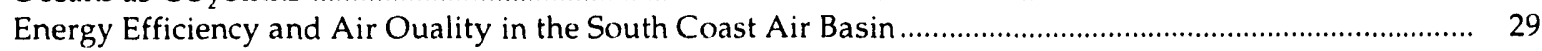

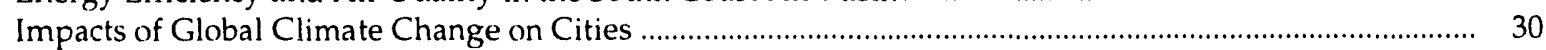

Global Environmental Impacts Network for Developing Countries ....................................................... 32

China's Energy System: Current Issues, Possible Evolution, and Global Warming .................................. 33

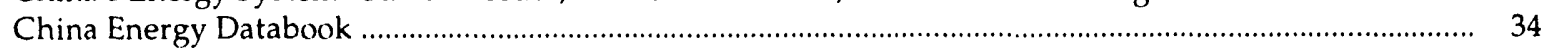

Electricity End-Use Efficiency: Experience with Technologies, Markets, and Policies Worldwide .............. 35

\section{International Energy Studies}

Using Scenarios to Explore Future Energy Demand in Industrialized Countries ..................................... 36

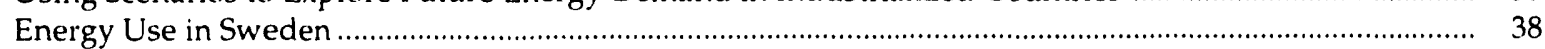

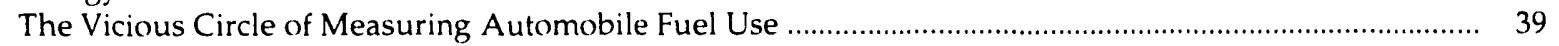




\section{Contents continued}

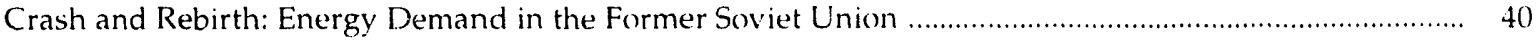

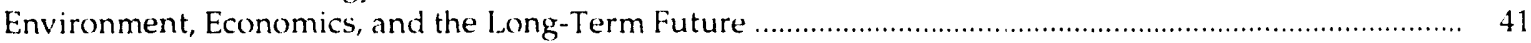

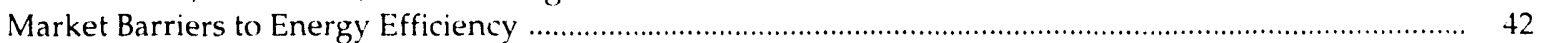

The Structure and Intensity of Energy Use: Trends in Five Industrialized Nations .................................. 43

Trends in Electricity Demand and Supply in the Developing Countries, 1980-1990 ............................ 44

Economics of Restraining Carbon Emissions from India, China, and Brazil ......................................... 45

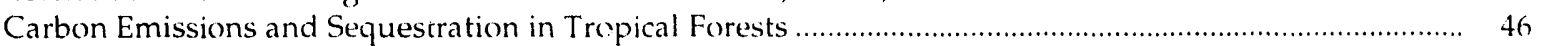

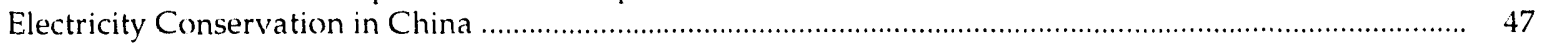

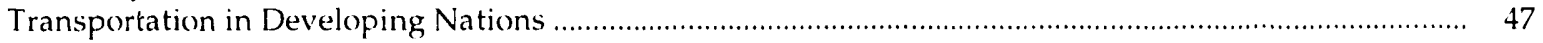

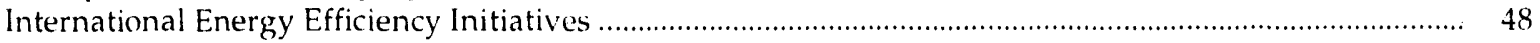

llumex, Mexico's Residential-Sector Lighting Efficiency Program: A Feasibility Study ........................... 49 
$\mathrm{T}$ his past year has been exciting and eventful for the lenergy Analysis Program. The Program continued its long-term growth, increasing expenditures and staff by more than 2(1"). The largest increases (xcurred in two areas: 1) energy demand forecasting and end-use policy analysis and 2) international energy studies.

This grow th has in many ways reflected the increasing concern the nation is showing for energy and environmental issues. Nineteen ninety-two marked the first vear in more than a decade that Congress passed national energy legislation. In particular, we are pleased that the final legislation included a large number of provisions for enhancing energy efficiency programs and policies. The bill mandates expanded activities in appliance efficiency standards, building stanctards, federal energy management, among others. These are all areas in which the Energy Analysis Program has played a very active role in support of DOE programs. We likely will be called upon to advise in expanded roles in the future.

A second major event of the past year was the United Nations Conference on
Environment and Development (LNCED) in Brazil. Many believe this conference initiated an intense awareness of the importance of a range of environmental issues that contain, in aggregate, global impacts. The Energy Analvsis Program played a key role in two of the small number of programs that the United States offered the developing world at LNCED). The first is the ADEPT program (Assisting Deployment of Energy Practices and Technologies). Along with colleagues from Oak Ridge National Laboratory, we proposed this new program to DOE and helped define many of its objectives. We were pleased that our government adopted it as a contribution to the UNCFD process, and we look forward to working with DOE, other national laboratories, and private firms in carrying out the program.

Similarly, we played an important role in supporting the concept of country studies to assist researchers in developing countries to formulate responses to global climate change. We have already begun working with DOE, the U.S. Environmental Protection Agency, and the U.S. Department of State to design the country study process.
The Program became deeply involved in establishing a Washington, D.C., project office during the last few months of fiscal year 1942. This project office, which reports to the Energy \& Environment Division, will receive the majority of its support from the Energy Analysis Program. We anticipate having two staff scientists and support personnel in offices within a few blocks of DOF. Our expectation is that this office will carry out a series of projects that are better managed closer to DOE. We also anticipate that our representation in Washington will improve and we hope to expand the Program, its activities, and impact, in policy-relevant analyses.

In spite of the growth that we have achieved, the Program continues to emphasize 1) energy efficiency of buildings, 2) appliance energy efficiency standards, 3) energy demand forecasting, 4) utility policy studies, especially if tegrated resource planning issues, and 5) international energy studies, with considerable emphasis on developing countries and coonomies in transition. These continuing interests are reflected in the articles that appear in this report.

\section{Program Staff}

Mark D. Levine, ${ }^{*}$ Program Lender

Ron L. Ritschard, ${ }^{*}$ Depully Program Lender

Hashem Akbari

Bo Andersson ${ }^{+}$

Barbara Atkinson

Celina Atkinson

Ross Baldick

Tim Belden

Stanley Boghosian

Sarah Bretz

Rich Brown

John Busch

${ }^{*}$ Group Leader

'Participating Guest

'Student Assistant

Acting Group Leader
Charles Campbell

Peter Chan

Terry Chan

Mark Christensen

Samuel Cohen

Deborah Connell

Caron Corper

Paul Craig

William Davis

Odón de Buen

Kari Dolan

Joseph Eto

Di Ann Fager

Lynne Ferrell

Maria Figueroa ${ }^{+}$
Anthony Fisher

Ellen Franconi

Rafael Friedmann

Ted Gartner

Gilberto Genga ${ }^{+}$

Jon Gimpel

Charles Goldman

Nina Goldman

Sajit Hakim

William Hanemann

James Hanford

Jeffrey Harris*

Dorothy Harvey

Kristin Heinemeier

Ellen Hodges
Richard Hiwarth

Xianqiang $f \mathrm{fu}^{+}$

Benson Hoang

Yul. Huang

Holly Hubbell

Roland Hwang

Katy Janda

Virginia Jenkins

Judith Jennings

Frank Johnson

Edward Kahn*

Ethan Kaplan

Andrea Ketoff

Jonathan Koomey

Florentin Krause
Martin Landsfeld

Siwei Lang ${ }^{+}$

Matthew Lecar

Lily Leeet

Barbara Litt

Feng Liu

Zhiping $\mathrm{Liu}^{+}$

Kenny Lo ${ }^{\ddagger}$

James Lutz

Willy Makundi

Chris Marnay

Eric Martinot

Omar Masera

Andrew McAllistert

(comtimuit) 
Program Staff

C. Bartlett McGuire James McMahon Andrew Megowan $\ddagger$

Alan Meier

Scott Mensing $\ddagger$

Stephen Meyers

Mithra Moezzi

Patty Monahan

Patrick J. Neale

Kara Nelson ${ }^{\ddagger}$

Hiroshi Nishimaki ${ }^{\ddagger}$

Bruce Nordman

continued

Richard Norgaard

Karen Olson

Shmuel Oren

Mary Orland $\ddagger$

Ken Orvis

Chris Payne

Mary Ann Piette

Gunars Platais

T. Brian Pon

Lynn Price

Zhigang Qin ${ }^{\ddagger}$

Leo Rainer
John Randolph

Munir Rashid

Gregory Rosenquist

Marc Ross

David Sailor

Jurgen Salay

Alan Sanstad

Jayant Sathaye*

Leon Schipper*

Ahmad Seifoddini

Agah Sezgen

Claudia Sheinbaum $^{+}$
Jonathan Sinton

Reneé Slonek

Ruth Steiner

Lisa Stewart

Steven Stoft

Haider Taha

Wienke Tax

Isaac Turiel

Robert Twiss

Pravin Varaiya

Edward Vine

Shumao Wang ${ }^{\dagger}$
Xunchang Wang ${ }^{+}$ Ronnie Weiner

Tom Wenzel Maggie Winslow Nancy Wishner Cheryl Wodley Winifred Wood Felix Wu Fu Qiang Yang Shuyu Zhang ${ }^{\dagger}$ 


\section{Building Energy Analysis}

\section{Load Shapes and End-Use Intensities for Commercial Buildings in Northern and Central California}

This study focuses on the application of the LBL end-use load shape estimation technique and the development of a database of commercial sector end-use load shapes and end-use intensities (EUIs). The database will be used by the California Energy Commission and Pacific Gas and Electric Company in their commercial energy and peak-load-forecasting models. The LBL technique relies on reconciliation of whole-building hourly electricity load data to energy simulations, which are developed from de- tailed survey data. The outcome of the project is a set of reconciled load shapes for as many as 10 end uses in all building types modified; the EUls are then indexed for three building vintages and techrology combinations.

The study is carried out in two phases. In Phase I, we developed load shapes and EUIs for offices and retail stores. In Phase II we collect data from buildings including grocery stores, restaurants (fast-food, sit-in), warehouses (refrigerated and non-refrigerated), health facili- ties, educational facilities, and hotels (motels). We focus primarily on electrical end uses including cooling, ventilation, lighting, cooking, refrigeration, water heating, office equipment, and miscellaneous equipment. The hourly load shapes a re aggregated to produce 12 monthly load shapes for three daytypes (peak, standard, and non-standard) and integrated to produce annual EUIs.

Investigators

H. Akbari

I. Eto

\section{Guidelines for Using Energy Management and Control Systems to Monitor Building Performance}

Although expensive, effective monitoring of energy consumption and building operations is an important part of conservation savings analysis, Energy Management and Control Systems (EMCSs) contain much of the same equipment that is usually installed for monitoring and often can be used for that application as well. Since EMCSs are installed in an increasing number of commercial buildings, the addition of conventional energy-monitoring equipment can be redundant.

EMCSs are not, however, usually designed with monitoring in mind. The characteristics of an EMCS are determined by building needs rather than by monitoring needs, so EMCS-based monitoring can encounter several complicating factors. Differences between the EMCS models, the installed options at sites with the same model, or the degree of system utilization at a site can mean the difference between a system that can be immediately used for monitoring and one that cannot be used at all.

We developed guidelines for EMCS monitoring based on our evaluation of monitoring procedures in earlier case studies. The guidelines discuss how to determine if the necessary elements are present and what to do if they are not. The guidelines also discuss the development of EMCS-based monitoring technology and the advantages that can be realized.

In a demonstration using a Barrington Systems EMCS installed at LBL, we collected data on one of the Laboratory's buildings. The Barrington Systems EMCS has several methods of collecting data. The simplest method includes the following:

- The EMCS automatically records the values of 3000 measurement points on its host computer and calculates averages at several intervals;

- Upon request, history reports can be saved to the host computer's disk in a spreadsheet data file.

- The supervisory control routines on the host computer can be used to issue automatic requests as often as necessary (e.g., once a day to obtain hourly data).

- Once on the computer, these data files can be transmitted to a remote comcomputer. The method chosen in the demonstration used the file-transfer capabilities of the PCAnywhere remote control program. Access can be password- protected, and the program is completely transparent to the users of the EMCS.

It is important to note that in our work no specialized remote monitoring routines were used; we relied exclusively on "off the shelf" software. Many different EMCS models have these same capabilities; however, the measuring methods used in each case can be quite different, often requiring specialized software. Coordinated research efforts are needed to ensure that the development of this technology meets the needs of building owners and operators and the utilities and building scientists who are interested in collecting energy data.

\section{Reference}

Heinemeier K, Akbari H. Proposed guidelines for using energy management and control systems for performance monitoring. In: Proceedings of the ACEEE 1992 Summer Study on Energy Efficiency in Buildings, August 30-September 5, 1992.

Vol. 3. Washington, DC: American Council for an Energy-Efficient Economy, 1992, pp. 3.111-3.120.

Investigators H. Akbari $K$. Heinemeier 


\section{Opportunities for Energy-Efficiency Improvements in HUD-Assisted Housing}

Implemention of energy-efficient improvements in HUD-assisted housing will likely encounter some unique and formidable difficulties. Two critical issues for local housing agencies are the selection of the most cost-effective retrofit measures and the availability of funds to install and maintain these measures. Another important issue identified in public housing from previous LBL studies is how well the energy savings resulting from energy conservation measures will persist over time.

During this fiscal year, we analyzed the post-retrofit energy performance of selected measures in 24 public housing projects located in New York, NY; Philipsburg, NJ; San Francisco, CA; and Trenton, NJ, for up to four years after initial installation. This analysis used the Princeton Score-Keeping Method (PRISM) and considered climate variation, type of building and occupant, type of conservation measure, and preretrofit energy use. The general approach used in this study followed three major steps. First, we collected utility data and other pertinent information (e.g., building characteristics, types of retrofit measures, occupant vacancy rates) from local housing agencies and updated our existing database on the public housing sector. Second, using PRISM, we normalized energy use for annual changes in weather to adjust the weather-sensitive component of space-heating fuel use. Also with PRISM, we regressed monthly energy use against daily average temperatures to estimate the normalized annual consumption (NAC). Finally, we normalized the energy use at each project by the number of apartment units in order to make comparisons on a per-unit basis. This normalization included a consideration of vacancy rates.

Several conclusions can be drawn from this analysis. First, the extent to which energy savings endured depended on the type of retrofit measure installed and the level of routine maintenance provided. The lack of adequate maintenance and improper operation of equipment drastically reduced the potential energy savings from the various equipment measures. For example, first year's savings did not persist in the heating control cases in three of the four Trenton projects (Figure). Second, we found that energy savings were strongly correlated with pre-retrofit consumption levels: large energy users generally saved more energy after the retrofit. Third, even though savings did not persist at some of the individual projects, significant median savings in the range of $5 \%$ to $44 \%$ were found over the full retrofit period with all but one of the retrofit strategies. Fourth, a major problemthe lack of credible data on building characteristics, vacancy rates, retrofit selection, and maintenance practicescontinues to exist in any study of public housing. Finally, we strongly suggest the need for tracking of monthly energy consumption in order to identify "problem" projects and buildings and to assist in the proper selection of retrofit measures.

\section{Reference}

Ritschard R, McAllister A. Persistence of savings in multifamily public housing. In: Proceedings of ACEEE 1992 Summer Study on Energy Efficiency in Buildings, August 30)September 5, 1992. Vol. 4. Washington, DC: American Council for an Energy-Efficient Economy, 1992, pp. 4.201-4.215.

\section{Investigators}

R.L. Ritschnrd R.C. Diamond

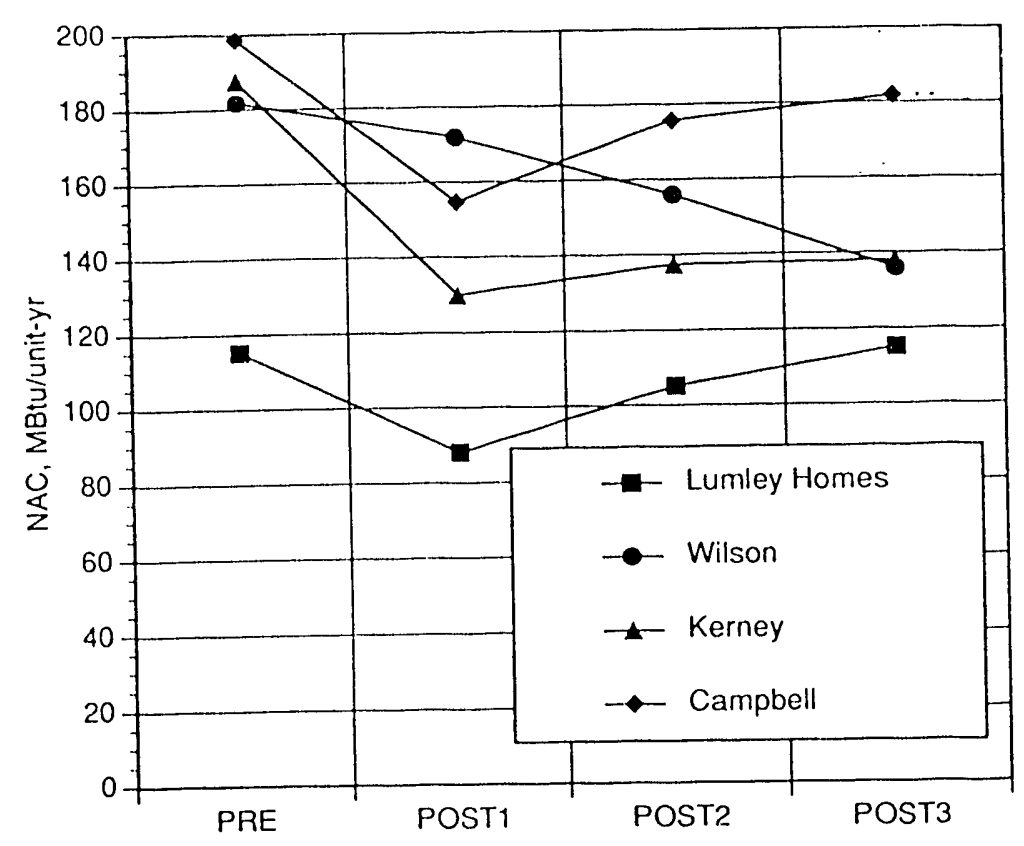

Figure.

Persistence of energy savings in four housing projects in Trenton, New Jersey. 


\section{Peak Power and Cooling Energy Savings from Trees and White Surfaces in Sacramento, California}

The direct effects of high-albedo coatings and shade trees on microclimates and cooling energy use were examined by monitoring several buildings in Sacramento. Of seven buildings monitored during 1991, four were re-instrumented in 1992 to monitor the indoor environmental conditions, outdoor microclimates, and cooling electricity use. Variables were logged every 20 minutes for the period July 1 to October 15, 1992.

These variables included:

- Solar radiation on vertical and horizontal surfaces,

- Wind speed,

- Wind direction,

- Surface temperatures at several outside and inside points (roofs, walls, ceilings, attics, etc.),

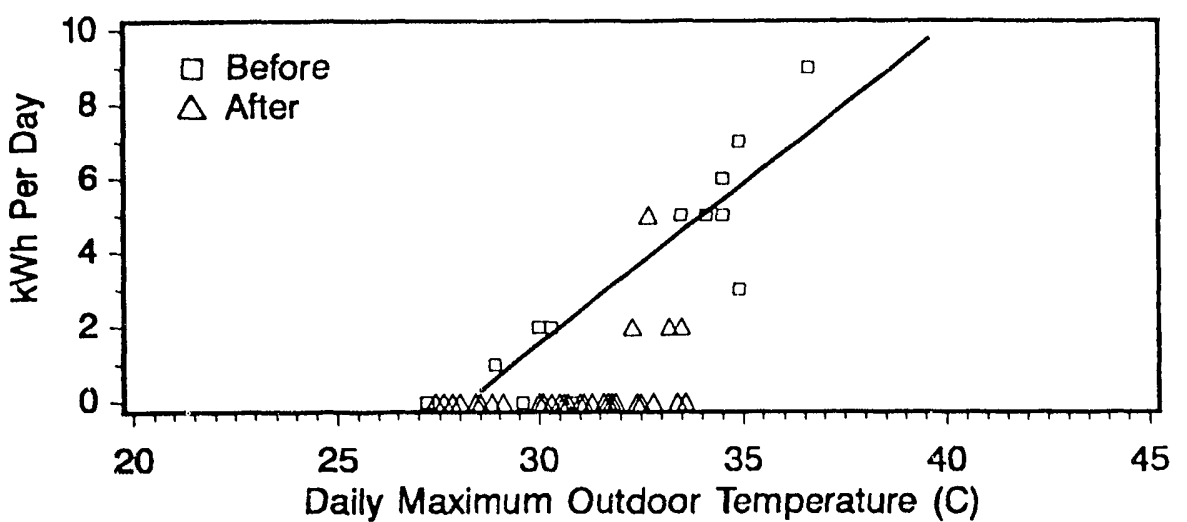

Figure 1.

Daily energy use zis. daily maximum outdoor air temperature before and after whitening the roof. The albeto was 0.18 before conting and 0.79 afterward.
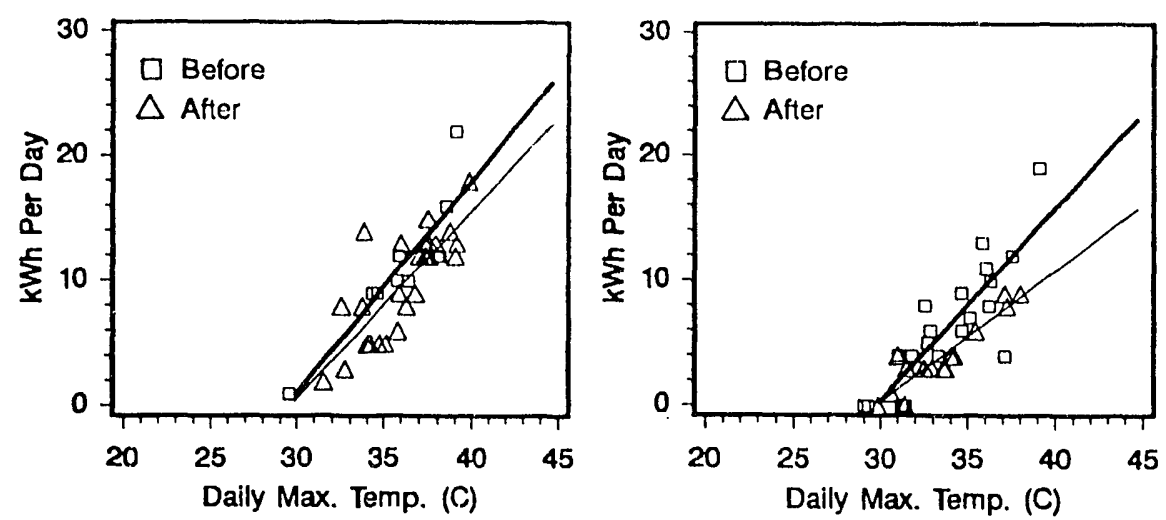

Figures 2a (above, left), 2b (above, right).

Daily energy use ws. maximum daily outdoor air temperature at two sites before and after vegetation was installed.
- Supply and return air temperatures,

- Indoor and outdoor air temperatures,

- Indoor and outdoor relative humidities,

- Air conditioner (condenser) electricity use.

Two buildings were tested for albedr modifications and two were tested for the impacts of shade trees. In one of the albedo tests, we continued to monitor the high-albedo roof to study the implications of high-albedo coatings over a variety of weather and insolation conditions (Fig. 1). In the other albedo test (two school bungalows), one unit was already coated white in 1991 and we continued to monitor it. The other unit (originally metallic) underwent two modifications during the summer of 1992: from metallic to brown and from brown to white. The performance of this unit was compared to the performance of the unaltered 1991 white unit.

The other two buildings were monitored to demonstrate the effects of shade trees. Eight tall trees ( $8 \mathrm{~m}$ tall, $4 \mathrm{~m}$ wide) and eight smaller trees ( $3 \mathrm{~m}$ tall, $2 \mathrm{~m}$ wide) were installed at one of the two vegetation sites for a full month. The trees were then moved to the other site for the remaining 1.5 month of the monitoring period. Each of these sites yielded at least one month's data for both the bare and "treed" exposures (Figs. 2a, 2b). We are continuing to analyze data from the 1992 experiment.

\section{Reference}

Akbari H, Taha H, Sailor D, Bos W.

Measured savings in air conditioning from shade trees and white surfaces. In: Prociedings of the ACEEE 1992 Summer Study on Energy Efficiency in Buildings, August 30-September 5, 1992. Vol. 9. Washington, DC: American Council for an Energy-Efficient Economy, 1992, pp. 9.19.10 


\section{Alternative to Compressive Cooling in the California Transition Climate Zones}

The use of compressor-based cooling systems is growing rapidly in California as more housing is constructed inland from the coastal urban centers. These inland areas-the California Transition Climate Zones-experience warmer summer weather than coastal zones, but temperatures do not reach the extremes of the Central Valley. For utility companies, the residential cooling-load profile is very disadvantageous, with sharp peaks that generally coincide with system peaks in the late afternoon. Paradoxically, since the cooling requirements in most California climates are not severe, this cooling load can be avoided or curtailed by improving the design and operations of typical houses so that they will not require air conditioning. The objective of this study is to demonstrate that, with proper design of the building shell and equipment and smart control strategies, typical residential buildings in the California Transition Climates Zones can maintain indoor comfort without using air conditioning. This project represents a major effort by the California Institute for Energy Efficiency to investigate how this residential cooling load can be avoided.

The project started in Fall 1992 and will continue for three years. A team of seven researchers from $L B L$ and four California universities will take a multi-disciplinary approach to investigate the technical, architectural, and sociological issues related to potential non-compressive cooling strategies. The first project year will be devoted to studying the technical performance of strategies such as natural and forced ventilation, evaporative cooling, thermal mass, optimized controls, and the institutional and sociological barriers to adoption of such strategies (Table). In the following two years, the project team will collaborate with builders and utility companies to design, construct, and monitor several demonstration houses.

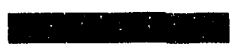

Investigator Y.J. Huang

Table.

First-year tasks of the research team.

\begin{tabular}{|c|c|c|}
\hline $\begin{array}{l}\text { Y.J. Huang } \\
\text { LBL }\end{array}$ & $\begin{array}{l}3 . \\
4\end{array}$ & $\begin{array}{l}\text { Characterize climate and building load } \\
\text { characteristics in Transition Climate Zones; } \\
\text { Identify appropriate alternative cooling } \\
\text { strategies using existing analytical capabilities; } \\
\text { Model evaporative cooling; } \\
\text { Overall research coordination. }\end{array}$ \\
\hline $\begin{array}{l}\text { H. Feustel, } \\
\text { LBL }\end{array}$ & 1. & $\begin{array}{l}\text { Couple air-flow model with the DOE-2 bldg } \\
\text { energy model; } \\
\text { Investigate effective ventilation strategies. }\end{array}$ \\
\hline $\begin{array}{l}\text { F. Winkelmann, } \\
\text { LBL }\end{array}$ & $\begin{array}{l}1 . \\
2\end{array}$ & $\begin{array}{l}\text { Improve convective coupling model in DOE-2; } \\
\text { Work with Huang and Feustel to add } \\
\text { evaporative cooling and ventilation } \\
\text { modifications to DOE- } 2 \text {. }\end{array}$ \\
\hline $\begin{array}{l}\text { H. Wu, } \\
\text { Cal Poly } \\
\text { Pomona }\end{array}$ & 1. & $\begin{array}{l}\text { Improve evaporative cooler designs and } \\
\text { operations; } \\
\text { Integrate architectural alternative strategies. }\end{array}$ \\
\hline $\begin{array}{l}\text { E. Arens, } \\
\text { UC Berkeley }\end{array}$ & 1. & $\begin{array}{l}\text { Test chamber studies of human comfort under } \\
\text { air movement and increased humidity } \\
\text { conditions. }\end{array}$ \\
\hline $\begin{array}{l}\text { B. Givoni, } \\
\text { UCLA }\end{array}$ & 1. & $\begin{array}{l}\text { Monitor test buildings for effects of thermal } \\
\text { mass, ventilation, and evaporative cooling; } \\
\text { Provide data support for computer models by } \\
\text { Feustel, Huang, and Winkelmann. }\end{array}$ \\
\hline $\begin{array}{l}\text { B. Hackett, } \\
\text { UC Davis }\end{array}$ & 1. & $\begin{array}{l}\text { Identify sociological, institutional, and industry } \\
\text { barriers affecting public acceptance of } \\
\text { alternative cooling strategies. }\end{array}$ \\
\hline
\end{tabular}




\section{Residential Heating and Cooling Loads Component Analysis}

According to the 1987 Residential Energy Consumption Survey, the heating and cooling of U.S. residential buildings is responsible for 5.4 Quadrillion Btus per year of site energy use. As a major research sponsor, the Office of Building Energy Research at DOE is interested in evaluating the potential impacts of different technologies on the residential energy consumption at a national level. This study represents an initial step toward this assessment by quantifying the approximate contribution of major building components, i.e., roofs, walls, foundations, infiltration, windows (solar and conduction), and internal gains to the total heating and cooling loads of the U.S. residential stock (.igure). These results can then be used to assess accurately the energyconserving potentials of new residential building technologies.

The analysis builds upon three previous LBL studies. The first two studies defined sets of single-family and multifamily building prototypes to represent the range of climates, building vintages, and conservation levels in the national residential building stock. The third study used the DOE-2 building energy simulation program to quantify the heating and cooling loads of various building components based on the building type, climate, and the thermal characteristics of that component. In this project, we combined the building characteristics from the first two studies with the component loads calculated in the third study, and then multiplied the calculated component loads by the estimat- ed building population by building type, vintage, and location.

The results are presented as a series of charts that show the component loads for the major subsectors of the residential building stock stratified by building type (all types, single-family, and multifamily); vintages (older uninsulated buildings, older insulated buildings, and new buildings); and location (national, north/south regions, and census regions). Lastly, the estimated heating and cooling component loads for a reduced set of building prototypes are used to make some simple technology assessments.

\section{References}

Hanford JW, Huang YJ. Residential Heuting and Cooling Loads Component Analysis. Lawrence Berkeley Laboratory Report No. L.BL-33102, 1992.

Ritschard RL, Hanford JW, Sezgen AO. Single-Family Heating and Cooling Requirements: Assumptions, Methods, and Summary Results, Gas Research Institute Report No. GRI-91/0236 (also as

Lawrence Berkeley Laboratory Report No. LBL-30377), 1992.

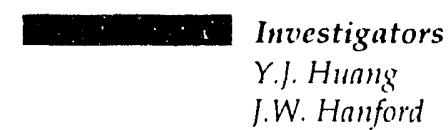

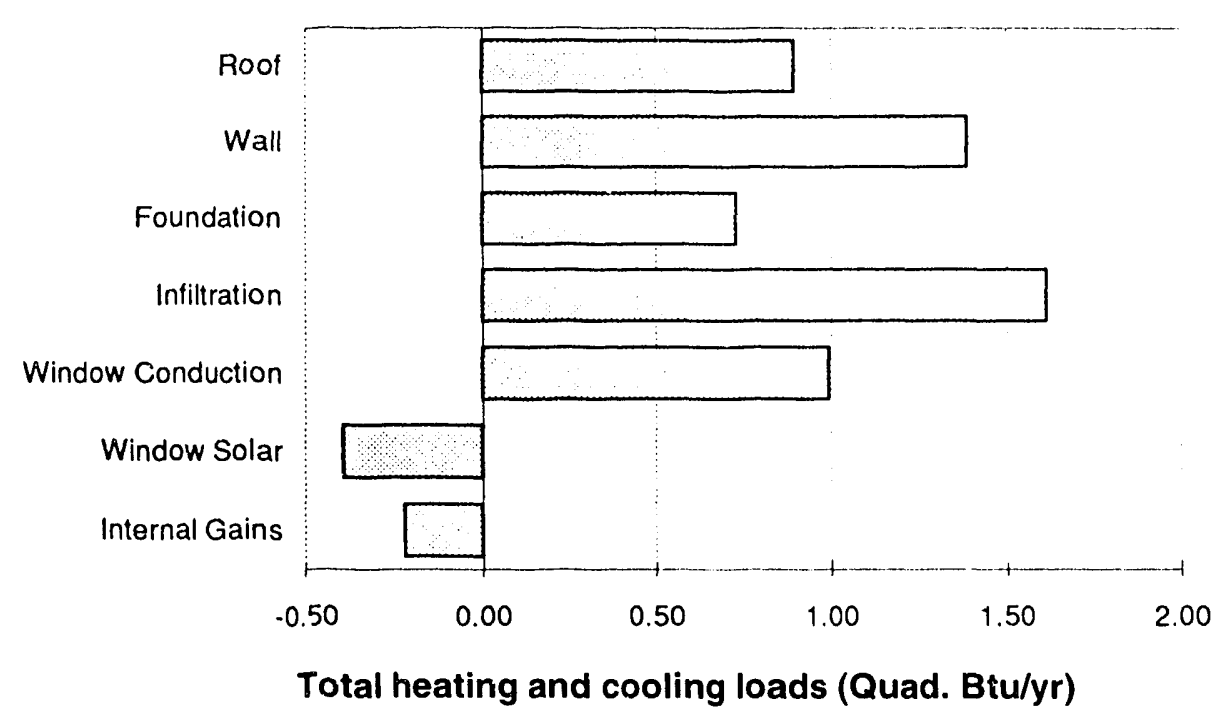

Figure.

Total residential sector heating and cooling loads by building component. 


\section{Building Energy Data}

\section{Multiyear Energy Performance of New, Low-Energy Commercial Buildings in the Energy Edge Program}

The Energy Edge Program, sponsored by the Bonneville Power Administration, involves 28 buildings designed to use $30 \%$ less energy than a baseline building built to meet the regional energy code, the Model Conservation Standards (MCS). Computer simulation models calibrated with end-use data are used to estimate the energy savings from each efficiency improvement. We have examined building energy use, the results of the simulation models, and issues in the evaluation methodology.

The 28 Energy Edge buildings as a group are using more energy than predicted, but are, for the most part, low-energy buildings. Based on the results from the first five tuned models, the measures are saving $13 \%$ less energy than predicted. Lightirg measures as a group are saving more than predicted, but HVAC and envelope measures are saving less. Based on two years of utility bills, the average energy use for twelve offices is about $13 \mathrm{kWh} / \mathrm{ft}^{2}$-year, slightly higher than predicted, but well below regional benchmark data (Figure). Energy consumption for all 28 buildings, based on the third year of utility bills, is increasing in $60 \%$ of the buildings.

Some of the increase in energy use beyond predictions is because of poor commissioning and operations and maintenance practices. This was illustrated in one building where the increase in heating energy from a damper stuck in the "open" position was greater than the energy savings from economizer cooling. A pilot commissioning project showed how implementing the time-clock functions as intended with the energy management and control system to control the unitary heat pumps and lights reduced annual energy use by about $8 \%$.

We recommend that future evaluation activities include more hands-on diagnostic testing and the use of mon- itored data to provide timely feedback to building operators.

Continuing work includes evaluating the cost effectiveness of individual measures from the calibrated models and tracking performance of the measures over time. We will also compare results from the Energy Edge buildings with the region's full-scale new commercial construction program, which uses prescriptive calculations to assign rebate levels and energy savings estimates for

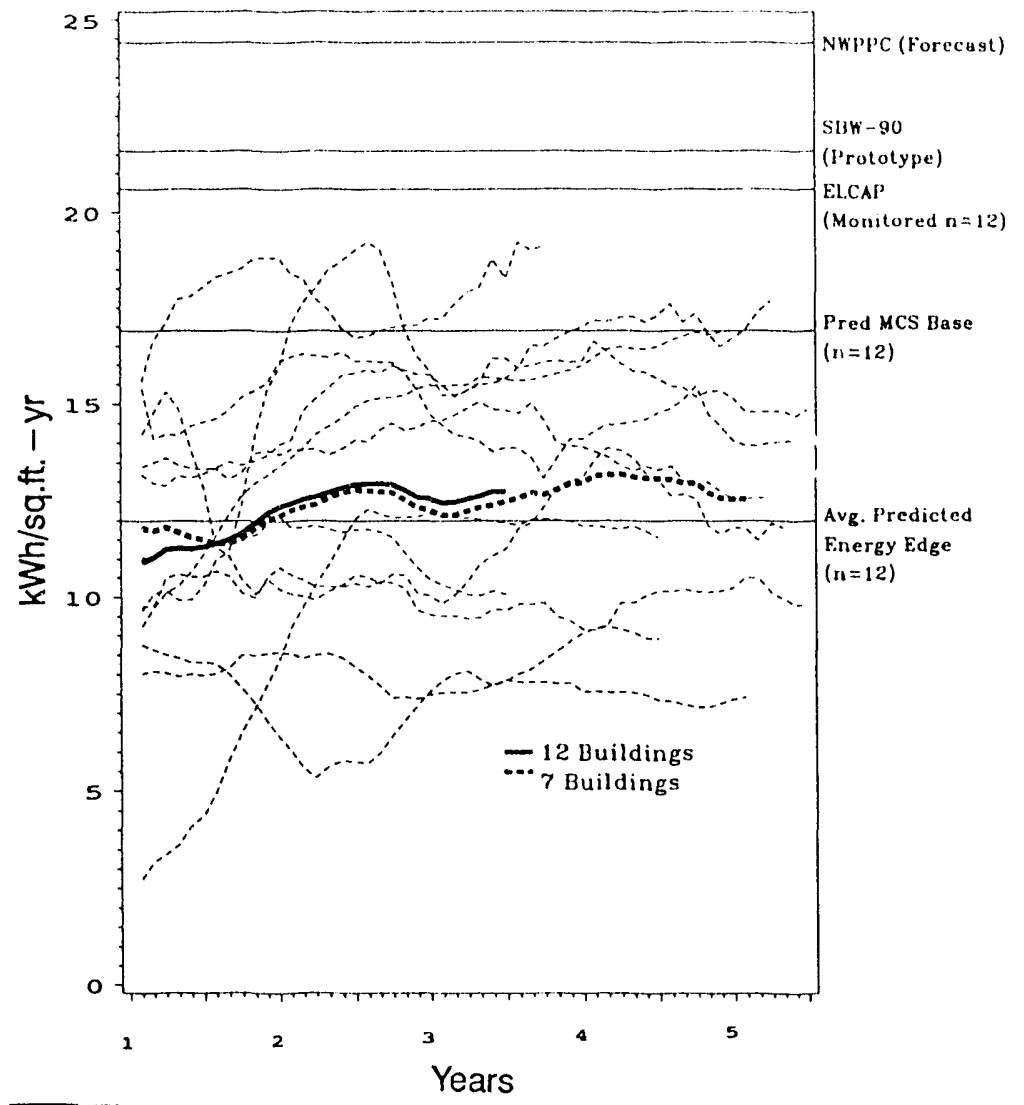

Figure.

Rolling average annual electricity use for twelve Energy Edge office buildings with comparison office building data. ELCAP data are from 14 post-1980 all-electric offices. NW. PPC are 1989 regional forceasts for newe construction SBW are prototypes for $1989 \mathrm{cur}$ rent practice. The predicted MCS baseline is the aterage code baseline from early designs. 


\section{Alternative Strategies for Reducing Refrigerator Energy Use}

Although utility companies have collected considerable data on the energy use and load shapes of residential refrigerators, they generally have little information at out the ch.nges in energy use resulting from conservation programs. We report nere the measured changes brought about by two conservation strategies: professional maintenance of older refrigerators and replacement of older refrigerators with new, efficient models.

The initial objective of the study was to estimate long-term energy savings from cleaning the coils and rep'acing broken gaskets in older refrigerators. Twenty-seven customers in northern New York state, with refrigerators older than 10 years, were recruited to participate. The electricity use of the participants' refrigerators was monitored for one year at 30-minute intervals. This served as our baseline for subsequent measurement;. Average electricity use was high- $2100 \mathrm{kWh} /$ year-but typical of 16-year-old refrigerators.

After one year, the utility hired two professional refrigerator contractors to inspect the refrigerators. They were instructed to check and record the extent of dirt and fouling on the (i) ndenser coils and to clean them. Next they inspected the gaskets and replaced any appearing to be cracked or otherwise providing diminished service. The contractors were also instructed to perform any other minor repairs that would affect the refrigerators' performance. Energy-use monitoring continued for a second year.

The changes in energy use were calculated from the pre- and postmeasurements. For the 27 refrigerators examined, the average electricity consumption increased $50 \mathrm{kWh} /$ year $(2.5 \%)$ (Figure). These numbers suggest that coil cleaning and gasket replacemont, even if performed by professionals, are not reliable conser- vation measures. Closer examination of the individual refrigerator data explained part, but not all, of the counter-intuitive results. Some of the refrigerators originally had relatively clean coils and others received gaskets that did not seal as well as the original factory-installed pieces. Finally, the contractors fixed some problems (broken baffles, inoperative fans, etc.) that improved the quality of refrigeration, i.e., produced lower or more uniform temperatures, which may have increased energy use. Nevertheless, we found nothing in the contractors' descriptions of the refrigerators' condition that correlated with energy savings. We conclude that refrigerator maintenance programs-whether performed by the occupants or skilled contractorsare unlikely to save significant amounts of energy.
In the second phase of the project, the occupants received new refrigerators. The new units were generally larger and equipped with more features than the units they replaced. Monitoring continued for a third year. The new units consumed on average only $869 \mathrm{kWh} /$ year, or $60 \%$ less than the units they replaced. Moreover, the variability in energy use among customers was much less than among those with older units.

Programs to upgrade existing refrigerators are expensive and unlikely to save significant amounts of electricity. The most effective conservation program for refrigerators is replacement of old units with new, efficient ones.
Investigators

A. Meier

A. Megowan

B. Litt

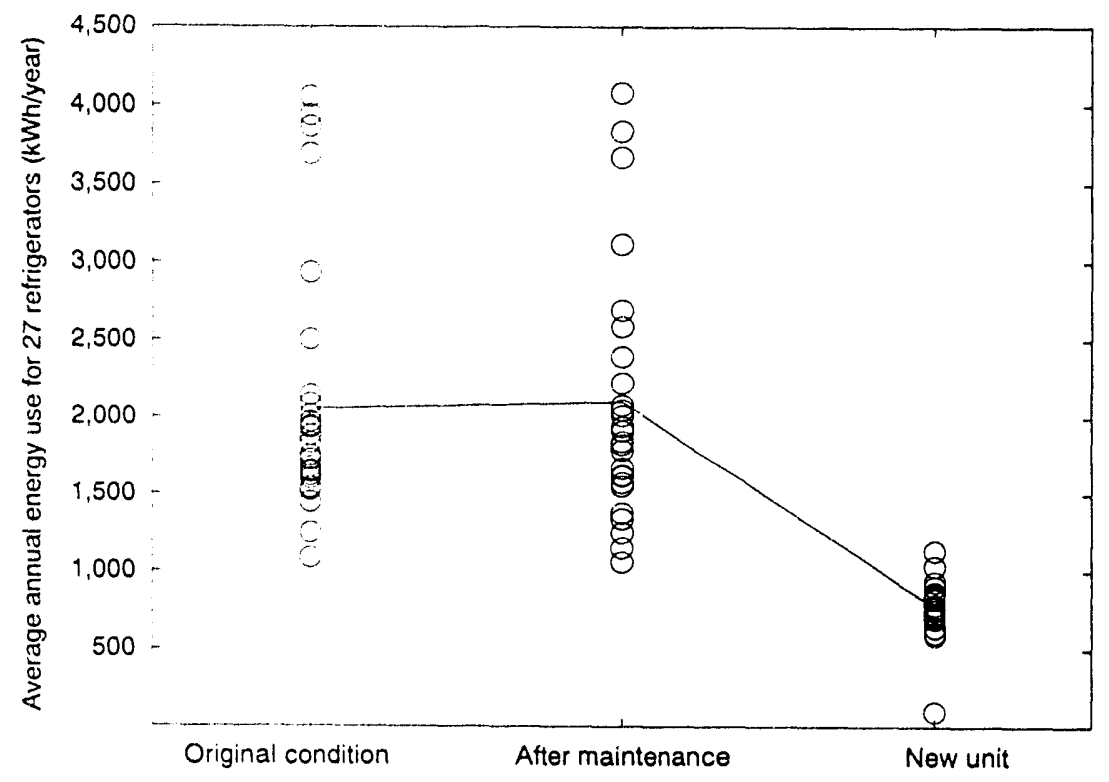

Figure.

Refrigerator energy use for the old units before and after maintenance and of the new', replaceme'nt units. 


\section{Synthetic Energy-Use Data}

In the next decade, utility companies will rely increasingly on measured data to verify the savings from their energy conservation programs. Several techniques have been developed to translate customer bills and building-monitoring data into estimates of building performance and energy savings. Most involve regressions of energy use against driving factors such as outside temperature and solar gain. The regression parameters are then used to estimate long-term performance and savings from retrofits. However, the relationship between the regression-derived parameters and thermo-physical properties of the building is poorly understood. When do changes in the regression parameters correspond to physical changes in a building's thermal characteristics? We investigated these relationships for one of the most widely used regression techniques, the Princeton Score-Keeping Method (PRISM).

"Synthetic" monitored data were created to remove the uncertainty in construction details and occupant behavior in real buildings. The synthetic data were generated from DOE-2 simulations of typical buildings. By simulating proto typical houses, the heat-loss coefficient (the "UA") is known exactly. The hourly DOE-2 energy outputs were then aggregated to resemble utility bills (the most common input for PRISM). This procedure allows PRISM and other measurement-based techniques to be evaluated under ideal conditions.

We evaluated PRISM parameters using synthetic data for houses located in Minneapolis, Minnesota, and San Francisco, California. For the cold Minneapolis climate, the PRISM regression parameters closely matched the physical attributes of the models, although tracking retrofit savings for small improvements appeared problematic. For San Francisco, the PRISM slope overestimated the building heat transfer coefficient, probably due to some heating being accounted for in the constant energy-use parameter.
Synthetic data are being used to assess PRISM parameters for typical houses in the Northwest. The builcing models include 36 houses that have varying levels of insulation, thermal mass, and ground coupling. Although the occupants in simulated buildings are generally "well behaved," i.e., stylized, we introduce irregular behavior by including occupancy schedules, seasonal appliance use, and variable thermostat settings.

Results for the simplest case studies are presented (Figure). The 12 houses have four insulation levels and three mass levels. For the cases presented, PRISM's slope is a good indication of the heat-transfer coefficient in the low- mass buildings. The slope overestimates the coefficient for the higher mass buildings, although it follows the change in the coefficient as insulation increases.

\section{Reference}

Minehart D, Meier A. Using simulations to explore the physical meaning of PRISM's parameters. In: Procecdings of the ACEEE 1992 Summer Study on Energy Efficiency in Buildings, August 30-September 5, 1992.

Vol. 4. Washington, DC: American Council for an Energy-Efficient Economy, 1992, pp. 4.145-4.155.

\section{Investigators}

$\begin{array}{ll}\text { E. Franconi } & \text { A. Mcicr } \\ \text { B. Nordman } & \text { D. Minchart }\end{array}$

\section{2. House Heat Transfer Coefficient Slope from PRISM Analysis}

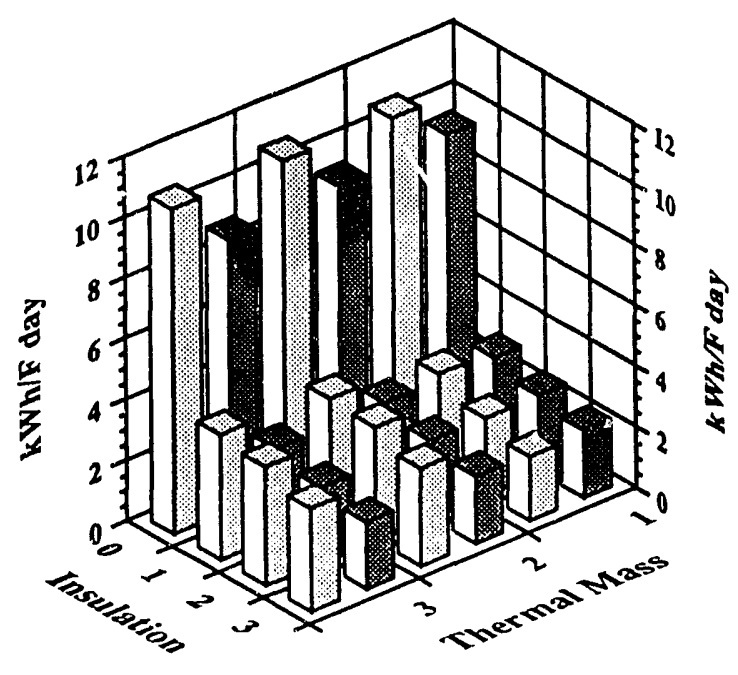

Figure.

Comparison of the modeled building heat-transfer coefficient and PRISM's slope for 12 houses in the Northwest. 


\section{Fifty Million Retrofits Later: Progress and Prospects for Residential Energy Conservation}

Approximately 50 million residential energy-saving retrofits have been implemented in the last decade, but data remain sparse since retrofits are undertaken by individuals, utilities, and government agencies. Adding to this, the energy-conservation industry is fragmented with few large suppliers and national associations. The lack of detailed information on residential retrofits and their actual energy savings hampers the creation of policies that encourage cost-effective retrofits.

This project seeks to obtain a snapshot of residential conservation activity. Much of the project focuses on accounting for the actual number of conservation measures that have already been installed. Also of interest are the kinds of retrofits undertaken, historic and current rates of retrofitting, the types of buildings that have been retrofitted, and the stock of buildings not yet retrofitted.

No single source of data offers a comprehensive assessment of residential retrofit activities. With the exception of data gathered through the Department of Energy's Residential Energy Consumption Survey (RECS), retrofit data are scattered and inconsistent. Many sources provide insights into specific aspects of the activities but are limited to small areas, small groups of projects, or a single technology. To obtain a comprehensive overview, data must be pieced together from numerous sources.

For example,., many utilities collect data on retrofit activities such as the amount of insulation sold, the results of homes audits, and so on in their own service areas. Most utilities also periodically conduct customer surveys (commonly called residential appliance saturation surveys or RASSes) to monitor appliance purchases, conservation activities, and customer attitudes. Examples of conservation measures surveyed in a typical RASS are floor insulation, wall insulation, attic or ceil- ing insulation, storm doors, storm windows, caulking and weatherstripping, and water flow restrictors. We have collected nearly 100 RASSes. Our collection offers a more complete picture than RECS because the cumulative sample size of our RASSes is over 90 times that of RECS.

Other sources of conservation activity data include individual corporate manufacturers of conservation supplies, installatio' 1 companies, and industry organizations involved in the residential energy-conservation market (insulation, fenestration, heating and air-conditioning equipment, appliances, etc.). Data from these sources provide additional estimates of retrofit progress. By linking the various sources of data into a comprehensive study, this project will obtain a snapshot, or mosaic, of conservation measures already implemented and the rate at which implementation is occurring. When assembled, these data can be represented geographically. For example, one might expect that the saturation of homes with either multi-pane or storm windows would be higher in the colder Northern states (Figure). This is indeed the case, but the variation among regions suggests that the trend is not uniform. At the same time, parts of the Middle West have unusually high saturations of multi-pane/storm windows. Special, localized policies-rather than a single national policy - may be warranted to encourage window retrofits (and other conservation measures) in those areas still lagging.

The tabulation or energy-saving conservation measures will provide data to improve forecasting, program and policy development, industry coordination, and retrofit research planning. The tabulation will also provide data for estimating the actual energy savings associated with these retrofits.

\section{Investigators}

A. Meier

B. Pon

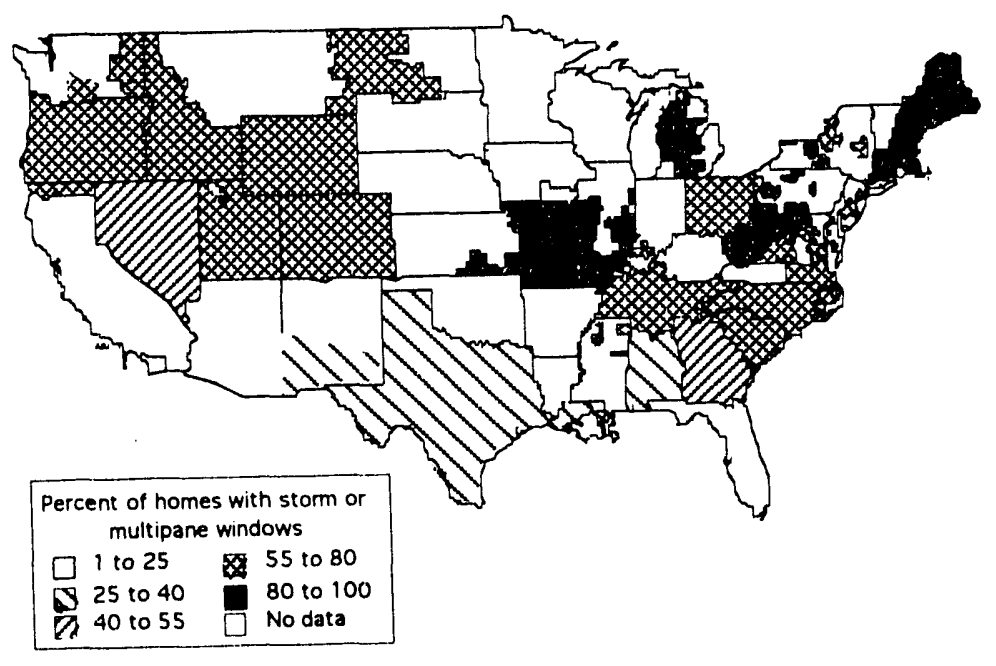

Figure.

Saturation of homes with multi-pane or storm windows. 


\section{Miscellaneous Electrical Energy Use In Homes}

The "miscellaneous" use of electricity in homes refers to that energy not consumed by the standard end uses such as space heating, refrigeration, and water heating. Historically, this use has been estimated as a residual by subtracting the estimates for the standard end uses from the total. This procedure introduces considerable uncertainty.

In this study, the saturations and unit electricity consumptions were estimated for over 35 appliances within the miscellaneous category of residential electricity use in the United States. Based on these estimates, the total national electricity consumption of these appliances was calculated. Altogether, the miscellaneous appliances consume about one-fifth of all residential electricity. The five most significant appliances in the miscellaneous category are: furnace fans, color televisions, waterbed heaters, microwave ovens, and dishwashers (Figure).

On a nationwide basis, no single appliance within the miscellaneous end use category consumes as much electricity as a standard end use. In a specific home, however, miscellaneous uses can easily exceed the electricity used by a water heater or refrigerator. Some of these appliances, such as waterbed heaters, aquariums, and pool equipment, are already present in up to $15 \%$ of American homes and higher in certain regions.

New appliances in the miscellaneous end use penetrate the market very rapidly. Microwave ovens, VCRs, and computers were relatively rare only ten years ago; now they are all present in a large fraction of homes. At least 300 million low-vol tage transformers are now used to power consumer electronics. Most draw power (1-3 watts) even when the appliance is switched off.
Similarly, electrical outlets equipped with ground-fault interrupts draw power continuously. The general decrease in residential electricity use caused by greater efficiency within the standard end uses conceals active growth in the miscellaneous end use.

The linkage between an end use and a specific appliance is weakening. This is most evident in the cooking end use, where once cooking was almost exclusively performed with the stove but is now shared among the stove, microwave, toaster oven, coffee maker, and a host of other specialized appliances. The cooling end use is undergoing a similar de-coupling as de-humidifiers and ventilation equipment (particularly ceiling fans) are providing an increas- ing share of the service. The decoupling trend has important implications for energy efficiency investments and programs. Efficirncy investments in a specific appliance will be harder to justify when the savings accrue to an appliance that is providing only, say, $40 \%$ of the service.

\section{Reference}

Meier A, Rainer L, Greenbery S. The miscellaneous electrical use in homes. Energy-The International Jourmal 1992; 17(5):509-518.

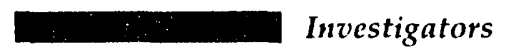
A. Meier
L. Rainer
S. Greenbers

\section{MISCELLANEOUS ELECTRICITY}

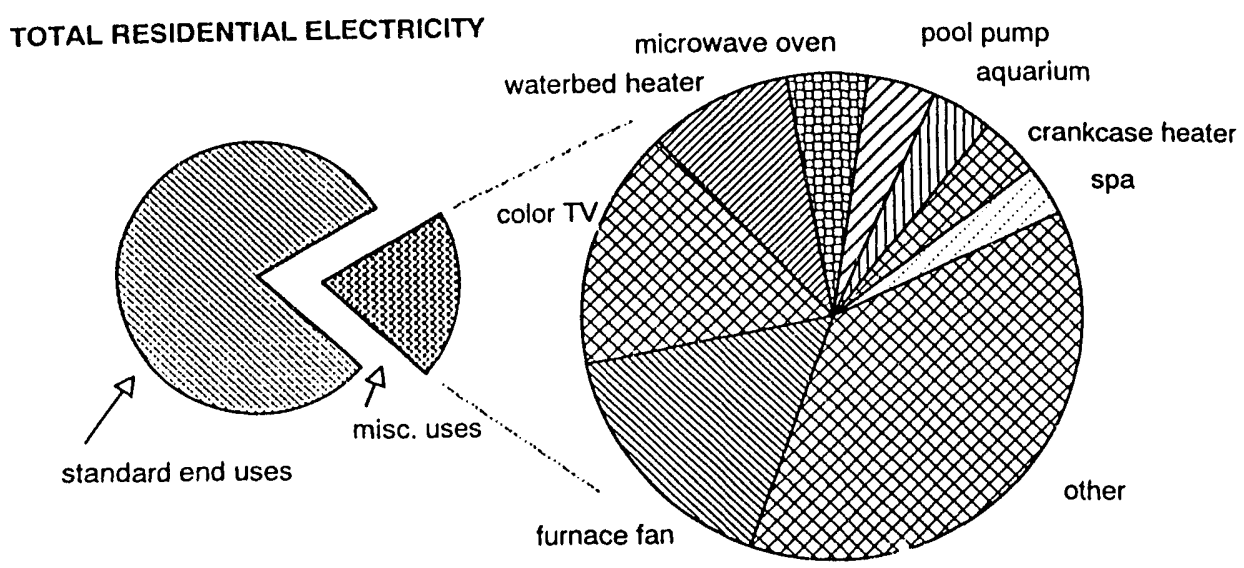

Figure.

The major components within the miscellaneous end use category. 


\section{DEEP: Database on Energy Efficiency Programs}

Utilities and government have sponsored hundreds of energy efficiency programs, and much has been learned about how to operate programs that achieve high participation rates and high energy savings and that are costeffective to the utility and to society. However, this information is not readily available to program analysts involved in designing, implementing, and evaluating programs conducted by their own organizations. If all this information is collected and concentrated in one place, the cost of obtaining such information becomes considerably reduced, and the potential for comparing programs and for sy nthesizing program experience is facilitated: data on similar programs can be summarized by marketing and delivery approaches, incentive mechanisms, and other program features to identify indicators of successful programs. These analyses can be used to improve program effectiveness and to develop more reliable demand-side management estimates for planning resources. Finally, by including a limited amount of information on the characteristics of the implementing utility, program planners can assess the transferability of the results to their own service areas.

In the past year, LBL began creating a national Database of Energy Efficiency Programs. When completed, DEEP will contain a description of each program and its critical features: energy savings and demand savings, participation rates, program costs, and measurementevaluation methodologies. The information in this database will be up-todate and directly accessible by individuals and organizations interested in designing, implementing, and evaluating energy efficiency programs. In addition, summaries of pertinent data and lessons learned from programs like new-residential, existing-commercial, appliance-rebates, will be presented periodically.

In the past year, we developed the first version of the database structure and the data-collection instrument and have started to collect evaluations of the programs. Next year, we will conduct the following activities: 1) pretesting of database templates, 2 ) pretesting of the data-collection instrument, 3) collection of data on energy efficiency programs, 4) data entry and analysis of data quality, 5) preparation of lessons learned reports, and 6) dissemination of database information.

Two advisory groups provide guidance to the activities undertaken in this project: the Management Board and the Technical Advisory Group. The Management Board provides advice at critical junctures during the process of designing and implementing the database (e.g., selection of contractors, initial scope of database, marketing efforts). The Management Board is composed of representatives of DEEP's co-sponsoring organizations. The Technical Advisory Group provides advice and input to the design of the database and in preparing data collection and data analysis activities. The Technical Advisory Group is composed of national experts in program design, implementation, and evaluation.

\section{Reference}

Vine E, Wolcott D. DEEP: database on energy efficiency programs. In: Proceedings of the 1992 ACEEE Summer Study on Energy Efficiency in Buildings, August 30September 5, 1992. Vol. 7. Washington, DC: American Council for an EnergyEfficient Economy, 1992, pp. 7.253-7.255.

\section{Investigators}

E. Vine

R. Weiner

C. Payne 


\section{End-Use Forecasting}

\section{The Potential for Efficiency Improvements in Residential and Commercial Buildings}

The first part of this project assessed the potential for improving the efficiency of electricity use in the U.S. residential sector. This potential is expressed in terms of cost and electricity savings. The results are presented in a supply curve of conserved electricity (Fig.1). The supply curve of conserved electricity consists of roughly 200 energy conservation measures, which fall into four distinct types:

- retrofitting of existing buildings and equipment;
- improving the thermal performance of new buildings and equipment;

- raising the efficiency of appliances as they are replaced;

- switching from electricity to natural gas.

The reduction in electricity use by the year 2010 is best shown in Fig. 2. The maximum technical potential is about $400 \mathrm{TWh} /$ year below the frozen-efficiency baseline, which represents a reduction of approximately $40 \%$. The next phase of this project involves refin- ing the supply curve in response to extensive comments from reviewers, calculating achievable potential from the technical potential estimates, and creating a supply curve for U.S. office buildings. These efforts will continue in FY 1993.

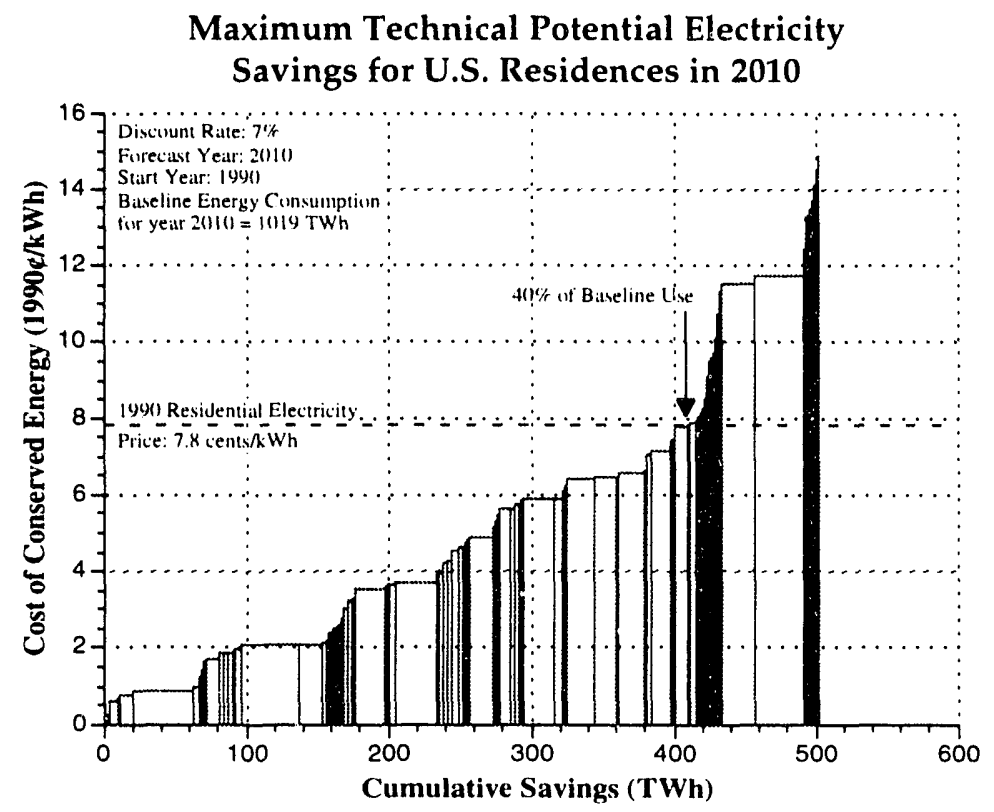

\section{Figure 1.}

A supply curve of conserved electricity. Each step represents a conservation measure. Height of each step is the measure's cost of conserved energy (cents/kWh); width is the 'stimated savings potential for that measure in the year 2010.
Figure 2.

Electricity use over time for the baseline ("frozenefficiency") forecast, a "business-as-usual" forecast, the achievable conservation potential, and the technical potential. In this analysis we estimate the frozenefficiency baseline and the maximum technical potential.

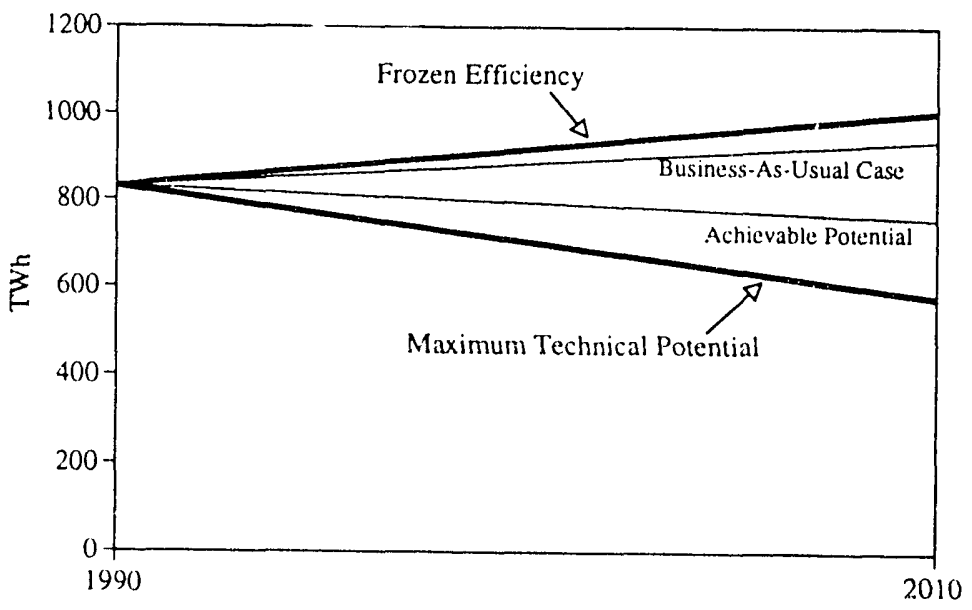

Investigators

$\begin{array}{ll}\text { C. Atkinson } & \text { S. Boghosian } \\ \text { R. Brown } & \text { I. McMahon } \\ \text { A. Meier } & \text { M.D. Lervine }\end{array}$




\section{An Assessment of Future Energy Use and Carbon Emissions in U.S. Residences}

Forecasting models have been used extensively to assess the effect of government policy initiatives on residential energy use. Such analyses have taken on greater urgency because of suggestions that greenhouse gas emissions from energy' use may affect the global climate. This ongoing research (to be completed in FY 1993) explores U.S. residential energy futures and their associated carbon emissions with a simplified representation of the electricity supply mix and a sophisticated end-use model that incorporates econometrically derived elasticities and engineering estimates of the cost of improving energy efficiency in appliances, space-conditioning equipment, and building shells.

This analysis draws upon the LBL Residential Energy Model (LBL-REM), a modeling framework that has been used for analyses of appliance efficiency standards since 1981 . The data in this model have been constantly improved over the past 11 years, by incorporating the results of surveys of appliance manufacturers and home builders and econometrically derived estimates of usage elasticities, crossprice elasticities, own-price elasticities, and other parameters.

This effort has two main purposes: 1) to derive general lessons for policy analyses that seek to understand the relationships between energy prices, energy use, government policies, and carbon emissions, and 2) to describe the characteristics and limitations of LBLREM by analyzing the outputs from a large number of different scenarios. In the process of achieving these two goals, the study will also provide infor- mation about the potential effectiveness of different policy options for reducing residential-sector carbon emissions.

Phase 1 of the analysis describes the input assumptions in detail and then estimates the effect of carbon taxes on residential energy demand and carbon emissions. These taxes are applied to a reference case and to a case in which markets for energy efficiency are assumed to use a utility discount rate to evaluate efficiency improvements. The carbon intensity of electricity production is also varied parametrically to assess the impact of changes in such intensity on the effect of the carbon tax.

Phase 2 of the analysis focuses less on input assumptions and more on an analysis of the effect of different policies in the face of uncertainty. These policies include advanced appliance standards, building standards, carbon taxes, and utility programs. Results will 'se calculated using a range of discount rates and fuel price assumptions.

\section{Reference}

Koomey J, Johnson FX, McMahon JE, Orland M, Levine MD, Chan P, Krause F. An Assessment of Future Energy Usc and Carbon Emissions from U.S. Residences. Lawrence Berkeley Laboratory Report No. LBL32183, 1992.

\section{Investigators}

$\begin{array}{ll}\text { J. Koomey } & \text { M.D. Levine } \\ \text { F. Johnson } & \text { P. Chan } \\ \text { J. McMahon } & \text { F. Krause } \\ \text { M. Orland } & \end{array}$




\section{Residential Forecasting Database}

The residential forecasting database is designed to support improved energy demand forecasting at LBL and within the U.S. Department of Energy. It will be a compilation of all data necessary for end-use energy demand forecasting in the residential sector. This effort is an attempt to assess and document these data systematically and to incorporate them into a computerized database system.

The database includes the following model input data:

- Baseline unit energy consumptions (UECs) of appliances and equipment,

- Baseline appliance and equipment saturations,

- Thermal shell characteristics of buildings,

- Population and households,

- Energy prices, and

- Consumer choice algorithms.

In addition, the database is designed to allow results from various forecasting scenarios to be stored in a readily accessible form. Forecasted data types include:

- Total energy use by fuel,

- Energy use by end use, and

- Market shares, UECs, and energy factors.

Model inputs and outputs, as well as all other information in the database, are fully documented with the source and an explanation of how they were derived. When complete, the database will be used as the source of input data for the residential forecasting models used in the Energy Analysis Program.

The work began with an analysis of existing UEC estimates. We compiled UECs from major data analysis and measurement projects and selectively aggregated the data to determine better model inputs for the most important residential end uses. To date, a prototype database application has been developed and approximately $75 \%$ of the required data has been collected and entered in the database format. The data-collection effort and database program will be completed in early FY 1993.

\section{Reference}

Lecar M, Hanford J. A Database of Residential End-Use Unit Energy Consumption Estimate's. Lawrence Berkeley Laboratory Report No. LBL-32721, 1992.

\begin{tabular}{ll}
\hline Investigators \\
J. Hanford & R. Hwang \\
M. Lecar & F. Johnson \\
I. Koomey & J. McMahton \\
L. Stewart & M.D. Levine
\end{tabular}




\section{Comparison of Residential End-Use Forecasting Models}

In the context of the biennial National Energy Strategy, the U.S. Department of Energy has become interested in the methodological characteristics of enduse forecasting models. This ongoing effort involves a comparison of three residential end-use forecasting models: the Energy Information Administration's Residential Energy End-Use Model (EIA-REEM), the Electric Power Research Institute's Residential Energy End-Use Planning System (EPRI-REEPS), and the LBL R.esidential Energy Model (LBL-REM).

The model comparison required normalization of the higher-level inputs shown in the accompanying figure and execution of the models for representative scenarios. Differences in the forecast results for space heating were assessed in the context of the methodological differences given in the lower part of the figure. We also analyzed the sensitivity of the models to changes in fuel prices and the consumer discount rate. Differences in the characterization of technology choices and in the baseyear calibration of the models were important determinants of differences in energy-consumption trends.

In the next phase of the project, we will focus on evaluations and comparisons of consumer choice algorithms within the EPRI-REEPS modeling framework. We will examine in more detail the structure of the market share algorithms and compare different approaches for representing fuel and technology choices for space heating. We will also analyze and update the efficiency choice algorithms for appliances. Results will be documented in a report to appear in FY 1993.

\section{Reference}

Johnson FX, Koomey JG, McMahon JE. Fuel and technology choice in residential enduse forecasting: evaluation and comparison of three models with respect to space heating. In: Proceedings of the ACEEE 1992 Summer Study on Energy Efficiency in Buildings, August 30-September 5, 1992, Vol. 4. Washington, DC: American Council for an Energy-Efficient Economy, 1992, pp. 4.105-4.115.

Investigators
F. Johnson
I. Koomey
I. McMalon
M.D. Levine'
P. Chan

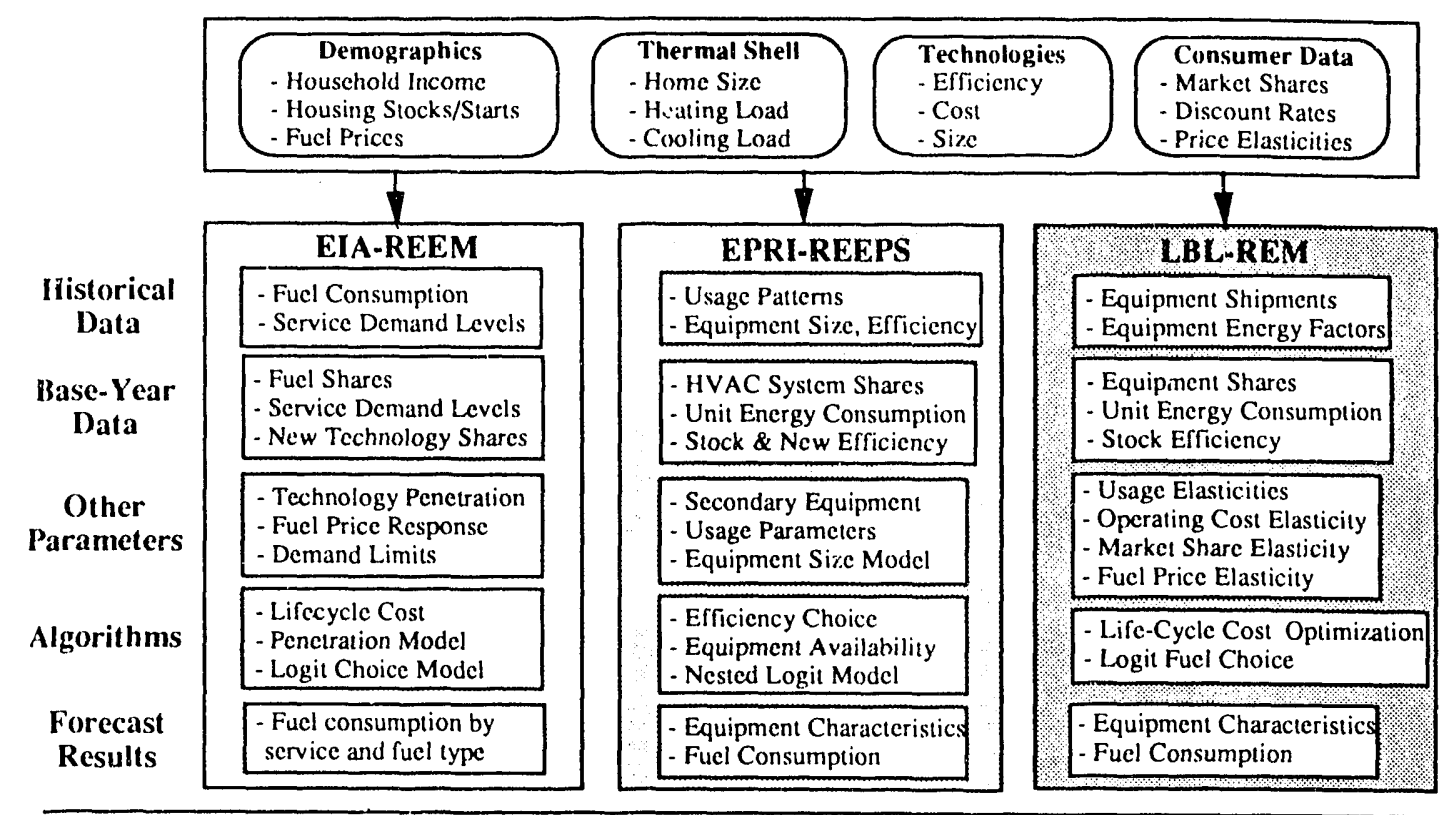

Figure.

Upper part of diagram shows higher-level data segments common to all three models while the lower part of the diagram shows important differences in parameters and methodology across the models. 


\section{Energy Conservation Policy}

\section{Analysis of Federal Appliance Efficiency Standards}

The Energy Policy and Conservation Act (P.L. 94-163), as amended by the National Energy Conservation Policy Act (P.L. 95-619) and by the National Appliance Energy Conservation Act of 1987 (P.L. 100-12) and by the National Appliance Energy Conservation Amendments of 1988 (P.L. 100-357), provides energy conservation standards for 12 of 13 types of consumer products*

\footnotetext{
*Products covered: (1) refrigerators, refrigeratorfreezers, and freezers; (2) room air conditioners; (3) central air conditioners and heat pumps; (4) water heaters; (5) furnaces; (6) dishwashers; (7) clothes washers; (8) clothes dryers; (9) direct heating equipment; (10) kitchen ranges and ovens; (11) pool heaters; (12) television sets; and (13) fluoresccnt-lamp ballasts.
}

and authorizes the Secretary of Energy to prescribe amended or new energy standards. The Energy Policy Act of 1992 (P.L. 102-486) adds five products: (14) general service fluorescent lamps and incandescent reflector lamps; (15) showerheads; (16) faucets; (17) water closets; and (18) urinals, for which test procedures and labels will be developed. This Act sets standard levels for lamps, motors, commercial heating and cooling equipment, and commercial water heaters, and inciudes a schedule for possible amendments to the standards.

Initiated in 1979, LBL's assessment of the standards is designed to evaluate

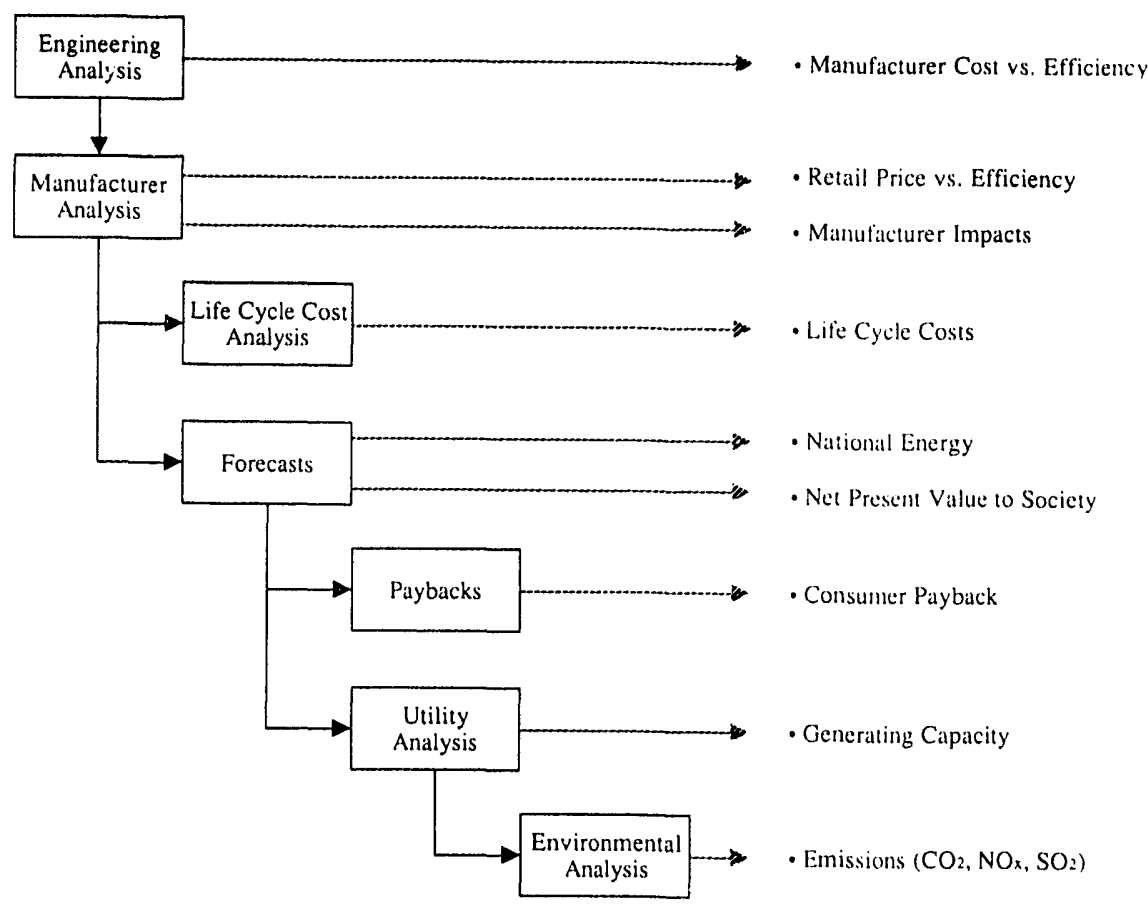

Figure.

Analytic framezoork for the appliance standards analysis.

their economic impacts according to the legislated criteria (Figure).

The economic impact analysis is performed in five major areas:

- Engineering Analysis, which establishes the technical feasibility and product attributes including costs of design options to improve appliance efficiency.

- Consumer Analysis at two levels: national aggregate impacts (forecasts) and impacts on individuals (life-cycle cost analysis). The national aggregate impacts include forecasts of appliance sales, efficiencies, energy use, and consumer expenditures. The individual impacts are analyzed by life-cycle cost, payback periods, and cost of conserved energy, which evaluate the savings in operating expenses relative to increases in purchase price.

- Manufacturer Analysis, which provides an estimate of manufacturers' response to the proposed standards. Their response is quantified by changes in several measures of financial performance.

- Utility Analysis that measures the impacts of the altered energy-consumption patterns $r$, electric utilities.

- Environmental Analysis that estimates changes in emissions of carbon dioxide, sulfur oxides, and nitrogen oxides, resulting from reduced energy consumption in the home and at the power plant.

This year, based on our analysis, DOE began considering possible updated standards for eight products: room air conditioners, water heaters, mobile home furnaces, direct heating equipment, kitchen ranges and ovens, pool 
heaters, televisions, and fluorescent light ballasts. Data collection and analysis began for possible updated standards for refrigerators and freezers, furnaces, central air conditioners, and heat pumps.

We also completed data collection and modeling of alternative policies for improving energy efficiency of lighting equipment in buildings, including residential and commercial applications. Results show energy and economic savings for a wide range of policies, including component standards, building codes, incentive programs (rebates and tax credits), and education. The policies differ in magnitude, timing, and certainty of savings, as well as ease of enforcement and administrative burden. In the next year, we will continue the analysis of possible energy efficiency standards for the eight products listed above. We will continue data collection and analysis for possible updated standards for refrigerators and freezers, fur- naces, central air conditioners, and heat pumps.

The Energy Policy Act of 1992 expands the appliance efficiency program at DOE to include lamps, motors, commercial heating and cooling, and commercial water heating. We will perform analysis of some or all of these products, as directed by DOE in 1993.

\section{References}

U.S. Department of Energy, Assistant Secretary, Conservation and Renewable Energy, Building Equipment Division. Energy Conservation Standards for Consumer Products: Water Heaters, Direct Heating Equipment, Mobile Home Furnaces,
Pool Heaters, Ranges and Ovens, Room Air Conditioners, Televisions, and Fluorescent Light Ballasts. U.S. Department of Energy Technical Support Document, 1993 (in preparation)

McMahon, JE. Imperfect markets and energy efficiency. Presented at California Energy Commission Workshop on Market Barriers to Energy Efficiency. Sacramento, CA, July 23, 1992.

McMahon, JE. Quantifying the benefits and costs of U.S. appliance energy performance standards. In: Proceedings of the International Energy Conference on Use of Efficiency Standards in Energy Policy. Sophia-Antipolis, France: Agence de l'Environnement et de la Maîtrise de l'Énergie. June 1992.

\section{Engineering Analyses of Appliance Efficiency Improvements}

The economic impacts of appliance efficiency standards depend largely on the relation between cost and energy consumption of a consumer product. Our engineering analysis seeks to identify this cost-consumption relationship for selected appliances.

In 1992, we modified analyses for eight products: water heaters, pool heaters, direct heating equipment, mobile home heaters, fluorescent ballasts, room air conditioners, ranges/ovens, and televisions. An analysis for lighting products was reviewed and revised in 1992. The advantages and drawbacks of lighting standards and of other lighting energy-conservation policies were addressed. We also initiated engineering analyses for three products: central furnaces and boilers, refrigerators and freezers, and central air condi- tioners and heat pumps.

The engineering analysis consists of the following steps: select appliance classes; select baseline units for each class; select design options for each class; and determine the maximum technologically feasible design, the efficiency improvement, and the cost for each option for each class. Data are obtained through contacts with trade organizations and manufacturers, from suppliers of purchased parts and materials, and from computer simulations.

In 1993, we plan to complete the engineering analysis of three products: central heating, central air conditioning and heat pumps, and refrigerators and freezers. We will also revise our report on the analysis of the eight products (see above), after receiving review comments.

\section{References}

Atkinson BA, McMahon JE, Mills E, Chan $\Gamma$, Chan TW, Eto JH, Jennings JD, Koomey JG, Lo KW, Lecar M, Price L, Rubinstein F, Sezgen O, Wenzel T. Analysis of Federal Policy Options for Improving U.S. Lighting Energy Efficiency: Commercial and Residential Buildingrs. Lawrence Berkeley Laboratory Report No. LBL-31469, 1992.

U.S. Department of Energy, Assistant Secretary, Conservation and Renewable Energ;, Building Equipment Division. Energy Conservation Standards for Consumer Products: Water Heaters, Direct Heating Equipment, Mobile Home Furnaces, Pool Heaters, Ranges and Ovens, Room Air Conditioners, Televisions, and Fluorescent Light Ballasts. U.S. Department of Energy Technical Support Document, 1993 (in preparation).

$\begin{array}{ll}\text { I. Turiel } & \text { I. Lutz } \\ \text { B. Atkinson } & \text { G. Rosenquist } \\ \text { S. Boghosinn } & \end{array}$




\section{Assessing the Impacts of Appliance Standards on Manufacturers}

The Manufacturer Analysis assesses the impact of appliance standards on the profitability and competitiveness of the various appliance-manufacturing industries affected by mandatory energy efficiency standards. The primary tool used for this evaluation is the Manufacturer Impact Model (LBL-MIM). LRL-MIM uses engineering cost and efficiency estimates as well as collected economic and financial data as inputs. Outputs include price, rate of profit, shipments, revenues, net income, and the standard errors of these estimates. LBL-MIM also provides estimates of retail prices used by the Residential Energy Model (LBL-REM) and the life-cycle cost analysis.

This year we used the LBL-MIM to perform an analysis of the impact of standards on water heaters, direct heating equipment, room air conditioners, kitchen ranges and ovens, pool heaters, mobile home furnaces, televisions, and fluorescent lamp ballasts. The results are contained in a technical support document submitted to DOE, to be published in 1993.

We wrote the manufacturer impact section of a report to DOE on the impacts of federal policies to improve the energy efficiency of lighting in U.S. commercial and residential buildings. Our analysis indicates that the diverse policy options available would not have significant adverse impacts on lighting equipment manufacturers.

Data collection for the next round of products was also begun. The products considered include refrigerators and freezers, central heating equipment (furnaces ard boilers), and central air conditioners and heat pumps. This effort includes a combination of questionnaires to firms; meetings with firms, ind ustry consultants, and trade associations; and plant visits.

In 1993, we expect to analyze public comments on, and begin a re-analysis of, the eight products and complete a preliminary analysis of the next three products.

We will also evaluate GRIM (Government Regulatory Impact Model), a new model under development by a coalition of industry trade associations. The features of MIM and GRIM will be assessed relative to DOE's needs, and the best combination of those features (one model, both models, or a new combined model) will be implemented.

\section{References}

Atkinson BA, McMahon JE, Mills E, Chan P, Chan TW, Eto JH, Jennings JD, Koomey JG, Lo KW, Lecar M, Price L, Rubinstein F, Sezgen O, Wenzel T. Amalysis of Fideral Policy Options for Improring U.S. Lighting Energy Efficiency: Commercial and Re'sidential Buildings. Lawrence Berkeley Laboratory Report No. LBL-31469, 1992.

U.S. Department of Energy, Assistant Secretary, Conservation and Renewable Energy, Building Equipment Division. Eneryy Conserzation Standards for Consumer Products: Water Heaters, Direct Heating Equipment, Mobile Home Furnaces, Pool Heaters, Ranges and Oevens, Room Air Conditioners, Tele'visions, and Fluorescent Light Ballasts. U.S. Department of Energy Technical Support Document, 1993 (in preparation).

Investigators

T. Chan

S. Stoft 


\section{Analysis of Federal Policy Options for Improving U.S. Lighting Energy Efficiency: Commercial and Residential Buildings}

In 1990, lighting systems in the U.s. consumed approximately $515 \mathrm{TWh}$ ( $19 \%$ of national electricity use) or 5.9 primary Quads (7\% of national energy consumption) at a cost of 36 billion dollars. The lighting end use provides a major opportunity for achieving savings by implementing energy efficiency improvements. Considerable interest in energy savings from lighting has been expressed at both the federal and state regulatory levels.

This study was undertaken to determine the impacts of various lighting efficiency standards, incentives, and information policies. We developed and applied a methodology to quantify savings from potential federal policies. We studied policies relevant to the following areas: mandatory component performance standards, system performance standards (e.g., building codes), consumer rebates, consumer tax credits, voluntary component performance standards, consumer/designer education programs, and component labeling. The report included engineering analysis of lighting products, consumer analysis, manufacturer analysis, utility impact analysis, and environmental analysis.

The analysis considered the commer- cial (indoor) and residential sectors. For the commercial sector, the Electric Power Research Institute's COMMEND end-use forecasting model was used. The study bounded national savings estimates between two forecasts, one assuming a baseline with considerable savings (High-Efficiency Baseline) and the other assuming modest savings (Low-Efficiency Baseline) from utility and government programs and standards. Technology-specific policies studied included standards for fluorescent and incandescent lamps, a combination lamp/ballast standard, fixture standards, prescriptive lighting controls, building codes, and combination standards for lamp/ballast/fixtures with controls. The study also analyzed two lamp standards, one proposed in federal legislation in 1991, and the second finalized in the Energy Policy Act of 1992. For the residential sector, the LBL-Residential Energy Model (LBLREM) was used to predict savings from component performance and prescriptive standards for lamps.

The study showed significant energy and economic savings from a diverse set of policies. However, the policies differ in the certainty of savings and administrative burden. The Figure shows a range of the cumulative lighting energy savings by policy for the commercial sector for the years 19952025.

The Energy Policy Act of 1992 mandates performance standards for some fluorescent and incandescent reflector lamps, testing and labeling of other lamps and luminaires, study of highintensity discharge lamp standards, and future lamp standards updates. The law also establishes a framework for amending lamp standards. In 1993, we will provide analysis to DOE upon request.

\section{Reference}

Atkinson BA, McMahon JE, Mills E, Chan P, Chan TW, Eto JH, Jennings JD, Koomey JC, Lo KW, Lecar M, Price L, Rubinstein F, Sezgen O, Wenzel T. Analysis of Federal Policy Options for Improzing U.S. Lighting Energy Efficiency: Commercial and

Residential Buildings. Lawrence Berkeley Laboratory Report No. LBL-31469, 1992.

\section{Investigators}

$\begin{array}{lll}\text { B. Atkinson } & \text { J. Eto } & \text { L. Price } \\ \text { I. McMahom } & \text { I. lennings } & \text { F. Rubinstein } \\ \text { E. Mills } & \text { I. Koomey } & \text { O. Sezgen } \\ \text { P. Chan } & \text { M. Lecar } & \text { T. Wenzel } \\ \text { T. Chan } & \text { K. Lo } & \end{array}$

Quadrillion Btu (Primary)

Figure.

Rang're of cumulation' lighting cin'rgy savings by policy 1995-2030, commercial sector. Percentages are portion of respective baseline lighting conergy; tops of bars represent savings under Lozu-Efficiency Baseline, bottoms of bars represent savings under HighEfficiency Baseline. $L C C=$ life-cycle cost.

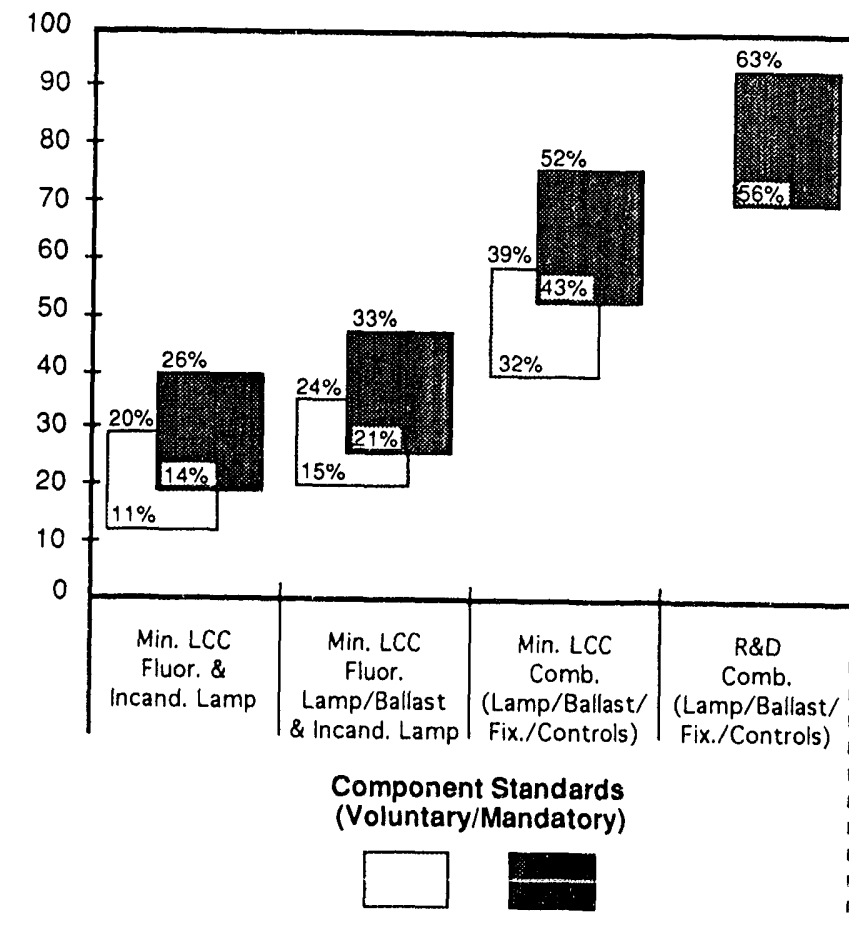

Site TWh

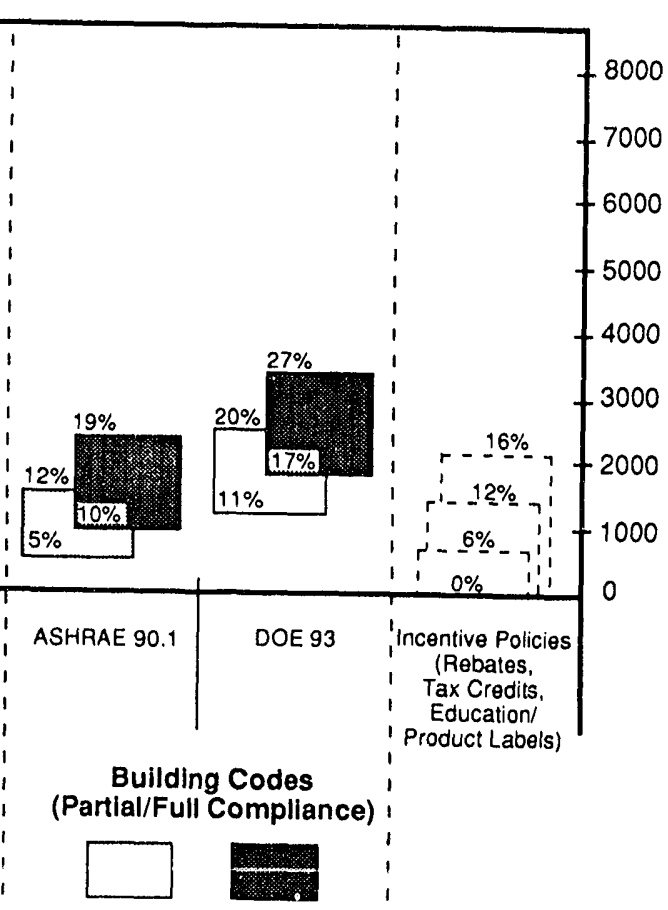




\section{Utility Planning and Policy}

\section{Future Directions: Integrated Resource Planning}

Integrated resource planning (IRP) is the process for integrating supply - and demand-side resources to provide energy services at a cost that balances the interests of all stakeholders. It now is the resource-planring process used by electric utilities in more than 30 states. The goals of IRP have evolved from leastcost planning and encouragement of demand-side management to broader, more complex issues including core competitive business activity, risk management and sharing, accounting for externalities, and fuel switching between gas and electricity.

In 1992, we prepared a status report on IRP as it is practiced today. We also suggested how IRP is transforming itself to pursue new objectives in a changing energy and competitive landscape.

IRP is primarily a process that has come of age within the investor-owned electric utility (IOU) sector. Originating in the 1980s in a handful of states as "least-cost utility planning (LCUP)," the objective of the effort was to rationalize the means of providing energy services to ratepayers. Utility motivation lay in avoiding the high cost of new generation, adopting smaller-sized resources, which would provide flexibility for handling uncertainties, and repairing badly frayed regulatory and public relations. Other parties had other motivations for seeking entry into the utilityplanning process. Energy conservationists sought to increase a utility's commitments to cost-effective energy efficiency. Environmentalists sought entry to advance an environmental agenda that, in turn, was closely tied to developing efficiency alternatives. These developments coalesce around several themes: the emergence of energy efficiency as a resource option, the process of IRP as an improved means for balancing resourceplanning objectives, and finally the changing structure of the electricity industry. These themes, in turn, are the points of departure for our views on the near-term challenges for IRP in the electric and gas sectors.

These challenges fall under two broad headings: (1) the maturation of IRP within the IOU electric utility sector currently practicing IRP, and (2) the expansion of IRP principles beyond this part of the industry.

While some form of IRP is being practiced by many utilities across the nation, IRP faces important challenges if it is to prove a robust planning method for meeting society's energy service needs. The excess capacity of the 1980 s-where it can still be found-will disappear before the end of the century. Utilities will have to plan for the retirement or repowering of their aging installed capacity. Non-utility generation and demand-side management have demonstrated their important roles in meeting future resource needs. At the s.me time, environmental and other non-market-priced costs of delivering energy services have increased in importance. For IRP to be successful, it must balance fairly these concerns to ensure equitable market shares for these (and other, as yet, unknown) options for providing future energy services.

We are also exploring the prospects for applications of IRP in those parts of the industry where IRP has not been formally adopted. IRP started within the IOU electric utilities largely as a result of state rules and directives on the East and West Coasts of the country (and in Wisconsin). Our review includes other IOU electric utilities, nonIOU electric utilities, regional electric or multi-utility planning, and lastly the natural gas industry.

Extending IRP principles to regional and inter-fuel issues will be a daunting task, challenged by a geometrically expanding number of affected institutions, jurisdictions, interests, and agendas to accommodate. Perhaps lessons learned from the IRP collaborative process will be helpful in successfully managing this expanded number of interests toward common goals. But any success will depend upon appreciating what has to be in place for IRP to have a chance of succeeding. We are studying those factors and also speculating about the possible application of IRP type "thinking," at least to a wholly different set of pressing public issues including transportation, surface water management, and national health care.

We believe there are many other settings where IRP "instincts" could find application. Increasing competition for scarce capital for public activities of all sorts and linkage between activities, e.g., gas-electricity, electricity-tranisportation, and electricity-water, will compel an application of IRP-like principles to achieve efficient and adequate results to a large group of affected and active stakeholders. We should anticipate further transformations of IRP in the years ahead. It would come as no surprise to us that in the next look at "Future Directions of IRP," developments within electricity will occupy one-third of the discussion and the applications outside energy the other two-thirds. Then we might comprehend the ultimate value of the uncertainly defined, highly useful, and ever transforming process we have come to know as integrated resource planning.

\section{Reference}

Bauer D, Eto J. Future directions: integrated resource planning. In: Proceeding's of the ACEEE 1992 Summer Study on Energ'y Efficiency in Buildings, August 30-September 5, 1992, Vol. 8. Washington, DC: American Council for an Energy-Efficient Economy, 1992, pp. 8.1-8.6.

\footnotetext{
Investigators

J.H. Eto

D.C. Baucr *

* Oak Ridge Nationel Laboratory Oak Ridge, TN
} 


\section{Transmission Planning in the Era of Integrated Resource Planning: A Survey of Recent Cases}

Electric power transmission syscem issues are increasingly important as utilities and their regulators evaluate options for expanding the capacity of utility systems and increasing the competition in the generation sector.

There has been growing interest in this subject, accompanied by a substantial policy ciebate. The focus of this debate has been primarily at the national level. Yet state action is critical to the expansion of the high-voltage transmission network because regulated utilities must seek approvai from utility commissions for proposals to site new lines. The siting process brings all the policy issues debated in gei.eral rerms down to case and circumstance specifics.

The purpose of th: project is to survey the regulatory treatment of issues that are unique to or ubiquitous in transmission planring and use. We review recent transmiscic $n$ siting cases to examine how the issues are presented tn and resolved by state regulatory commissions and to provide a perspective for nore general discussion of transmission policy. Our primary focus is on planning issues. Regulatory approval requires that salisfactory answers be given to the basic question, "Why should a particular project be built?" This is typically the framework aciopted when utilities propose new bulk power capacity facilities.

Transmission capacity expansion is not typically treated in integrated resource planning. It is usially assumed that there is adequate transmission to achieve any particular plan. We believe that one imp. rtant reason for this omission is the inherent complexity of trans- mission system expansion. It is among the most technically difficult aspects of electric utility planning and $o_{F}$ rations, relying on detailed teciunical data. This complexity is exacerbated by conflicts that arise from the increasing competition in the generation sector. This competition leads to conflicts over the use of the transmission system.

Unfortunately, handling difficult and detailed technical information in settings of conflict can easily lead to opportunism. Regulators and competitors may be at a serious disadvantage in negotiating or adjudicating specific transmission proposals with utilities, who generally have greater knowledge of both general technological considerations and case specifics. This problem of asymmetric knowledge must be addressed at some level in planning and dispute resolution. However, we will observe that explicit consideration of the information problem is absent from most regulatory and technica! analysis of transmission.

We first define a typology of issues that will be used to organize our survey of cases. The typology considers three general categories' institutional, technology structure, and informational complexity. The case studies are divided into three groups. In one group we examine the treatment of transmission in utility Integrated Resource Plans (IRPs). We find that current practice of IRP involves a very limited role for transmission issues. These limits are due to the information complexity problem, the regional niiture of major transmission projects (as opposed to the state focus of IRP), and other factors.
In the second group, we examine transmission construction projects under the jurisdiction of state commissions. Each study highlights one or more of the issues raised in our typology. Collectively, the studies indicate that errh of the issues we raise has been left unresolved in practice in some major transmission project.

Third, we review a number of initiatives by bot 1 . private and public organizations for frameworks to resolve transmission issues. They treat both the issues involved with new construction, and also access to visting transmission by third parties. vve examine each proposal, legislation, framework, or case from the perspective of the issues described in our typology. We ask, "If the key points of this initiative were used to assess the transmission projects described in our case studies, then would the basic issues be resolved coherently?"

We conclude that many policy proposals perform relatively poorly on various issues; however, combinations of initiatives, particularly combinations of complementary state and regional initiatives, may be able to resolve almost all of the issues simultaneously.

\section{Reference}

Baldick R, Kahn E. Transmission Planning in the Era of Integrated Resource Planning: $A$ Surcey of Recent Cases, Lawrence Berkeley Laboratory Report No. LBL-32231, 1992.

Investigators
E. Kahn
R. Baldick




\section{Evolution of DSM Bidding:}

\section{A More Constructive Role for Energy Service Companies}

This study explored alternative program designs that involve energy service companies (ESCOs) in the delivery of demand-side management (DSM) resources and which attempt to address problems that have risen in the first generation of utility DSM bidding programs. The Table provides a capsule history of the evolution of DSM bidding. The origins of DSM bidding in the mid-1980s can be traced to pilot performance contracting programs that relied on competitive solicitations to select third-party providers of comprehensive DSM services. Often, the principal objective was to experiment with ESCOs as an alternative DSM delivery mechanism and, in some cases, these programs were promoted by regulators who were frustrated by the utilities' failure to aggressively implement DSM.

The principal rationale for ESCO involvement changed however as the regulatory context shifted toward efforts to apply integrated resource planning (IRP) concepts to competitive resource acquisition processes (see Table, second-generation programs). Several regulatory commissions accepted arguments in favor of "allsources" integrated bidding, in part because it sent an additional signal to utilities that DSM resources should be considered on a comparable basis with supply-side options. In these bidding programs, independent power producers and ESCOs are competing against the utility to acquire electric resources, i.e., their efforts "replace" the utility's efforts. Most of the problems that arose in these solicitations are a byproduct of the difficulties involved with direct comparisons of supply and DSM options in resource acquisition. Problems include: bid evaluation and scoring systems that do not establish appropriate weights for non-price factors relevant to DSM; measures of cost-effectiveness that do not account for the manifold costs of DSM programs (i.e., utility, customer, and societal costs); and contract terms and conditions that are not well suited to DSM resources.

During this same period, a number of other utilities initiated DSM bidding programs without significant urging from their regulators. Most of these utilities were less experienced with DSM and viewed bidding as an effective way to assess DSM market potential and jump-start their DSM efforts by building on the experience of ESCOs.

The next (i.e., third) generation of bidding programs will include "partnership" bidding in which ESCOs offer to provide saved energy or comprehensive services that complement and expand on the type of activities offered by utilities, "replacement" bidding in

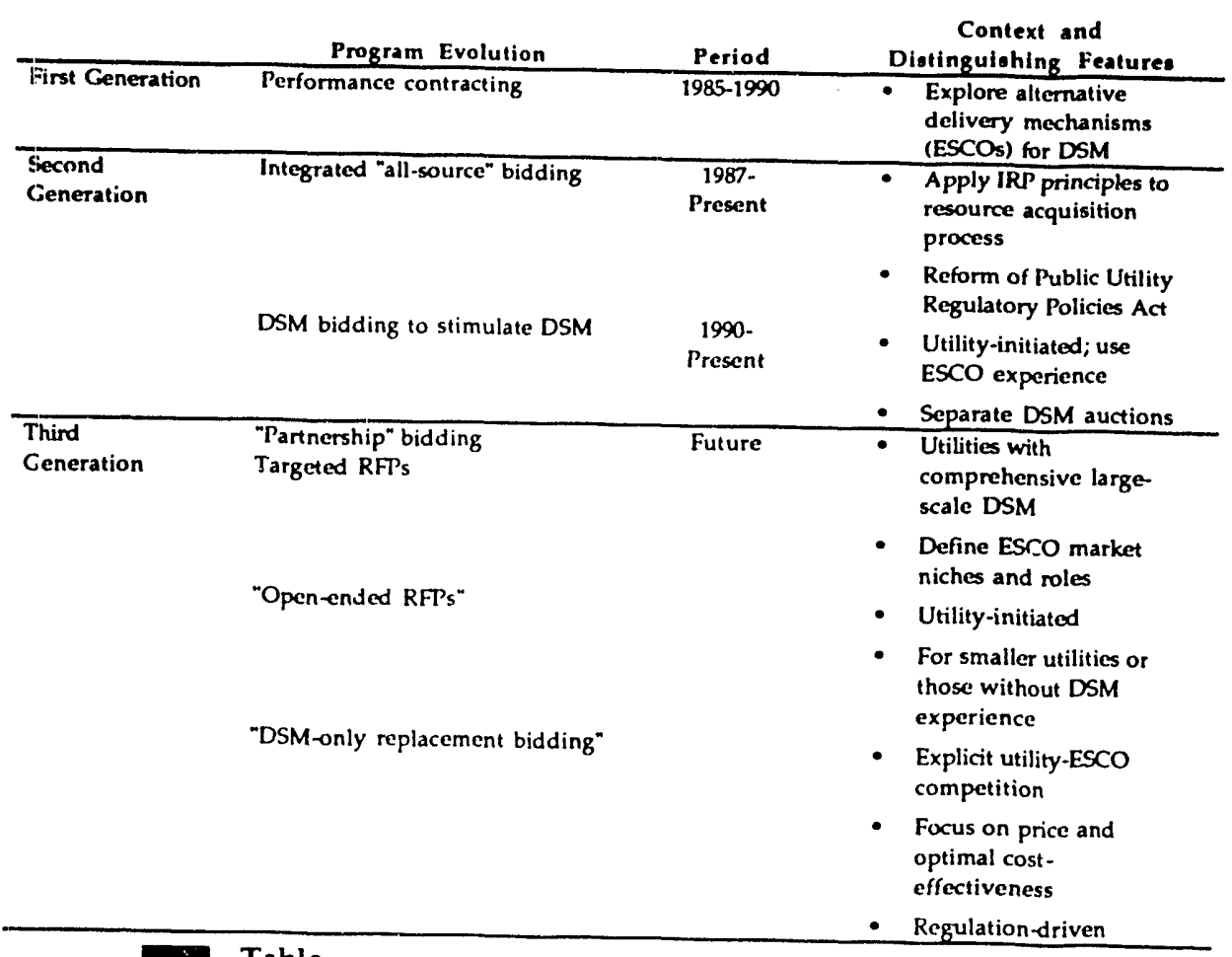

Evolution and future prospects of DSM bidding. 
which ESCOs compete against a utility's own program, and DSM "standard offer" contracts which allow ESCOs to sign up customers and receive a fixed price for energy savings. In partnership bidding, there is an explicit recognition that utility and ESCO activities are complementary and that the ESCO in effect acts as an agent of the utility.

For utilities that already offer comprehensive DSM programs, DSM bidding will involve more targeted and narrowly focused solicitations (e.g., specific market niches or sectors). From a policy perspective, a crucial issue is to what extent the utility's DSM planners are allowed to define and shape the roles and types of services provided by various entities in the energy services market (e.g., ESCOs, vendors, contractors, equipment manufacturers, trade allies) that are involved in the delivery of the utility's DSM programs.

For those utilities that have not had much experience implementing DSM, the bidding programs could involve open-ended, broad requests for proposals (RFPs) that seek offers from large customers or ESCOs because the utility does not have to address coordination issues with its own DSM programs. In the future, smaller utilities that are resource-constrained might find that ESCOs are ar. tractive way to deliver DSM. However, these programs are relatively complex to design and administer so relatively inexperienced litilities will need to proceed cautiously.

Over time, the attention of regulators will shift from ensuring that DSM programs are cost-effective and can produce long-term, reliable savings to ways to ensure that utility DSM programs are being delivered in an optimal fashion. As these types of concerns are raised, we would expect to see more experimentation with "demand-side only replacement bidding programs" that will focus on explicit "price" competitions between non-utility entities and utilities to deliver specified DSM programs. Based on limited experience to date, these types of structured competitions will require significant regulatory oversight. The challenge in these programs will be to articulate objectives clearly, assess anticipated benefits to ratepayers, and avoid destructive competition.

\section{Reference}

Wolcott DR, Goldman CA. Moving beyond DSM bidding: A more constructive role for energy service companies. In: Procedings of ith ACEEE 1992 Summer Study on Energy Efficiency in Buildings, Augusst 30-September 5, 1992. Vol. 8 . Washington, DC: American Council for an Energy-Efficient Economy, 1992, pp. 8.177-8.186.

Investigators C.A. Goldman D.R. Wolcott * ${ }^{*}$ RCG/Hagler, Bailly, Imc. Arlington, VA

\section{Analysis of Residential End-Use Metered Data to Improve Electricity Demand Forecasts}

Forecasting electricity demand in an era of integrated resource planning requires detailed information on the enduse energy services provided by electricity. End-use information on the hourly pattern of electricity use is especially important because electricity cannot be readily stored. As a result, electricity resource-planning decisions (on both sides of the customer's meter) are strongly influenced by the expected timing and magnitude of system peak demands.

This project represents a collaborative research effort by Pacific Gas and Electric Company (PG\&E) and the California Energy Commission (CEC) to develop a common set of residential sector end-use, load-shape-forecasting inputs from the end-use metered data collected by PG\&E from over 700 customers. While the individual features of the forecasting models used by PG\&E and CEC precluded development of an identical set of inputs for both, the application of consistent analytical approaches to the metered data ensured agreement of the modelspecific results.

The project was organized in three phases: (1) data review; (2) modelspecific data input development; and (3) exploratory analysis, focusing on the CEC model framework.

For the CEC model, we analyzed five years of residential air-conditioning data to develop time-temperature matrices. Time-temperature matrices express hourly air-conditioning energy use as a function of both time of day and a measure of climatic severity called the temperature-humidity index. A single matrix was developed from all five years of data. To ensure continuity between adjacent values and also to allow CEC to use the matrix to forecast conditions not observed in the original data, we developed an extrapolation and smoothing technique and applied it to the data.

We conducted limited evaluations of the accuracy of the time-temperature matrix in "predicting" the actual load observations that were used in its development. We found that there are important, but not well-appreciated, trade-offs in accuracy between the different forecasting applications of the CEC time-temperature matrix and the PG\&E model. That is, the matrix is not currently capable of forecasting all quantities of interest with equal accuracy. For example, in forecasting loads on the system peak day, there are tradeoffs in accuracy between forecasting the absolute $\mathrm{kW}$ value of the peak for the 
space cooling end use, the timing of that peak, and the load that is coincident with the time of the system peak. At the present time, the relative importance of these trade-offs has not been assessed.

For the PG\&E model, we analyzed five years of residential air-conditioning data to develop daily weather response functions and binned hourly load shapes according to definitions established by PG\&E in previous research. The weather response functions allocate forecasts of annual energy use (developed by a separate PG\&E forecasting model) to the days of the year based on a combination of average temperature on the current and previous two days. We also identified options for future en- hancements to the specification of the functional form of the weather response function and its development from the metered data.

We also initiated an exploratory analysis to address issues regarding the cost-effectiveness of end-use metering. Working within the framework of the CEC model, we considered (but by no means reached complete resolution of) two issues: to what extent does air-conditioning energy use vary by region within the large PG\&E service territory; and how does inclusion of additional years of metered data improve the accuracy of the load shapes.

End-use metering is expensive. Its cost must be justified by the value that the information collected brings to the planning process and to other uses of the data. We believe that this value is enhanced by cooperative research sponsored by the uitimate users of the data. We also believe that we have only begun to tap the wealth of information contained in them.

\section{Reference}

Eto J, Moezzi M. Analysis of PGEE's Residential End-Use Metered Data to Improve Electricity Demand Forecasts. Lawrence Berkeley Laboratory Report No. LBL-32118, 1992.

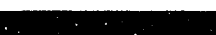

Investigators

J.H. Eto

M. Moezzi

\section{Case Study of Integrated Resource Bidding}

Since the mid-1980s, many U.S. electric utilities and their regulatory agencies have been experimenting with competitive resource-procurement procedures as a more efficient way to encourage private electricity supply. In 1988, the New York Public Service Commission ordered the state's investor-owned utilities to develop competitive bidding programs that included both supply- and demandside management (DSM) resource options. In response, the Niagara Mohawk Power Company (NMPC) issued a request for proposals (RFP) in 1989 soliciting offers from potential supply-side and DSM bidders to supply $350 \mathrm{MW}$ of capacity by 1994 . This study is a critical review of this early experiment with integrated bidding, from which a number of policy recommendations on the design and implementation of competitive resource procurements emerge.

- Competitive bidding represents an attempt to introduce the benefits of competition into a largely regulated framework. In the planning and resource acquisition framework practiced in New York (and represented in NMPC's "all-sources," integrated solicitation), the utility defines the total resource need, which can be filled either by independent power producers, energy service companies (ESCOs), large customers, or utility-sponsored generation projects (Figure). However, integrated bidding creates real or potential conflicts which involve placing the utility in both the buyer and seller role. Our analysis suggests that "selfdealing" problems, even if they are primarily perceptual, undermine the credibility of competitive processes. Competitive processes work best when applied to a set of competitors that have relatively equal market power. Thus, an alternative model of the relationship between planning and bidding should be examined in which the utility regulatory commission makes an initial determination of resource and supplier mix issues as part of their review of a utility's integrated resource plan. The effort to determine market share in advance would allow participation of the utility and its resources on a priority basis, reserving the competitive process for residual needs. On the demand-side, the utility would offer a combination of its own programs and programs delivered by ESCOs. The primary advantages of this "preferred resources" approach would be to reduce the potential for self-dealing by the utility. This administrative approach is admittedly "second best," but it would then allow competitive bidding processes among independent power producers to function more efficiently and fairly. These more targeted and structured solicitations would still preserve the "yardstick" function of competition in regulated industries, as well as a potential "second-sourcing" capability in the event of poor utility performance.

- There are two broad approaches to evaluating bids: "open" and "closed." "Open" approaches typically employ scoring systems with specified point values for various project attributes that bidders can self-score, and which allow an objective method for ranking bids. The most important element of a scoring system 
is that the buyer's preferences and relative valuations of major bid evaluation criteria are explicitly communicated in the RFP; however, this can be accomplished without relying on self-scoring. "Closed" bid evaluation systems represent an alternative approach that emphasizes discretion for the utility in selecting the optimal mix of projects and negotiated solutions with bidders. In our view, the preferred approach is strongly influenced by the utility's decision regarding its own participation as a seller in the bidding process. Objective, self-scoring systems are probably the most appropriate bid evaluation process in situations

\section{New York Planning/Acquisition Framework}

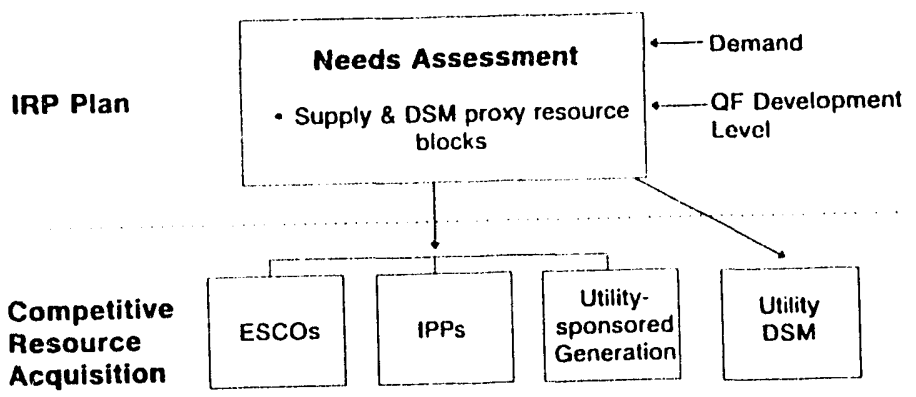

\section{Alternative Planning/Acquisition Framework}

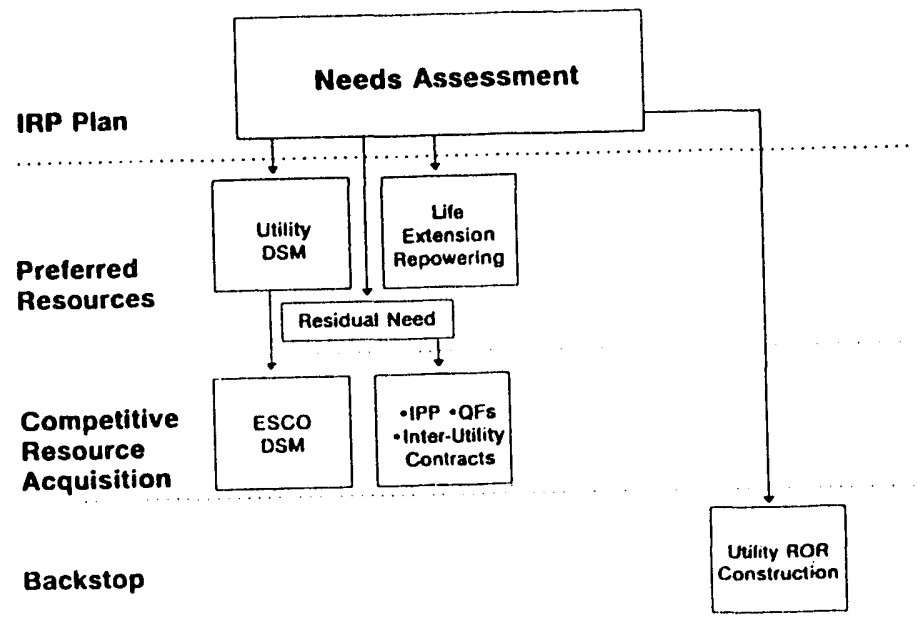

Figure.

Alternative models for the relationship between planning and competition (IRP = Integrated Resource Planning: $Q F=$ Qualifying Facilities: $I P P=$ Independent Power Producers; $R O R=$ Rate of Returu).

where utility affiliates are allowed to participate or utility life-extension/repowering projects are included.

- Separate solicitations for DSM and supply-side resources are preferable given inherent differences in resource characteristics and market structure. This allows utilities to design scoriı'g systems that are specifically tailored to evaluate the attributes and distinctive features of each resource.

- Few large customers are likely to participate in DSM bidding programs as currently structured. Customers should be encouraged to participate directly in other DSM programs offered by utilities. Or separate, simplified bidding processes that are specifically tailored to customers should be considered. However, having large customers as "resource suppliers" complicates the utility's traditional relationship, which is based on customer service and poses additional monitoring problems for regulators. Thus, we are not convinced that bidding-type programs are best suited for customers.

\section{Reference}

Goldman C, Busch J, Kahn E, Stoft S, Cohen S. Review of Integrated Resource Bidding at Niagara Mohazwk. Lawrence Berkeley Laboratory Report No. LBL-31667, 1992.

Investigators

$$
\begin{array}{ll}
\text { C.A. Goldman } & \text { E.P. Kalhn } \\
\text { J.F. Busch } & \text { S.O. Stoft }
\end{array}
$$




\section{Analysis of Debt Leveraging in Private Power Projects}

Financial structures in the private power industry differ from those used by regulated utilities. These differences have been the focus of policy disputes. Critics of the private power industry assert that high debt leveraging, characteristic of this industry, confers an unfair competitive advantage by lowering the cost of capital, and that this leveraging is only possible because risks are shifted to the utility. Further, debt leveraging is claimed to be a threat to reliability. On the opposite side, it is argued that debt leveraging imposes costs and obligations not borne by utilities, and so there is no financial advantage. The private producers also argue that on balance more risk is shifted away from utilities than to them, and that provisions for reliability are strong.

In this work we examine the project finance mechanisms used in private power lending in detail, relying on a sample of actual loan documents. Project finance lending, the dominant financial structure in the private power industry, means that the lender looks solely to the assets and cash flows of the project for repayment. The lender reviews the quality of projects, their contracts, and participants to determine the level of risk and appropriate pricing associated with the loan. In the loan agreement itself, the lender will impose constraints on the behavior of project owners and operators to preserve this risk allocation and to manage risks over the long term. The process is much more constraining than corresponding features of corporate finance, where lenders can look to a portfolio of assets as support for their loans.

Our review of project finance for private power shows a consistent approach to imposing operational and financial constraints on project developers and owners. We list below the major areas in which lenders allocate and manage risk.

Managing construction risk means as- suring that the project will be built on time, on budget, and will meet performance expectations. Lenders control operating risk by imposing operational controls. Financial risk is limited by prohibitions on additional debt, restrictions on sale of project assets, maintenance of debt and working capital reserves, and restrictions on the developer's access to project cash flows until all outstanding obligations are satisfied.

Fuel risk is controlled by lender review of fuel supply and transport arrangements and restrictions on changes in these arrangements over the term of the loan. Regulatory and environmental risks are limited by requiring that all permits and other necessary governmental approvals are in place or will be obtained, and that the project will be able to operate within limitations imposed by permits.

In light of this survey, we consider three issues associated with debt leveraging that the Energy Policy Act of 1992 requires state regulatory commissions to examine. These are 1) whether a high degree of leverage creates reliability problems, 2) whether purchasing power through long-term contracts affects the utility's cost of capital, and 3) whether the capital structure used in project finance confers a competitive advantage.

We find that project finance loan agreements provide extensive protection against reliability problems through maintenance and overhaul reserves, insurance, debt reserves, and independent engineering oversight. There is reason to believe that high leverage induces closer management attention to reliability and therefore superior performance to the behavior of regulated utilities. The issues associated with the impact of long-term purchase contracts on the utility cost of capital are probably the most indeterminate of all the leveraging issues, and our investigation of project finance has little to say about it. Finally, the ques- tions of capital structure and competitive advantage are examined in the context of both the cost of capital and the maturity of loans.

We find that the financial effect of shorter loan maturities in project finance more than offsets the cost of capital advantages it may have over typical utility corporate finance structures.

\section{Reference}

Kahn E, Meal M, Doerrer S, Morse S. Analysis of Debt Leveraging in Prizate Power Projects. Lawrence Berkeley Laboratory Report No. LBL-32487, 1992.

Investigators

$$
\begin{aligned}
& \text { E. Kalm } \\
& \text { M. Menl } \\
& \text { S. Doerrer * } \\
& \text { S. Morse * }
\end{aligned}
$$

*MRW and Associate's Oakland, CA 


\section{Global Energy/Environmental Issues}

\section{Oceans as $\mathrm{CO}_{2}$ Sinks}

Critical uncertainties remain in our current understanding of global biogeochemical cycling, particularly the global carbon budget. Carbon dioxide $\left(\mathrm{CO}_{2}\right)$ is an important greenhouse gas, and there is little disagreement over the amounts of $\mathrm{CO}_{2}$ being released into the atmosphere. However, we remain unable to account for all the $\mathrm{CO}_{2}$ that is leaving the atmosphere and going into either terrestrial or oceanic sinks. Oceanic primary productivity, especially "new production," exported to the oceanic bottom waters is an important component of global climate flux. Recently, high-resolution measurements of variation in atmospheric oxygen have suggested that global oceanic new production may be at least twice as high as had been previously calculated based on estimates of ${ }^{14} \mathrm{C}$ uptake by marine phytoplankton. Knowledge of these ocean and coastal margin dynamics is required if one is to understand the slowly changing response of climate to a gradual increase in atmospheric greenhouse gas concentrations.

In an effort to initiate a major effort on oceans research at LBL, a project was begun this year to investigate several research topics related to the fate of $\mathrm{CO}_{2}$ in the oceans. During the first year, these studies focused on three areas: 1) use of ocean color data from satellites to monitor phytoplankton primary productivity in selected Pacific Ocean waters, 2) review of the "iron limitation hypothesis," and 3) initiation of laboratory studies to investigate the relationship between quantum yield of fluorescence and carbon fixation for the purpose of developing new methods to sense remotely chlorophyll production (i.e., primary production) in oceans. The preliminary results of these studies are briefly summarized below.

Remote sensing of phytoplankton biomass and production offer one way to gain an understanding of new production. Ocean surface radiometry data (e.g., from the Coastal Zone Color Scanner [CZCS]) are now routinely used to estimate phytoplankton biomass. However, these data cannot be directly used to estimate phytoplankton carbon production. Studies have been conducted that apply mathematical models of photosynthesis to estimate primary production from surface chlorophyll and incident irradiance.

The major drawback to this approach is that the models are calibrated with the same ${ }^{14} \mathrm{C}$ production measurements that have been brought into question by the global rates inferred from oxygen variations. In an attempt to address this topic, we are comparing satellite imagery (CZCS data of chlorophyll concentrations) to measured levels of primary production off the Southern California coast. From this comparison, we will develop specialized algorithms for the analysis of phytoplankton pigment concentrations from CZCS in areas influenced by Los Angeles Basin aerosols. These revised algorithms will be needed in the future when data from more advanced ocean color scanners become available.

The "iron limitation hypothesis" proposed in 1990 suggests that low concentrations of surface nutrients, especially iron, limit the biological activity, and thus the atmospheric drawdown of $\mathrm{CO}_{2}$ of ocean phytoplankton in polar oceans. According to this hypothesis, if sufficient iron were added to the open ocean in these areas, a "new" $\mathrm{CO}_{2}$ sink would 
result. Through participation in several key workshops, sponsored by the U.S. Department of Energy, the Environmental Protection Agency, and others that have evaluated the iron limitation hypothesis, and through an extensive literature review, we prepared a paper on the use of marine algae as $\mathrm{CO}_{2}$ sinks.

It is clear that new approaches for measuring oceanic primary productivity are needed to address the discrepancy between existing estimates of $\mathrm{CO}_{2}$ uptake by marine phytoplankton and recent high-resolution measurements of variation in atmospheric oxygen. A possible new approach is to monitor phytoplankton processes through the associated emission of fluorescence by chlorophyll $a$. Most of the physiological processes that regulate photosynthesis also have some effect on fluorescence. As an initial step to developing fluorescence-based approaches for measuring ocean primary production, we initiated laboratory experiments to study the fluorescence characteristics of selected phytoplankton species under varying light conditions (Figure). The objective of these experiments is to investigate fluorescence yield under conditions resembling surface layer irradiance and examine the relationship between the quantum yield of fluorescence and carbon fixation. The results of these experiments will help in the interpretation of sea surface fluorescence as observed by various remote sensing platforms.

\section{Reference}

Ritschard RL. Marine algae as a $\mathrm{CO}_{2}$ sink. Water, Air, and Soil Pollution 1992; 64:2893() 3$.

\section{Investigators}

R.L. Ritschard

K.H. Orvis

P.J. Nenle
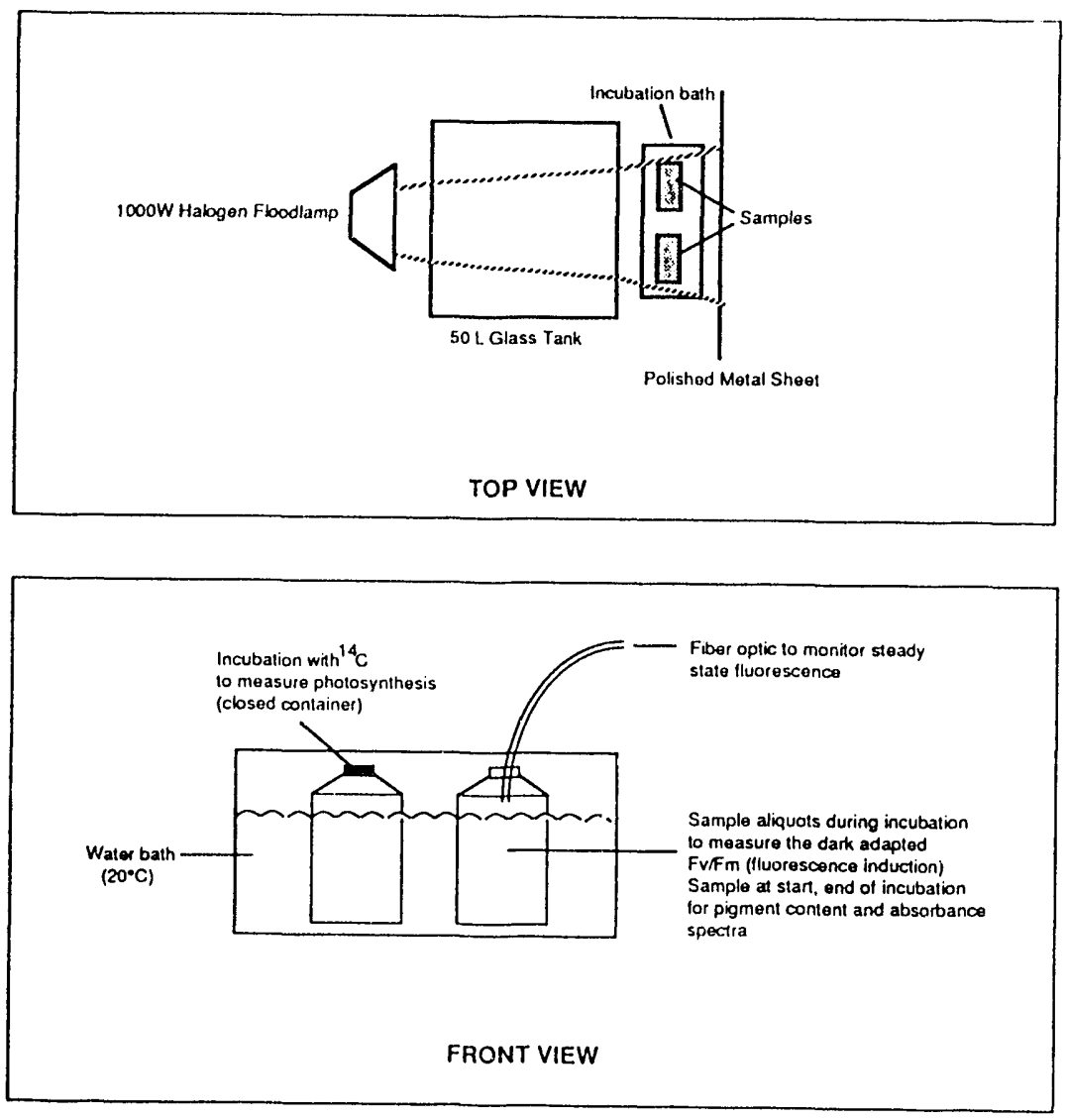


\section{Energy Efficiency and Air Quality in the South Coast Air Basin}

A multiyear project was started last year as part of the California Institute for Energy Efficiency's Emission Reduction Strategies to investigate the direct and indirect effects of end-use efficiency on the reduction of photochemical smog in the South Coast Air Basin. The project addresses two aspects of this broad research area by focusing on 1) existing methods for projecting emissions from fuel combustion and opportunities for reducing these emissions through energyefficiency improvements in the buildings sector, and 2) novel, indirect approaches for reducing or delaying the production of photochemical smog that include varying the surface characteristics of the Basin (i.e., vegetative cover, surface albedo, soil moisture, and roughness length) to reduce temperatures.

The overall goal of this project is to assess both the direct effects of end-use efficiency on emissions (e.g., nitrogen oxides, NO, from the buildings sector and environmental variables affecting them, such as temperature, and the indirect effects of surface changes resulting from trees and white surfaces on smog formation (Figure). Since the indirect approach is broad, studies during the first year focused on how changes in surface characteristics affect meteorological conditions within the Basin (modeled with the Colorado State University Mesoscale Model). During later phases of the study, we plan to evaluate how these surface modifications affect the production of photochemical smog (using the U.S. Environmental Protection Agency's Urban Airshed Model [UAM]) in the Basin. It is anticipated that this multiyear study will help resolve the issue of the causality between urban temperature reduction and smog formation in the Basin and will develop data and model enhancements that can be incorporated into future air quality assessments.

In order to determine the effects of additional trees on air quality of the Basin, a baseline vegetative emissions

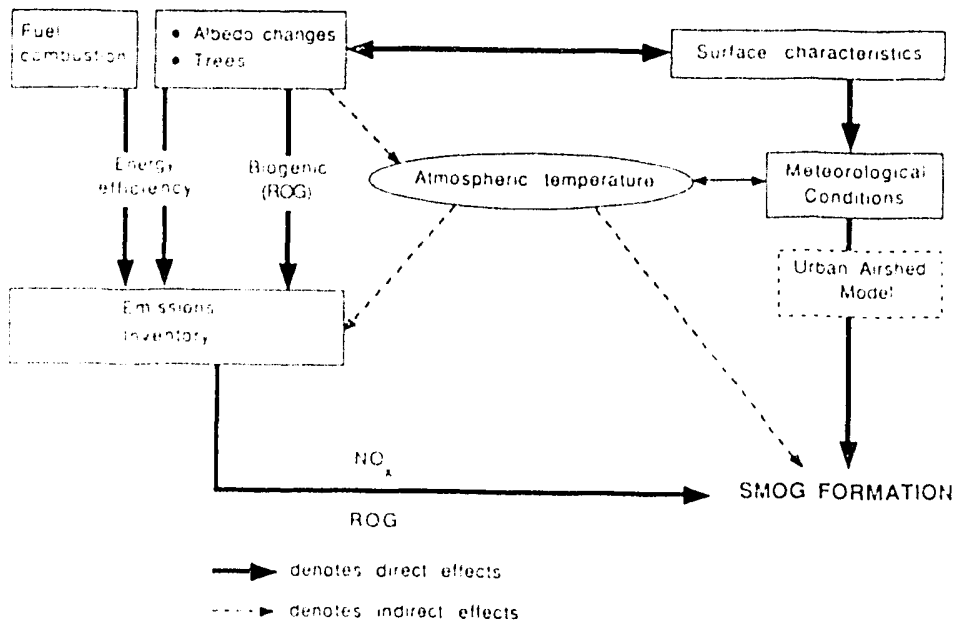

Figure.

Direct and indirect ways to improwe air quality in the South Coast Air Basin (ROG = reactive organic gases).

inventory was developed by the University of California at Los Angeles (UCLA). First, an estimate of the total vegetative biomass was obtained from a previous survey of the Basin, sponsored by the South Coast Air Management District. Next, hydrocarbon emission rates were developed for all identified plant species. The third phase of the UCLA effort was an evaluation of the effects of environmental conditions (e.g., temperature, light intensity, humidity) on vegetative hydrocarbon emissions from plants. The total biomass, emission rates, and an environmental algorithm were used to develop a gridded vegetative hydrocarbon emission inventory for the Basin. The inventory will be included in the UAM and used to predict the impact of vegetative hydroca:bon emissions on the air quality of the Basin.

A characterization of the surface conditions in the Basin was needed to develop credible information about variables that can later be modified and evaluated by prognostic meteorological models. The surface variables included vegetative cover, surface albedo, roughness length, and soil inoisture. This year, using existing data and available methodologies, we developed a preliminary database on these surface characteristics. The database will be modified next year using more advanced methods (i.e., satellite and aircraft data) and onsite measurements.

Meteorological modeling is important to determine to what extent modifications of the urban surface resulting from increased tree planting or increased albedo affect the many meteorological variables. Since the causality between reducing urban temperature and decreasing or delaying photochemical smog episodes has to be demonstrated conclusively, this task provides data that are critical to the overall project goals. To date, LBL (with cooperation from Systems Applications International) has conducted sensitivity tests and preliminary two- and three-dimensional simulations of the mesoscale conditions resulting from changes in albedo, soil moisture, and surface roughness. From 
the initial three-dimensional simulations, we demonstrated the impact of topographical variations and coastal proximity on wind speeds and air temperatures. For example, we found that the variations in surface conditions resulted in average and maximum temperature differences of $-0.44^{\circ}$ and $-3.2^{\circ} \mathrm{C}$, respectively. Next year we will analyze four scenarios: base case (existing Basin conditions), extensive tree planting, changes in surface albedo, and combined effects of trees and albedo changes. The results of these meteorological simulations will serve as inputs to the UAM so that the effects of these surface modifications on smog prodoction can be evaluated.

\section{Reference}

Ritschard R, Winer A, Kessler R, Taha H, Sailor D. Analysis of Energy Efficiency and Air Quality in the South Coast Air Basin: Results of Phase 1. Lawrence Berkeley Laboratory Report No. LBL-33051, 1992.
Investigators

$\begin{array}{ll}\text { R. Ritschard } & \text { H. Talia } \\ \text { A. Winer* } & \text { D. Sailor } \\ \text { R. Kessler } & \end{array}$

* University of California, Los Angeles, CA

${ }^{+}$Systems Applications International

San Ramon, CA

\section{Impacts of Global Climate Change on Cities}

Last year we initiated a study of the potential impacts and mitigation of climate change on energy and air quality with an emphasis on cities since these urban areas have already experienced increased temperature trends over the past several decades. The goal of this work is to understand better the relationship among urban/global warming, air quality, surface characteristics, and regional-scale utility loads. Over the course of this study, we expect to determine the ability of tree-planting programs and changes in surface albedo to reduce annual and peak energy use and temperature within an urban environment. These reductions of temperature may lead, in turn, to a reduction or delay in photochemical smog episodes.

Major tasks during the first year include: 1) characterization of five U.S. metropolitan areas in terms of synoptic weather, long-term urban warming, smog levels vs. urban temperatures, and regional-scale utility load vs. urban temperatures; 2 ) development of scenarios of possible future global warming as predicted by General Circulation Models; and 3) simulation of the potential of large-scale surface modifications for slowing potential future warming trends and offsetting some of their past effects, using one-dimensional climate models.

During the first year, we focused on evaluating the order of magnitude in- volved in urban/global warming, impacts on energy use, air quality (ozone concentrations) sensitivity to temperature, and potentials for mitigation with surface modifications such as massive tree planting and surface albedo changes. In the second phase, the utility load, temperature, and ozone data will be refined. One-dimensional urban meteo- rological simulations were performed for selected urbanized areas for the first phase, but two- and three-dimensiona! models will be used in future years.

The metropolitan areas selected for study are Philadelphia, Los Angeles, New York, Houston, and Denver. These cities were selected because they represent large population areas that

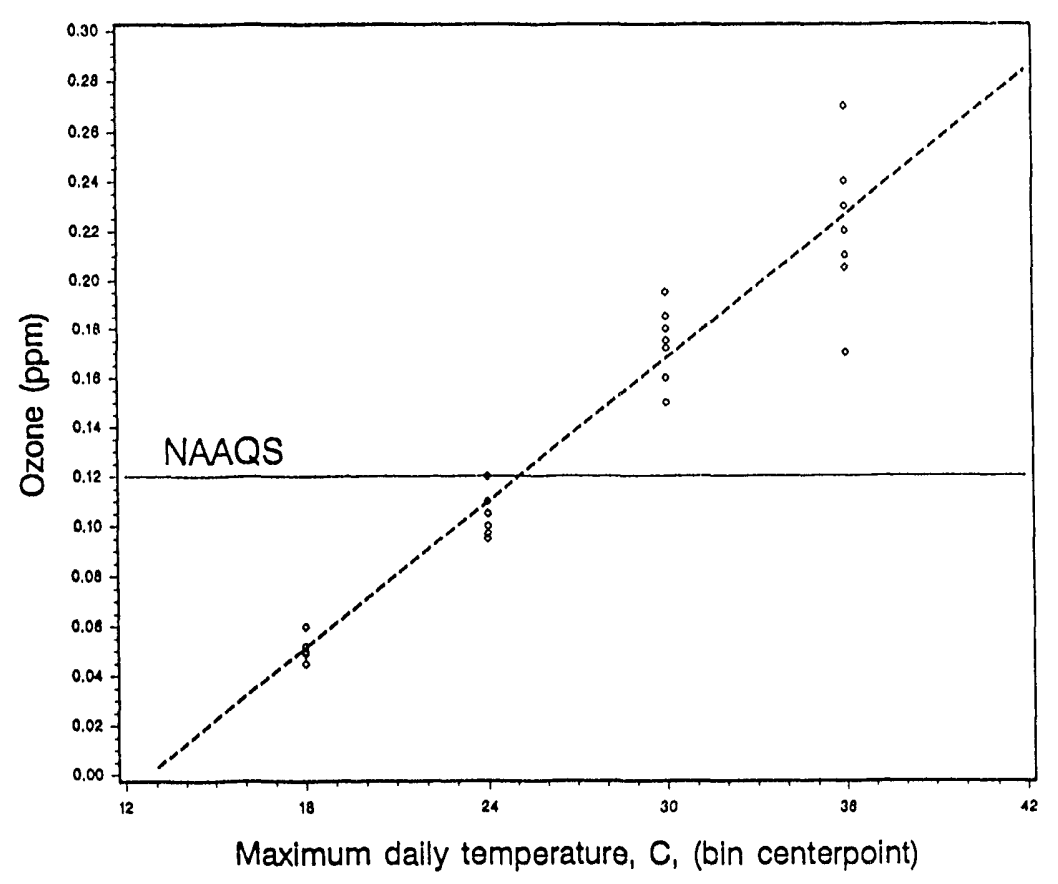

Figure 1a. Average daily maximum one-hour ozone vs. daily maximum temperature for Los Angeles (1980)-89). NAAQS = National Ambicnt Air Quality Standard. 


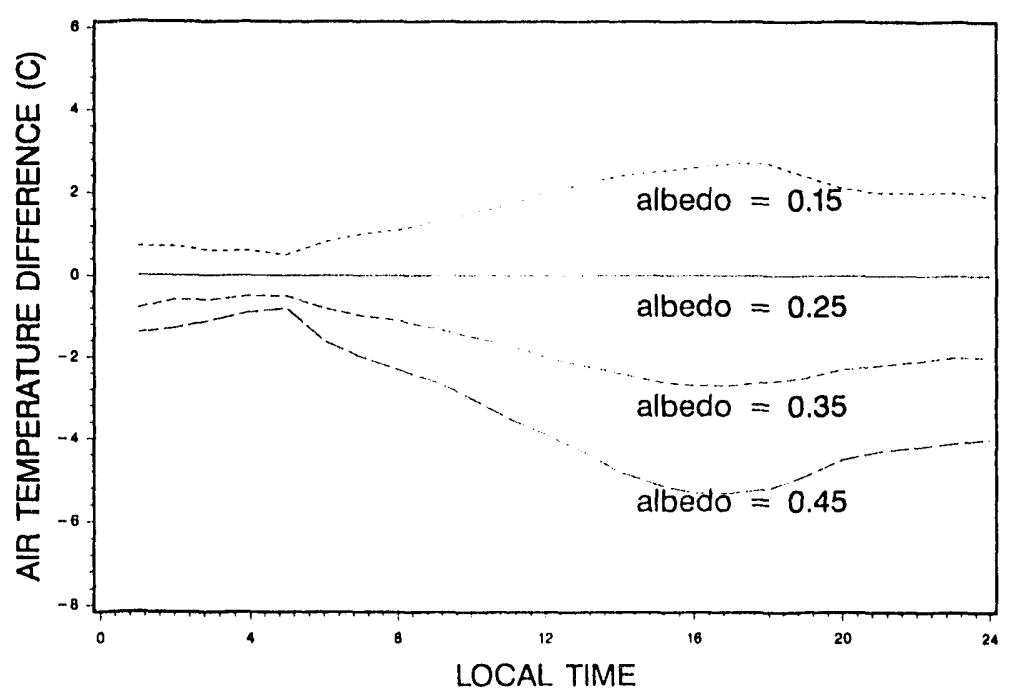

already have experienced periods of poor air quality. Furthermore, over the past 50 years, these areas have warmed by about $1,5,3,3$, and $2^{\circ} \mathrm{C}$, respectively and currently experience a change in system-wide utility load of about $1.3,2$, $2.7,5$, and $1.3 \%$ per $1^{\circ} \mathrm{C}$, respectively.

The correlation between ozone and urban temperatures was investigated. Figure 1a, for example, shows a correlation of these variables for Los Angeles and indicates that lowering urban air temperatures may help reduce smog occurrence. We also investigated the potential of large-scale vegetation and albedo modifications for offsetting all or part of the effects of past urban warming. In Figure 1b, the simulated potential impacts of surface albedo modifications on urban air temperatures show that a change of 0.10 in albedo can result in temperature depressions of $2^{\circ} \mathrm{C}$ in the afternoon on clear summer days. Our simulations of
Investigators

H.G. Taha

R.L. Ritschard the vegetative effects indicate that adding a $20 \%$ vegetation cover to otherwise bare soil has the potential for reducing the air temperature by about $7^{\circ} \mathrm{C}$ under the vegetation in the afternoon on clear summer days. These preliminary onedimensional simulations will be extended to all of the study areas during the second phase and will be refined through the use of two- and threedimensional models.
Figure 1 b.

Air temperature differences $\left({ }^{\circ} \mathrm{C}\right)$, Los Angeles, after albedo modifications (simulated). 


\section{Global Environmental Impacts Network for Developing Countries}

Impact assessments of global climate change conducted to date through the Intergovernmental Panel on Climate Change (IPCC) process have not always been able to consider adequately the potential environmental effects of climate change on developing countries. This deficiency has resulted both from the lack of organization on the part of the environmental scientists in the developing countries and from an inability to articulate clearly country-specific issues. Physical and biological scien- tists as well as policy analysts who can represent the key environmental issues within their countries must form cooperative networks if environmental impacts are to become part of future global climate change assessments. Future impact assessments and country studies will require country-specific data and expertise. In an effort to address this need, a study was initiated in 1992 to establish a network of environmental scientists and policy analysts in key developing countries. Using data

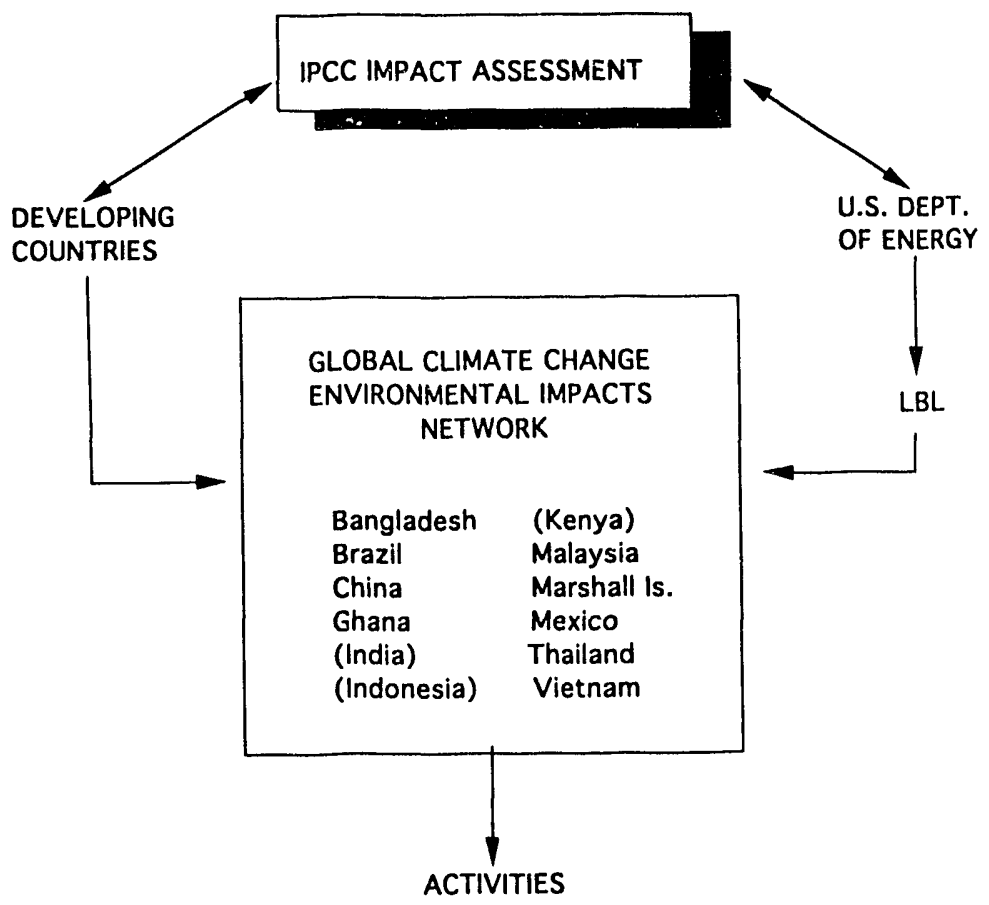

- Identify country-specific issues

- Conduct assessments of these issues

- Share data, methods, and experience

- Convene workshops on impacts in developing countries

- Prepare position papers for DOE

o Participate in IPCC, IGBP \& other activities

Figure.

Schematic of global climate change environmental impacts network (IGBP = International Geosphere-Biosphere Programme).

and expertise from the participating countries, this network will conduct environmental assessments of countryspecific climate change issues (Figure).

The goal of the study during the first year was to organize the network and identify which climate change issues are of critical importance to each country. We selected 12 developing countries for the network and invited participation from each of them. To date, nine countries have agreed to join: Bangladesh, Brazil, China, Ghana, Malaysia, Marshall Islands, Mexic(), Thailand, and Vietnam. We are awaiting confirmation from representatives in India, Indonesia, and Kenya.

We have asked participants to identify key environmental issues facing their countries with special emphasis on those issues perceived as potential impacts of global climate change. We also requested information about available data that might already exist from monitoring activities, satellites, model simulations, and published reports. In addition, we collected information on in-country research capabilities, the availability of resources for doing environmental assessments, and existing in-country environmental expertise. The results of the first year will be documented in a preliminary report that will summarize the environmental science "infrastructure" (i.t., who is doing what, what is currently known) in each country.

Next year, we plan to host a workshop of the network representatives to allow for more in-depth discussion of the specific environmental issues and methodologies and to assist in the selection of one or more assessment topics that will be initiated during the second year of the study. We anticipate that this network will provide DOE with a working group of high-level environmental scientists and policy analysts who can assist DOE in some of its IPCC assessment activities.

Investigators

R.L. Ritschard K.L. Nelson 


\section{China's Energy System: Current Issues, Possible Evolution, and Global Warming}

This project studies three themes that are raised by the energy-consumption patterns in China. The first is the importance of energy for economic development, which has already seen exceptionally rapid growth (averaging more than $10 \%$ real per year since 1982 , the highest of any major country in the world). The second theme is the emphasis that China has placed on energyconservation programs and investments since 1981 . The third relates the consequences of economic and energy grow th to the critical worldwide issue of globa' warming.

China is the third largest consumer of energy in the world after the U. S.and the former Soviet Union. Its system of energy supply and consumption is unique among those of large countries: it relies heavily on coal and biomass, and a large part of commercial energy is consumed by heavy industries. China's pattern of energy resource endow ments virtually ensures that coal will be its main source of energy during the next several decades. Industry will also continue to be the largest consumer and will account for the bulk of increases in energy demand.

The rapid economic growth of China has far cutstripped the ability of energy production to keep pace with demand. While the shortages have had major adverse effects throughout the economy, energy continues to be used in backward and inefficient ways.

In order to achieve its goals, China has reorganized the importance of energy efficiency. It is virtually impossible for energy grow th to keep pace with the economic goal of quadrupling GNP between 1980 and 2000. Energy and economic growth have been partially decoupled in China since 1980. As a result, energy growth fell from 150 to $200 \%$ of economic growth prior to 1980 to $50 \%$ of economic grow th post1980. In our study we examine the changes in energy consumption pat- terns since 1978 that account for the remarkable drop in the energy elasticity of gross domestic product (GDP) ( $\triangle \%$ Energy $/ \Delta \%$ GDP), as well as the policies and programs that caused these changes in consumption patterns.

Energy-conservation investments and policies implemented by the central government during the Sixth and Seventh Five-Year Plans (1981-1985 and 1986-1990 respectively) are examined. The cost of conserved energy of investments undertaken in the Sixth FiveYear Plan was considerably below the cost of new energy supply, and the programs can be considered for the most part successful. The energy intensity of important energy-consuming industrial subsectors decreased markedly over the same period, in part due to the conservation investments.

The significance of China's experience to the international community is important. If the experience of reducing energy intensity can be sustained, China could play a critical role in reducing projected growth of $\mathrm{CO}_{2}$ emissions worldwide even as its share of total emissions continues to grow. The major focus of our continuing research on energy in China is to collaborate with the Chinese in understanding the opportunities for increased gains in energy efficiency.

\section{Reference}

Levine MD, Liu F, Sinton JE. China's energy system: historical evolution, current issues, and prospects. Annual Reriere of Energy and Entrironment 1992;17:405-435.
Investigators

M.D. Levine

F. Lill

J.E. Sinton 


\section{China Energy Databook}

This project, conducted in association with the Energy Research Institute (ERI) of the State Planning Commission of the Peoples Republic of China, resulted in publication of the China Energy Databook, a compendium of data on multiple aspects of China's energy system and related topics. Some of the data in this volume are available scattered throughout other English-language sources, but no other reference dedicated to China has energy as its central theme and pulls together the same variety and quality of material.

Several features of the Databook are worth noting. First, because much of Chinese statistical material is classified as officially secret, we were able to use only material that had been published and was nominally available to the public in China and abroad. Much of the material, however, had limited circulation within China and was difficult to obtain even there. ERI collected much of this hard-to-find information, and its inclusion in the Databook represents a significant contribution to the body of material available to Western analysts. Second, most of the contents of the Databook had not been previously available in English. Lastly, the data have been extensively researched and are annotated more thoroughly than in most of the original sources, making the volume a more useful tool for analysis than other statistical compilations.

The Databook is organized into nine chapters; each details a different aspect of China's energy system. Each chapter has a short introduction, designed to stand alone, covering points of major interest in the chapter. Chapter I describes
China's energy resources (potential energy stocks) and reserves (known energy stocks), and compares them with those of some other major countries.

Chapter II addresses energy production. The major themes are sustained production increases and the dominance of coal, which accounts for $74 \%$ of primary energy production. In addition to information about the supply of main energy sources, data on trends in production capacity and regional differences are also presented (Figure).

Chapter III details investments in China's state-run sector, a key element in preparing near-term forecasts of energy supply. Industry accounts for the greatest part of state investment in China, and the energy ind ustry accounts for $30 \%$ of that. When all investments (including the increasingly large collec-

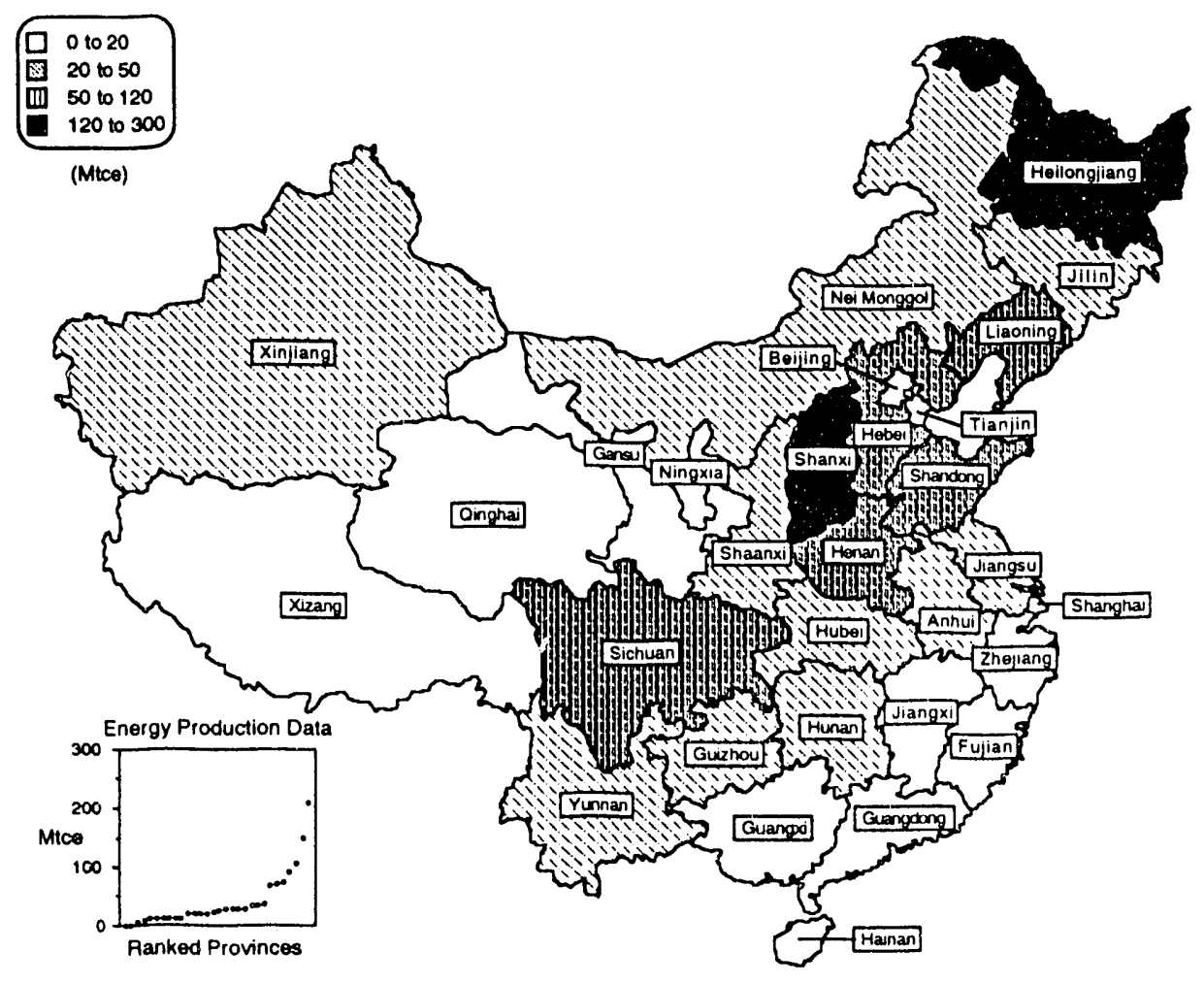

Figure.

Commercial energy production in China. 1989. 
tive and private in 'es' nents) a:e considered, the energy industry still receives about $20 \%$

The fourth and largest chapter of the Datalook addresses energy consumption. Nearly two-thirds of energy is used in industry, a fraction that has remained stable throughout the 1980 s. Of special interest in this section are newly available subsectoral industrial energy consumption data (1980-1990) that are paired with subsectoral gross output value data.

Chapter $V$ describes activities and

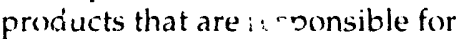
growth in energy demand. The chapter includes trends in transportation, stocks of energy-consuming equipment, and production and energy intensity of a few key inclustrial products.
Impor's and exports of energy and energy-intensive products are presented in Chapter VI. Chapter VII, a short chapter on energy-related environmental topics, $r$ resents the limited data available on carbon dioxide emissions as well as industrial emissions of particulates and sulfur dioxide. Chapter VIII compares Chinese energy data with those from several other countries: India, Japan, the U.S., and the former Soviet Union. The last chapter contains data on various economic indicators (gross national product, gross output value, and nation. 1 in sme) and on population.

Because new energy and other data become available constantly, we plan to issue cipdaies to this volume annually, as well as to expand the scope based on comments from users of the Databook. We intend to reissue the entire volume on a triannual basis.

\section{Reference}

Sinton JE, Levine MD, Liu F, Davis WB, jiang $Z P$, Zhuang $X$, Jiang $K J$, Zhou DD. China Energy Datebook. Lawrence Berkeley Laboratory Report No. LBL32822,1992

\section{Investigators}

$$
\begin{array}{ll}
\text { I.E. Sinton } & \text { Z.P. Jiang* } \\
\text { M.D. Levine } & \text { X. Zhuang* } \\
\text { F. Liu } & \text { K.I. liang* } \\
\text { W.B. Davis } & \text { D.D Zhou* }
\end{array}
$$

"Energy Research linstitufe, State Plaming' Commission, People's Republic of China

\section{Electricity End-Use Efficiency: Experieiıce with Technologies, Markets, and Policies Worldwide}

In its August 1992 meeting in Geneva, Switzerland, the Energy and Industry Subcommittee of the Policy Response Panel of the Intergovernmental Panel on Climate Change (IPCC) requested a report on electricity end-use' efficiency to understanci better opportunities to reduce the grow'th of carbon emissions. We were requested to produce this report, which provides an indepth review of:

- the status of available technologies for increasing electricity end-use efficiency,

- factors currently limiting application of end-use efficiency technolorgies, and

- policies available to increase electricity end-use efficiency.

The report provided detailed analyses of these topics. The major conclusions were as foilow:

- Half of the increases in energy-related carbon dioxide emissions in the last two decades are a result of electricity production. A comparable share is likely tor be produced from eiectricity genes aitum in the future.

- Increases in electricity end-use effi ciency beyond those expected to occur under current policies can significantly reduce the growth of electricity use and associated carbon emissions.

- Because of sufficient experience with both technologies and policies, we can be confident that significant increases in electricity end-use efficiency are possible in practice.

- Many end-use efficiency investments are more cost-effective than new electricity supply investments when evaluated with common criteria (e.g., using the same discount rate).

- Policies such as utility demand-side management programs, information and labeling programs, voluntary and mandatory appliance and building standards, and "golden carrot" financial incentives have been successful in accelerating inv'estments in end-use efficiency. Policies that remove market distortions serve to promote both economic and end-use efficiency. Care must be taken to make certain that poltcres are aciopted that promuie both energy and economic efficiency.
- Making these efticient electricity end-use technologies widely available in developing countries could contribute in important ways to a global effort to increase electricity end-use efficiency, thus reducing growth in electricity supply and in greenhouse gas emissions.

Future work for the IPC.C is likely to involve reviews of technologies, market factors, and policies in various counti es for reducing the grow th of greenhoruse gas emissions.

\section{Reference}

Levine MD, Celler H, Koomesy J, Nadels, Price L. Eneryy End-Lse Effickency: Experience with Techologies, Markets, and Policies Throughout the World. Wa nington, DC: American Council for an EnergyEfficient Economy, 1992

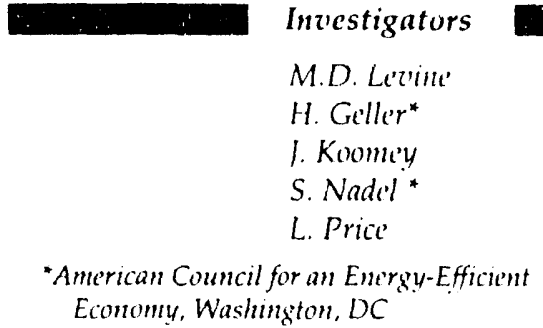




\section{International Energy Studies}

\section{Using Scenarios to Explore Future Energy Demand in Industrialized Countries}

The question of how much energy could be saved in the industrialized countries through improved energy efficiency has been the subject of many studies and considerable debate. To explore this question further, we constructed a plausible portrait of how energy intensities in the member countries of the Organization for Economic Cooperation and Development (OECD) will evolve over the next 20 years, and then we estimated how this projection might be different given changed "boundary conditions" with respect to energy prices and efficiency policies. The scenarios draw on a detailed sectoral database covering the $1970-1988$ period that we developed for the U.S., Japan, and seven European countries. The scenarios are built from patterns of energy use in 1985 for approximately 25 end uses.

Within each sector, each scenario embodies the same growth in activity and structural change. The Trends scenario reflects our judgment about energy efficiency improvements that are likely to occur if energy prices evolve as currently expected and if policies and programs now in place or under development are reasonably effective. In many cases, the stock-average intensities in 2010 are near the average values for new technologies in 1990.

The scenario called Efficiency Push envisions a future in which full adoption of marginal-cost pricing and internalization of some environmental externalities boost real energy prices to

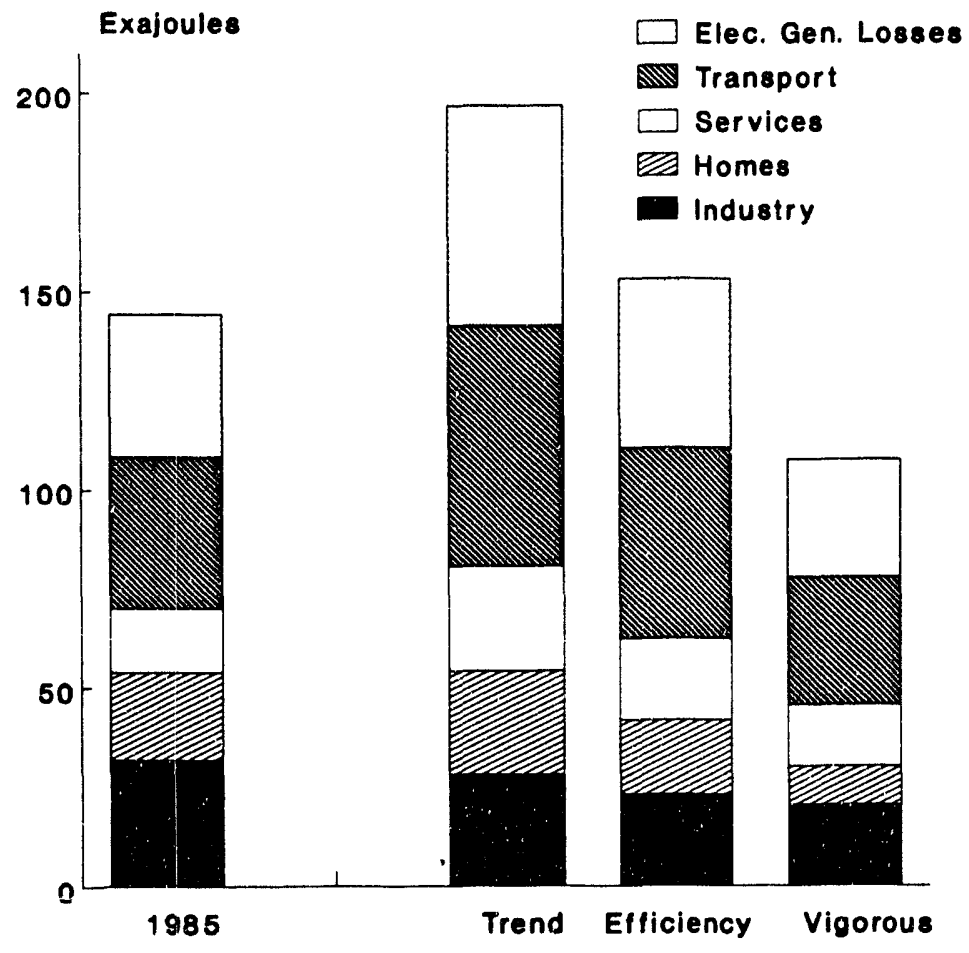

users by $25-50 \%$ relative to the Trends scenario. Governments step up the role of energy efficiency policies, with particular emphasis on automobiles and retrofit of existing buildings. Most intensities decrease between 1985 and 2010 at approximately the same rate as they did between 1972 and 1985. For many end uses, the average intensity levels in 2010 are near the lowest of new technologies in 1989.

The Vigorous Effort scenario depicts what might be attained if energy prices rose significantly, if a very strong effort were made to improve new energy-using technologies, particularly for motor vehicles, and if a comprehensive program of retrofitting buildings and factories were undertaken as well. Energy prices rise to $50-100 \%$ higher than in the Trends scenario, reflecting incorporation of strong carbon taxes as well as more aggressive internalization of externalities associated with local environmental problems related to energy production and use. National and international consensus to improve the efficiency of new and existing technologies is reached in the mid-1990s, leading to rapid response from transnational manufacturers, national and local energy supply authorities, and other actors. Energy efficiency research and development are pursued in earnest, leading to cost reductions. The rate of decline in

\section{Figure.}

Primary energy use in the OECD: 1985 actual and 2010 scenarios. 
intensities resembles that which occurred in the 1979-1983 period, when energy prices and programs stimulated much action to save energy. Average intensities in 2010 lie below the lowest of new technologies on the market in 1989 , but are close to the levels achieved by the best products expected to be available by the mid-1990s, or at levels represented by current prototypes.

Whereas in Trends the energy intensity reductions relative to 1985 are mostly in the 15-25\% range, Efficiency Push results in reductions of $35-50 \%$. Intensities in the Vigorous Effort scenario are $50-75 \%$ less than 1985 levels. The intensities of automobile travel and home heating in particular fall considerably. In Vigorous Effort, the energy/ gross domestic product ratio is about $60 \%$ lower than in 1985 . The improvements in Efficiency Push yield a reduction in total OECD primary energy use in 2010 of $22 \%$ relative to Trends, and demand is about the same as it was in 1989 (Figure). In the Vigorous Effort scenario, energy use is $44 \%$ less than in Trends and is nearly $30 \%$ less than the actual use in 1989.

To judge the plausibility of the intensity declines described in the scenarios, we compared the rates of change to historical experience. The average decline in the weighted average of the energy intensities is $2 \%$ /year in Efficiency Push-slightly less than the $2.3 \%$ /year achieved between 1972 and 1985 . In Vigorous Effort, average energy intensity declines by $3.6 \% /$ year, close to the rate experienced in many countries during the period 1979-1982, when energy prices rose sharply and various policies were implemented. Sustaining such a rate over 20 years would require a major and concentrated effort. It would not take an enormous amount of technological innovation, but would require great effort to accelerate the market penetration of highly energy-efficient technologies and practices.

\section{References}

Schipper L, Meyers S. Using scenarios to explore future energy demand in industrialized countries. Energy Policy (in press)

Schipper L, Meyers S, Howarth R, Steiner R. Energy Efficiency and Human Activity: Past Trends, Future Prospects. Cambridge, UK: Cambridge University Press, 1992.

\section{Investigators}

\section{Schipper}

S. Meyers 


\section{Energy Use in Sweden}

We were asked by the Swedish government to analyze developments in energy use in that country since the 1970s, to evaluate Sweden's achievements in energy conservation, and to compare those achievements with developments in other industrialized countries. In our work, we found that Sweden achieved modest energy savings of $5 \%$ of 1990 primary energy use relative to its position in 1973.

The study was initiated with a thorough analysis of the structure of Swedish energy use-characteristics of housing and household equipment, the structure of transportation activity, the production mix in industry-as well as the use of energy associated with each of these features. From these data we developed time series of energy intensities of energy use per unit of activity or of output for manufacturing industries, of space heating, electric appliances, travel and freight activity, and other energy uses.
From this analysis, we found many surprising characteristics of Swedish energy use. Swedes have the highest indoor living standard in Europe, and own among the most, as well as the heaviest, automobiles. They travel somewhat more than average for people in Northern Europe. Sweden's industrial mix is weighted toward more raw materials than those of most of her neighbors (with the important exception of Norway). This activity mix is important for Sweden: changes in the mix of sectoral activities and structure led to an increase in energy use in Sweden of $32 \%$ between 1973 and 1989 , slightly less than the increase in Gross Domestic Product (GDP) during the same period. Unlike many other countries, Sweden saw an internal canceling of many of the important structural changes within sectors of energy use.

Energy intensities in Sweden have declined since the early 1970s (Figure). The most important component of this drop has been that of oil in buildings and industry, but not in transportation. Using a methodology we developed, we aggregated the impact of the overall changes in energy intensities.

Weighted by 1973 energy use, these changes caused a decline in delivered energy of $26 \%$ and a decline in primary energy of $8 \%$. The difference between these two figures reflects the $43 \%$ increase in electricity intensity, caused mostly by large-scale substitution of electricity for oil as a space-heating fuel, and to a smaller extent by the stable electricity intensities in industry. These two results lie, interestingly enough, close to the changes observed in the ratio of delivered or primary energy use to GDP in Sweden, reflecting the way in which major structural shifts canceled each other out.

In the coming year, we will compare the achievements in efficiency in Sweden with those in Denmark and Norway, with particular emphasis on changing lifestyles of the Scandinavian people.

\section{References}

Schipper L, Howarth R, Andersson B, Price L. Encrgy Use in Denmark: An Intermational Perspectize'. Lawrence Berkeley Laboratory Report LBL-32362, 1992.

Schipper L, Howarth R, Carlesarle, E. Energy intensity, sectoral activity, and structural change in the Norwegrian economy. Energy-The litirnational fourmal 1992; $17(3): 215-233$.

- Air Travel (p-km)

- Manufacturing

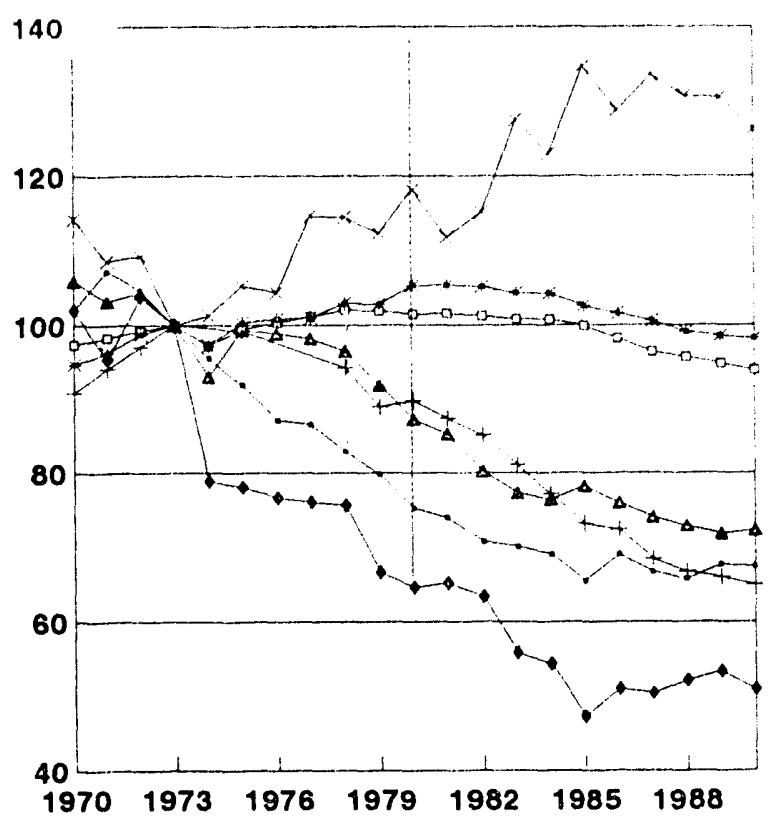

Figure.

Relatize changes in Suedisin cenergy intensilies 


\section{The Vicious Circle of Measuring Automobile Fuel Use}

Automobiles are a significant source of air pollution as well as of carbon dioxide, a major greenhouse gas. Unfortunately, obtaining data that accurately reflect actual fuel consumed by automobiles is one of the most serious problems facing research on this topic. In the course of our study, we carefully collected or derived data on all aspects of transportation activity and energy use. The structure of fuel consumption that we found using our detailed data is considerably different from that based on the traditional international sources of data.

We identify a number of difficulties inherent in measuring the fuel use of automobiles. The most important is that international analyses of automobile fuel use often incorrectly employ the values for "total gasoline" found in traditional international data sources as a proxy for actual fuel consumed by automobiles. This is a problem because these data represent total gasoline used for all vehicles including automobiles, motorcycles, buses, trucks, and other miscellaneous vehicles and because these data do not include other fuels used by automobiles. As shown in the Figure, in the early 1970 s, values reported for total gasoline use by all vehicles were typically 10 to $50 \%$ higher than actual total automobile fuel used in industrialized countries. That differ- ence shrunk over time as more trucks, buses, and cars switched to fuels other than gasoline. In the 1980 s, because of the prominence of diesel fuel and liquefied petroleum gas, total road gasoline consumption for all purposes was actually less than total automobile fuel consumption in France, West Germany, and Italy. We found that growth rates in the use of fuels for automobiles between 1970 and 1990 are as much as $2 \%$ per year higher than those for total gasoline. Thus, we reject "total gasoline" as a useful proxy for the fuel consumed in automobiles.

A variety of earlier studies has modeled gasoline or automobile fuel use as a function of price, income, and other variables. We formulated our own simple model and tested it using both "total gasoline" and the correct quantity of automobile fuel consumed. We found that using total gasoline to represent automobile fuel leads to a slight overestimate of price elasticities and an important underestimate of income elasticities for automobile fuels. Using gasoline prices rather that the price of fuel weighted by actual gasoline and diesel consumption, however, leads to only very small and insignificant errors.

We identify a vicious circle among four parameters used to describe automobile use: automobile fuel consumed,

Road Gasollne/Total Auto Fuel

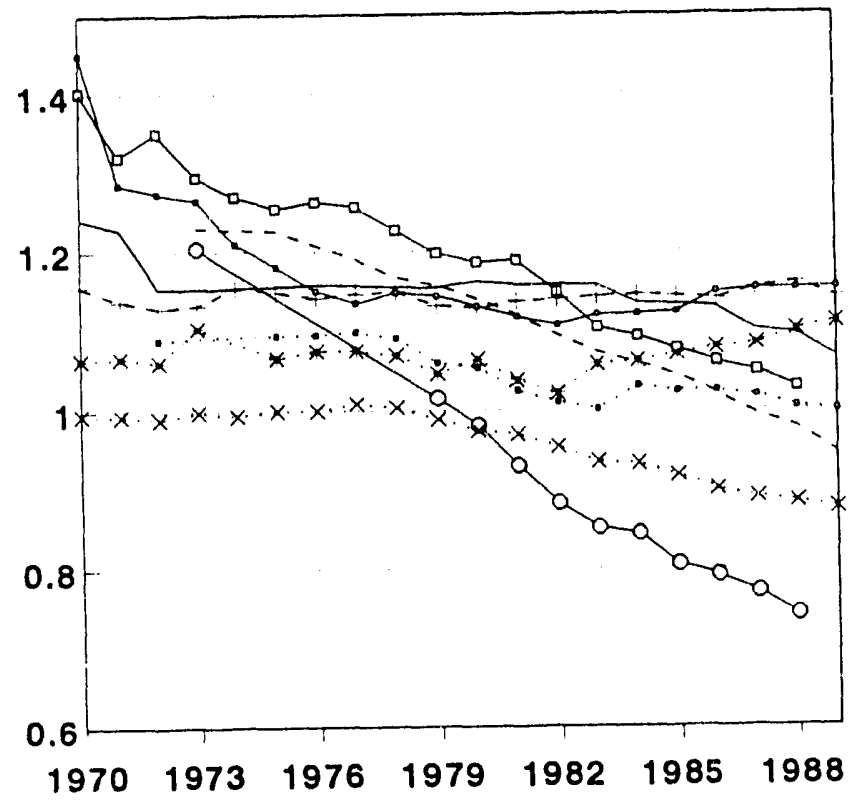

$$
\begin{aligned}
& \text { - Norway } \\
& + \text { U.S. } \\
& \text {-*. Sweden } \\
& - \text { U.K. } \\
& - \text { - Japan } \\
& \text {-.. Denmark } \\
& \text { - France } \\
& \text {-x. W. Germany } \\
& \text { - Italy }
\end{aligned}
$$

distance traveled per vehicle, total number of automobiles, and fuel use per kilometer traveled. Each of these elements is hard to measure and subject to errors in analysis. Thus, indicators of fuel use per car or fuel use per kilometer are only valid for analyses if they can be shown to belong to a self-consistent circle of these basic data. For the first time, we provide our own data on automobile fuel use and distance traveled. While our results are under constant revision, we argue that important gaps in our knowledge of automobile fuel use can be filled.

Finally, we reflect on the fuel intensity gap, the well-known disparity between the tested fuel intensity of new cars and the actual intensity obtained under real driving conditions. We find that in the U.S., France, West Germany, and the U.K., published test figures for fuel intensity (in liters of fuel per kilometer traveled) for new cars underestimates actual consumption by 15 to $25 \%$. As with the other data problems identified above, we conclude that the fuel economy gap can only be resolved through careful collection of consistent, detailed data.

\section{References}

Schipper L, Figueroa MJ, Price L, Espey M. Mind the Gap: The Vicious Circle of Me'usuring Automobile' Fucl Use. Lawrence Berkeley Laboratory Report No. LBL33163, 1992.

Schipper L, Meyers S, Howarth R, Steiner R. En'rgy Efficiency and Human Activity: Past Trends, Future Prospects. Cambridge, UK: Cambridge University Press, 1992.

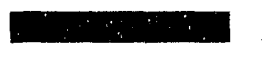

Investigators

$$
\begin{aligned}
& \text { L. Schipper } \\
& \text { M.J. Figucroa } \\
& \text { L. Price' } \\
& \text { M. Esprey * }
\end{aligned}
$$

* Department of Agricultural Economics Unizersity of California Daris, $C A$

Figure.

Ratio of total road gasoline to all automobile fuels. 


\section{Crash and Rebirth: Energy Demand in the Former Soviet Union}

Using a detailed, bottom-up model of the demand for energy in the former Soviet Union, we built scenarios of energy use there in 1995 and 2010. At the heart of our analysis is a major decline in industrial production, which accompanies a crash in income over the period 1990-1995. Under our detailed assumptions, final energy demand falls for all sectors (Figure). The largest change occurs in industrial energy demand, which drops by $39 \%$. A smaller decline occurs in the transportation sector, while the residential and services sectors remain equal to their 1985 levels. Consumption of all fuel types (excluding feedstocks) declines significantly, and the decline in oil consumption is probably great enough to keep pace with a fall in oil production expected to continue in 1993 and 1994.

Our earlier work noted that energy use in the former Union is extremely inefficient. What could happen if an effort is made to improve this dismal situation? Here we consider three scenarios for efficiency and conservation improvements by the year 2010. Based on previous estimates of energy efficiency prospects, we calculate total energy consumption for each main end use.

The "Slow Reform" scenario illustrates what might happen if the dissolution of the Union and public opposition hinder the momentum of reform, and if energy is deemed a plentiful resource (in Russia) relative to important energy efficiency ingredients such as capital and technical know-how. Prices are allowed to rise slowly to internal replacement levels, roughly 2-3 times the 1985 levels, although these still would lie below Western levels in many cases. However, no special effort is undertaken to meter and charge for energy as used. As of late 1992, energy prices rise, but do so less rapidly than prices for most other goods and services. Under these circumstances, we expect a slow decline in the energy intensities of industry, household, and service-sector heating through gradual replacement of old facilities and equipment. Relatively little effort and scarce capital are focused on energy efficiency however; and only a modest amount of Western technology penetrates into the former Soviet economies.
In the "Rapid Reform" scenario, development of a market economy proceeds at a relatively fast pace with substantial assistance and investment from the West. Energy prices rise to their border levels, i.e., levels reflecting what energy (at least oil and gas) brings in hard currency in international markets. As long as the ruble is weak, or virtually non-convertible, energy prices will remain very high. Energy intensities decline to average 1985 Western European levels. Today's least productive factories are closed and there is considerable investment in new factories that utilize state-of-the-art technology. A rapid upgrading of the quality and durability of components of industrial and consumer goods takes place, which helps to boost energy efficiency. The energy efficiency of new homes increases, bolstered in part by improvect quality of design and components. Energy users face prices that reflect actual consumption, not just allocations.

The "Extra Effort" scenario is similar to "Rapid Reform" except it assumes that energy efficiency is given higher priority by authorities and energy users alike. The result is that average intensities fall to, at, or below the same level as current new Western European intensities, or approximately the level of Western European energy intensities we expect in 2010.

The Figure also shows final energy demand for the 2010 scenarios. In "Slow Reform," the final demand for energy is about at its 1985 level. In "Rapid Reform," the level has fallen, and in "Ex-

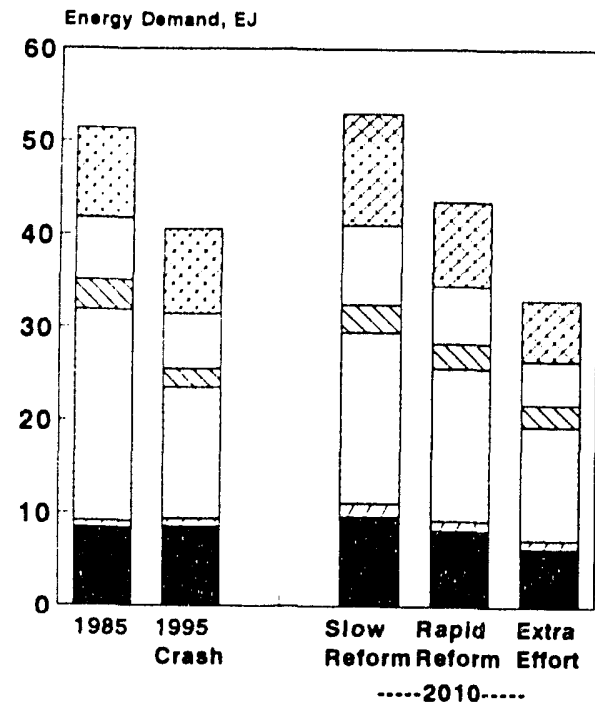

tra Effort," energy demand is far below its 1985 level. The main uncertainty is the rate at which market reforms and institutional measures together increase the incentive to improve energy-use ef ficiency and remove historical (as well as lingering) barriers to efficiency. Because of uncertainties over the longterm fuel mix in the former Soviet Union, we did not make any estimates of the components of primary energy in 2010, but we expect oil and gas to be the main fuels in that year.

With the economic crisis worsening daily, the pace of efforts there to focus on long-term economic reform-including energy efficiency - has slowed. Future research will focus on how these two goals can be linked. Because energyuse patterns in the individual former republics of the former Union are so poorly known, both by insiders and outsiders alike, we will focus our efforts on understanding energy use and efficiency in the former republics in the coming year.

\section{References}

Cooper RC, Schipper L. The efficiency of energy use in the USSR-an international perspective. Energy--The International fournal 1992;17(1):1-24

Schipper L, Martinot E. Lecline and Rebirth: Eneryy Demand in the Former Sorviet Union. Part I: The Coming Crash. Part II: Towoards Efficiency in 2010. Lawrence Berkeley Laboratory Report No. LBL-33162, 1992.
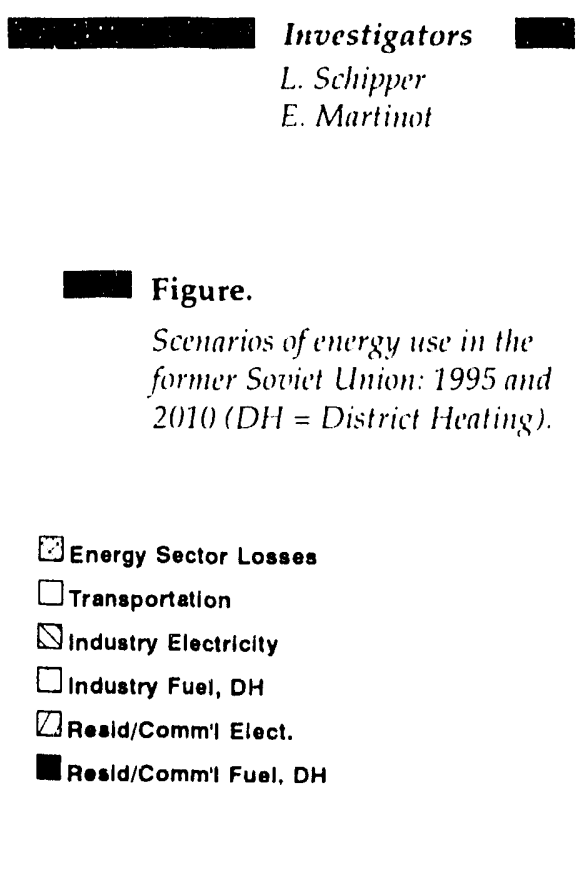


\section{Environment, Economics, and the Long-Term Future}

A broad class of environmental problems is characterized by the asymmetric distribution of benefits and impacts over time. Activities that generate toxic and radioactive substances, greenhouse gases, and other environmental insults yield perceived benefits to today's economy. While such activities have few immediate effects, cumulatively they threaten the long-term environmental stability with potentially farreaching implications for human and ecological systems.

The impacts of such long-term environmental threats are highly uncertain. Many products of modern technology do not exist apart from their manufacture by humans. Others, while naturally occurring, are today released by human activities at rates rivaling or exceeding the assimilation capacity of nature. Because we are perturbing the environment in a manner lying outside the range of historical experience or the capabilities of laboratory simulation, there can be no certainty regarding the impacts of climate change, the safety of hazardous waste storage, and other environmental insults.

Approaching the policy challenges posed by long-term environmental problems is controversial both in theory and in practice. Some argue that policies should be designed to equate the marginal costs and benefits of pollution abatement, measured in monetary terms. Others argue that the imposition of long-term environmental risks is morally unacceptable because it threatens the welfare of future generations.

Untangling the issues behind this controversy is the focus of this work. We explore the theoretical foundations of cost-benefit analysis, outlining two characteristics that constrain its usefulness in the analysis of long-term environmental problems. First, the approach is blind to the distribution of impacts between social groups and between present and future generations. To the extent that issues of distributional equity are important to decisionmakers, this necessitates the use of explicit ethical criteria in policy formulation and evaluation. Second, cost-benefit techniques are generally illsuited to the analysis of problems characterized by substantial uncertainty. In theory, cost-benefit analysis under uncertainty is a simple extension of wellestablished methods. In practice, the information requirements are often beyond the means of practical implementation.

As an alternative to cost-benefit analysis, this project explores the implications of the precautionary principle as a normative approach to long-term environmental management under uncertainty. The precautionary principle is derived from the concept of sustainable development, and holds that policies should seek to reduce threats to future welfare if the costs of doing so would not significantly reduce the subjective well-being of present or future persons. If one accepts this value judgment as reasonable, then one is left with a policy criterion that is operationally decisive under a wide array of circumstances.

Ongoing research focuses on the application of these principles to the policy challenge posed by global climate change.

\section{References}

Howarth RB. Environmental risks and future generations: criteria for public policy. Paper presented at the Conference on Clean Water and the American Economy, Arlington, VA, October 19-21, 1992 (also as Lawrence Berkeley Laboratory Report No. LBL-32993).

Howarth RB, Norgaard RB. Environmental valuation under sustainable development. American Economic Revicu 1992; 80:473477.

Howarth RB, Norgaard RB. Intergenerational transfers and the social discount rate. Paper presented at the International Society for Ecological Economics, Stockholm, Sweden, August 3-6, 1992 (also as Lawrence Berkeley Laboratory Report No. LBL-32667).

Norgaard RB, Howarth RB. Economics, ethics, and the environment. In: J. Hollander, ed. The Energy-Environme'nt Connection, pp. 347-364, Washington, DC: Island Press, 1992. 


\section{Market Barriers to Energy Efficiency}

The efficacy of the market mechanism in achieving a socially desirable level of energy efficiency has generated considerable debate. According to the simplest neoclassical models of competitive markets, perfectly informed, rational individuals consider the total costs of their decisions when purchasing energy-using equipment. If the value of the energy savings generated by improving the energy efficiency of a device exceeded the cost of the improvement, competitive producers could increase their profits by exploiting consumers' willingness to pay for the change. It follows under these assumptions that all efficiency measures that were cost-effective at prevailing prices would be realized by competitive markets. The problem of energy policy would thus be reduced to ensuring that energy prices reflected the full social costs of energy production and utilization.

The validity of this idealized mode, as a description of observed reality ha: been cast into doubt by a large body of literature showing that many technologies yielding cost-effective energy savings fail to achieve full market penetration. The factors behind this "efficiency gap" have been explained mainly in terms of "market barriers" related to consumer decision-making. Consumers are said to lack full information regarding available energy-efficient technologies, use a discount rate that is "too high" in evaluating investments in energy efficiency, or simply lack the means to evaluate carefully the consequences of their decisions. In some cases, the costs and benefits of energy efficiency improvements may accrue to different agents, splitting the incentive to invest in otherwise attractive technologies. Finally, transaction costs may swamp the often small net benefits achievable by individual consumers.

The existence of an efficiency gap suggests the possibility that energy use may be reduced relative to status quo levels at a net cost saving. The achievement of an ideal level of energy efficiency would thus involve a two-step process (Figure). First, energy prices would be set to reflect the full social costs of energy production and utilization, including external environmental costs. Proper pricing shifts the energy supply curve inward from the $S$ to $S^{*}$. Second, policies should be implemented to improve market performance given prevailing prices, shifting the demand curve from the laissez faire $D$ to the cost-effective $D^{*}$ without reductions in energy services. Only when these measures are imple-

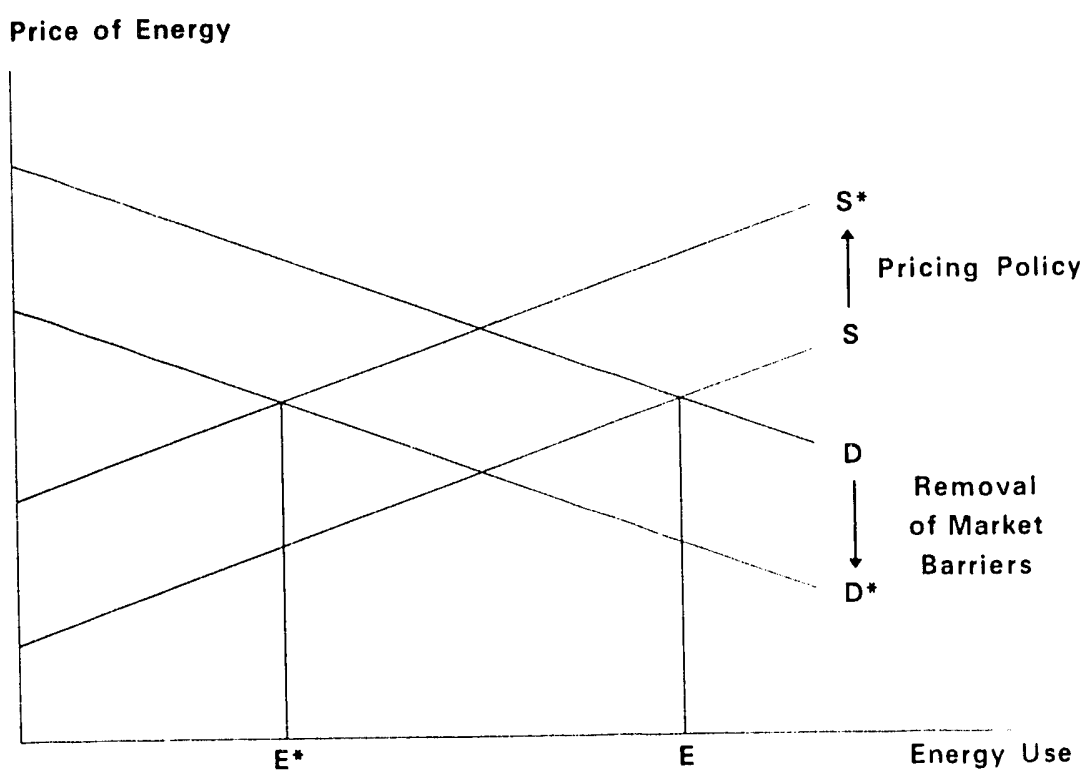

mented in tandem is energy use reduced from the status quo $E$ to the socially efficient level $E^{*}$ without incurring offsetting social costs.

Such arguments have had a significant impact on energy policy. The economic underpinnings of the presumed efficiency gap, however, have not been firmly established. While a plausible case may be made that market barriers impede the adoption of certain energy-efficient technologies, little effort has focused on the analysis of these barriers using formal models rooted in economic theory. The argument that consumers use especially high discount rates in evaluating the present-value costs of energy-using technologies, for example, is theoretically objectionable. Why would a rational person pass up a $100 \%$ return when alternative investments yield only 5 to $10 \%$ ? Either the facts are wrong, or consumers are "irrational" in the sense that they do not evaluate energy-using technologies in a manner consistent with life-cycle cost criteria, or there is more to the story than meets the eye.

This project examines a theoretical analysis of demand-side market imperfections that drive a wedge between the cost-effective level of energy efficiency and the level that is realized by the interaction of rational agents in the marketplace. We find that consumer perceptions regarding the performance of energy-using equipment have an important impact on the market potential of energy-efficient devices. Even when consumers correctly estimate and seek to minimize the total costs of equipment ownership, anomalies in the transmission of information between producers and consumers may result in an inadequate level of energy efficiency in unfettered competitive markets.

\section{Reference}

Howarth RB, Andersson B. Market Barriers to Energy Efficiency. Lawrence Berkeley Laboratory Report No. LBL-32541, 1992.

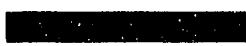

Investigators R.B. Howarth B. Andersson

Figure.

Coordination of energy pricing and policies to remove market barriers. 


\section{The Structure and Intensity of Energy Use: Trends in Five Industrialized Nations}

This project examines the structure and intensity of energy demand by presenting a descriptive history of the coupling between energy and economic activity in five nations: the United States, Norway, Denmark, West Germany, and Japan. The time frame of our analysis1973 to 1988-allows us to examine the trends that prevailed during periods of both increasing and decreasing energy prices. We decompose and analyze the changes in the level of energy end use to estimate the contribution of changes in both energy intensities and the corresponding activities that drive energy use.

Our focus is on the use of fuels and electricity to provide energy services to end users. Both purchased and nonpurchased fuels are considered, including for example the use of waste biomass in industry. Although we do not explicitly examine the energy sector, we weight district heat and electricity by factors of 1.15 and 3.24 to obtain a measure of primary energy use that accountsin an approximate way - for the thermal losses associated with the production and distribution of these energy carriers.

We decompose energy use by category according to the sector and/or context in which it occurs. For each category we define an indicator that measures the activity associated with the energy use. Our activity indicators conform to established conventions in the energy literature. For residential space heat, for example, activity is defined as heated residential floor area. For the iron and steel sector, activity is measured in terms of real value-added, whereas passenger-kilometers are used for automo-

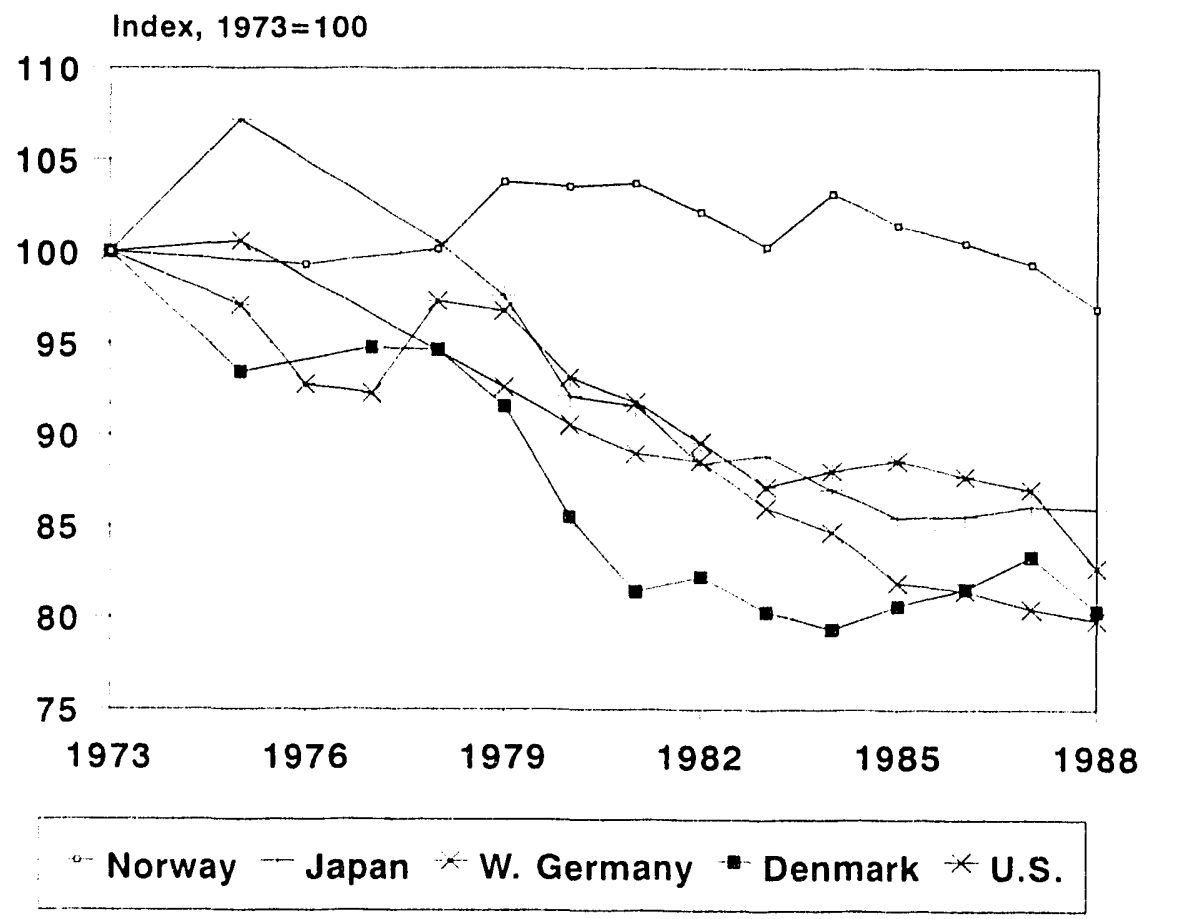

bile transportation. For each category, we then define energy intensity as the ratio of energy use per unit of activity.

Between 1973 and 1988, primary energy use per unit of gross domestic product (GDP) fell by $24 \%$ in West Germany, $27 \%$ in Norway, $29 \%$ in the United States, $34 \%$ in Japan, and $35 \%$ in Denmark. While these figures are similar in aggregate terms, the factors behind them vary from nation to nation. We calculated the development in energy use that would have occurred if energyusing activities had remained frozen at their 1973 levels while energy intensities followed their actual paths (Figure). The data indicate that energy intensities were relatively constant in Norway while reductions of up to $20 \%$ occurred in the other nations. For the United States and West Germany, the change in real energy intensity (the index of changes in individual intensities weighted by base-year activity levels) closely matched the change in the energy/GDP ratio. In Japan, however, real intensity fell by just $14 \%$-only half the reduction in the energy/GDP ratio. A smaller gap $(20 \%$ vs. $26 \%)$ was observed for Denmark.

Energy intensity reductions were most rapid in the late 1970s and early 1980 s, a period marked by high and unstable oil prices. In most cases, the trend slowed or reversed by the mid1980 s as real energy intensity approached an apparent plateau. This pattern was observed first in Denmark where energy intensity was relatively stable after 1981 . Intensity changes varied among the sec-

Figure.

The hypothetical development of primary energy use given actual energy intensities and fixed 1973 activity levels. 
tors and countries, but common trends prevailed in many cases. Fuel intensities fell considerably in manufacturing, air travel, residential space heating, and in the service sector. There was also a strong decrease in automobile fuel intensity in the United States, but not in Europe and Japan. Higher energy prices, autonomous trends in technology (especially in manufacturing and air travel), and, in some cases, energy efficiency programs and policies caused the declines in intensities. Electricity intensity behaved rather differently, increasing in some cases (the service sector and manufacturing in some countries) or remaining relatively unchanged.

We also examined the change in energy services relative to GDP. The ratio of total energy-using activities (weighted by their corresponding 1973 energy intensities) was relatively constant in West Germany and the United States, but fell by $4 \%$ in Denmark, $17 \%$ in Norway, and $13 \%$ in Japan. Thus, structural change-shifts in energyusing activities relative to the aggregate economy-caused essentially all of the decline in the Norwegian energy/GDP ratio and half of the decline in Japan.

\section{Reference}

Howarth RB, Schipper L, Andersson B. The structure and intensity of energy use: trends in five OECD nations. En'rgy Journal, 1993;14(2), in press.

Investigators

R.B. Howarth

L. Schipper

B. Andersson

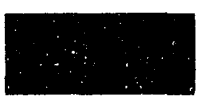

\section{Trends in Electricity Demand and Supply in the Developing Countries, 1980-1990}

Energy usage in developing countries is studied in this project. The countries13 of the largest developing nationswere chosen because of their size and energy usage. They also have accessible data sources to facilitate this investigation.

Using statistical reports issued by electric utilities or government agencies, we assembled a consistent data series for the countries. Electricity production in the countries as a whole averaged nearly $7 \%$ annual grow th in the 1980-90 period. However, this average obscures major differences among regions: generation grew much faster in China and the rest of Asia than in Latin America and Africa. Growth in electricity consumption in 1980-90 ranged from only $4.2 \%$ per year in the Philippines to nearly $13 \%$ per year in Indonesia. In most cases, residential- and commercialsector consumption grew faster than industrial use, aithough the latter still accounts for over half of total electricity consumption in most of the 13 countries.

The mix of power sources for electricity generation shifted strongly toward coal in the 1980s for the 13 countries as a whole. The share of coal in total generation rose from $28 \%$ in 1980 to $37 \%$ in 1990 , while the share of oil fell from $24 \%$ to $12 \%$. Most of the oil backout occurred in the first half of the decade; there was an increase in oil-fired generation in some countries in the late 1980s.

The importance of different sources varies: considerably. Coal is the dominant source only in China and India, but these two countries together account for half of the total generation for the 13. The share of coal rose in both China and India, and also increased in several other Asian countries. Natural gas became more important in Malaysia and Thailand, while oil continued to play a major role in Indonesia, Malaysia, the Philippines, and Mexico. For the 13 countries together, the share of hydroelectric power declined slightly, but continued to play a dominant role in Pakistan, Venezuela, and especially Brazil.

The generating efficiency of thermal power plants increased in a number of the 13 countries in the 1980 s as new power plants came on line. The average efficiency varied considerably from only around $25 \%$ in China and India to more than $35 \%$ in Malaysia, Thailand, South Korea, and Taiwan. Transmission and distribution losses rose in some of the countries, but declined in others. Here too there is a wide range among the countries-from only $6-7 \%$ in South Korea and Taiwan to over $20 \%$ in India and Pakistan.

Carbon dioxide emissions from electricity generation rose considerably in the 1980s. Emission per total GWh gen- erated are highest in China and India because of their heavy reliance on coal. The ratio rose in India in the 1980sand also in Mexico-but declined in a number of the other countries as nuclear power and natural gas played greater roles.

The future evolution of electricity demand and supply in the larger developing countries is the subject of a current project whose findings will be reported in 1993. The information from this project provides a background for consideration of future prospects. It shows that the evolution of the power sector in the 1980s was quite varied around the developing world. While some common trends are apparent, such as the relatively more rapid grow th in residential and commercial consumption, in many respects countries have had differing experiences. Thus, generalizations across the developing world must be made with care.

\section{Reference \\ Meyers S, Campbell C. Trends in Electricity De'mand and Supply in the Dereloping Countries, 1980-1990. Lawrence Berkeley Laboratory Report No. LBL-33166, 1992.}
S. Meyers
C. Campbell

nvestigators 


\section{Economics of Restraining Carbon Emissions from India, China, and Brazil}

This project is intended to examine the economics of restraining carbon emissions on the basis of long-term energy scenarios for developing countries.

The first phase of the project began in FY 1988 and focused on an end-use approach to developing long-term energydemand scenarios for the developing countries. In the second phase, initiated in early FY i989, we established a network of analysts from institutions in several of the largest energy-consuming developing countries to develop scenarios of long-term energy use for each country in order to project greenhouse gas emissions.

Economic analyses of carbon emissions from India, China, and Brazil were addressed last year. The India analysis suggests that while capital constraints on economic development would probably be addressed through efficiency improvement, reducing the foreign exchange burden of oil imports will be far more difficult.

The China analysis shows that with the anticipated decrease in energy intensity coupled with rapid economic growth of the Chinese economy, neither capital nor foreign exchange are likely to pose major constraints to economic development. However, allocation of capital and other resources will have to shift increasingly toward reduction of power-sector losses and end-use efficiency improvements.

The potential for reducing emissions is limited in India and China by the lack of alternatives to coal. However, in the case of Brazil, alternative resources of hydroelectricity and biomass have the potential to reduce carbon emissions substantially - but at a higher cost.

We analyzed various scenarios using the same model for each country. A scenario advocating $50 \%$ higher carbon emissions for developing countries by 2010, which was used in Stanford University's Energy Modeling Forum12 study on global warming, was also tested. With the use of our model, we showed that none of the three countries could meet the $50 \%$ limit on carbon emissions without substantial reduction in gross national product (GDP). For India, even steep reduction in GDP was not enough; energy demands would have to be left unsatisfied.

Additional analyses of the India and China options are being completed. Similar analyses are also being conducted for Thailand and Nigeria. These findings will be reported in FY 1993.

\section{Reference}

Wu Z, He J, Wei Z, Zhang A. Technological options and economic ernaluation for reducing $\mathrm{CO}_{2}$ emissions in China's energy system. Report submitted by Tsinghua University, Beijing, China, to Lawrence Berkeley Laboratory, 1992.

Investigators

1. Sathaye

Z. Qin

S. Zhang 


\section{Carbon Emissions and Sequestration in Tropical Forests}

Carbon dioxide emissions from tropical forests rival those from energy use in the developing countries. However, estimates of emissions from tropical forests in the literature vary considerably. The Tropical Forestry and Global Climate Change research network (F-7) was established in 1990 during a meeting of the Intergovernmental Panel on Climate Change in São Paulo, Brazil. The main objectives were to improve the precision of the estimates of emissions from tropical forests and to identify and study the response options in the forestry sector. Unlike past methods of estimation, we have relied on a network of participants from eight developing countries, using a spreadsheet model that was developed at LBL, to prepare estimates of emissions and sequestration of carbon in their countries. These countries are Brazil, Mexico, Indonesia, Malaysia, Thailand, China, India, and Nigeria. By 1990, these countries were estimated to represent about two-thirds of the annual deforestation of closed moist forests.

The deforestation rate for 1990 seems to have substantially declined from the high levels of 1987 in many of these countries. The new estimate for corresponding emissions from the participating countries is about half of the earlier estimates. Proportional projection of these estimates to the tropical biome shows that the total emissions are between 1.1 and 1.7 billion tonnes of carbon per year, with working average of 1.4 billion tonnes, which is significantly less than other estimates. Whereas the current estimates for Indonesia, Malaysia, China, and Thailand are higher, those of Brazil, India, and Mexico are lower than in most other recent estimates (Figure).

In China, carbon dioxide emissions from forestry are considerable, although the amount is about half of the 1980 level. Some countries such as
China, Malaysia, and Indonesia have large human-grown tree plantations which sequester large a mounts of carbon. The total afforested area through the base year for the F-7 countries exceeds 60 million hectares. The 1990 uptake by growing stock in these countries was estimated at 374 million tonnes of carbon, with another 180 million tonnes as committed sequestration from landuse activities in the base year.

At present we are investigating response options to increase carbon sequestration and reduce emissions at a net economic benefit and the potential consequences of these measures. A workshop was held in April 1992 to discuss the methodology for the economic evaluation, and another meeting was held in October 1992 to present preliminary results of economic and policy evaluations of response options. Future plans include completing the economic and policy evaluations of response options, refining the carbon estimates, extending the work to other forest-based greenhouse gases, expanding the network to include other countries, and evaluating the feasibility of tradable emissions rights for each participating country.

\section{Reference}

Makundi W, Sathaye J, Cerutti OM. Carbon Emissions and Siquestration in Forests: Case' Studies from Se'ren De'uloping Countrie's, Volume 1: Simmmary. Lawrence Berkeley Laboratory Report No. LBL-32119, 1992.

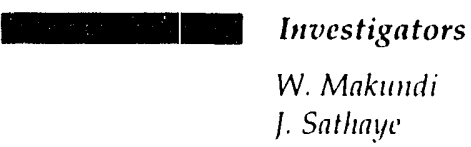

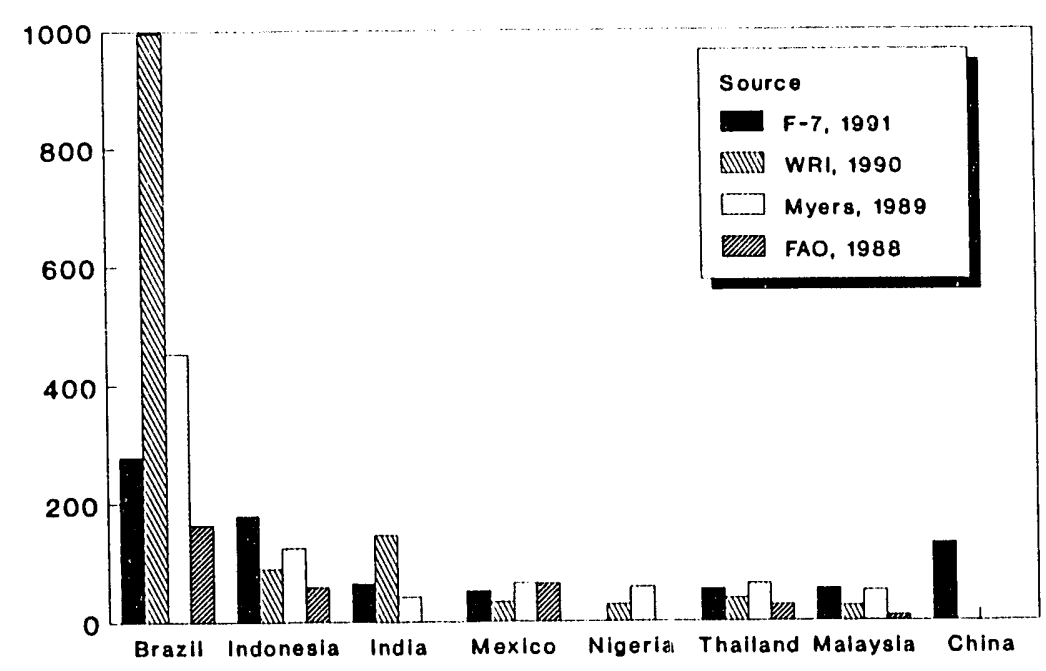

Floure Sources: "I World Rosources Inalltule, 1990. Oxford Univelolly Press. N.Y. 2) Myers. N. 1988.

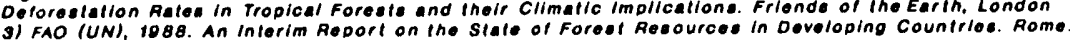

\section{Figure.}

A comparison of carbon emissions from forestry in F-r contrites, 1988-1990. 


\section{Electricity Conservation in China}

Economic growth in China has been remarkable during the 1980s. Annual gross national product (GDP) increased at $8.7 \%$ and recorded double-digit levels during this period. However, a concerted effort at all levels of government managed to reduce energy growth to only half that of GDP. Electricity generation grew more slowly than GDP until 1985 and has continued at about the same rate since then.

On the supply side, the focus of efficiency improvement has been to reduce the heat rate of electricity generation at the expense of increased losses in transmission and distribution (T\&D). T\&D losses are reported to be around $8 \%$ nationwide. Detailed analysis of $T \& D$ losses shows that they are actually closer to $20 \%$, with rural circuits experiencing losses up to $30 \%$. Our analysis shows that improving power factors, replacing inefficient transformers, reconfiguring networks, and upgrading wiring are cost-effective means to reducing losses. Indeed, improving power factors is the most cost-effective way to increase power-sector efficiency.

On the demand side, ind ustries successfully introduced measures to reduce the intensity of their electricity use, particularly during the early 1980s. Most of these improvements were realized by electricity savings from individual pieces of equipment. Significant potential for improving efficiency lies in further improvement of the efficiency of end-use equipment, optimization of production processes, and modernization of plants.

Implementation of the following types of measures can yield significant efficiency improvements in China:

- Increase investment allocation to reverse the declining share of investment for T\&D;

\section{Transportation in Developing Nations}

Satisfying transportation needsboth for economic activities and for individual citizens-is a critical requirement of socio-economic development. However, the construction of a complete transportation system can burden both a nation's economy and its environment. The development of transport systems in most developing countries has been dictated by skewed administered prices of fuels, taxes and subsidies for various types of vehicles, ignorance of environmental externalities, colonial inter-urban rail and highway systems, and other similar circumstances. The result is a transport system which is barely coping in most countries and yet is largely ignored by development banks and donors because it is tion complex to attempt to fix. We have explored these issues in a recent project to examine the management of the institutional and technological transition to a low-emissions future.

Congestion and air pollution are the two important impediments to future development of urban transport. Congestion has increased travel time in urban a reas of the developing countries. Air pollution has become a major concern in most large developing country cities. Private vehicles, which account for $96 \%$ of all passenger vehicles on the road in Mexico City but provide only $23 \%$ of the person-trips per day, are clearly the cause of congestion in the city. These vehicles also account for an estimated $70 \%$ of the hydrocarbons, $\mathrm{CO}$, and $\mathrm{N}_{2} \mathrm{O}$ in the region. Confronting these twin problems is not easy and only strong government intervention, such as in Singapore, has succeeded in controlling them.

Production and/or import of cars of recent vintage has helped to improve fuel efficiency over time in countries where incomes have not fallen. Nevertheless, increased urban congestion has limited the on-the-road efficiency improvement. Vehicles speeds have de-
- Establish standards for new highefficiency equipment;

- Eliminate regulations requiring industries to invest a fixed portion of their depreciation funds in energy savings;

- Adopt uniform electricity pricing based on cost of marginal supply and environmental considerations.

\section{Reference}

Sathaye J. Economics of improring efficiency of China's electricity supply and use: are' 'fficiency investments cost-cffective? Paper presented at the World Bank-Chinese Ministry of Energy Workshop on Coal Utilization and Energy Efficiency in China, Beijing, China, April 22-25, 1992.

\section{Investigator} 1. Sathaye clined, which has increased fuel consumption. Fuel consumption in Jakarta is $30 \%$ higher due to traffic congestion, amounting to $\$ 133$ million of additional fuel consumption. These monies could be productively spent in Jakarta to reduce congestion.

During the next year, we will examine the prospects and barriers to energy-efficient transportation in Mexico City, and ways to improve the efficiency of transport systems in China and India.

\section{Reference}

Sathaye J, Walsh M. Transportation in developing nations: managing the institutional and technological transition to a kow-emissions future. In: I. Mintzer, ed. Confronting Climate Change: Risks, Implications and Re'sponse's. Cambridge, UK: Cambridge University Press, 1992. 


\section{International Energy Efficiency Initiatives}

During the last few years the energy community has increased its interest in the transfer of energy efficiency information and technology to developing countries. This concern culminated in the summer of 1992 with the Rio Summit on the Environnient. The Summit resulted in the commitment by participants of the Climate Convention to reduce pollution from energy use, promote technology transfer, and foster sustained economic growth in developing countries.

This project reviews ongoing activities that promote partnerships between industrialized and developing countries on issues concerning energy efficiency and sustainable development, with particular focus on three recent initiatives: the Global Environmental Facility (CEPF), the International Energy Initiative (IFI), and the Cilobal Energy Eifficiency Initiative (CFEE). CiEF, formed through a unique tri-partite arrangement with the World Bank, the U.N. Environment Program, and the U.N. Develepment Program, has the largest budget and the largest mandate, i.e., to protect the global environment. Given such a broad edict, it is unclear what role energy efficiency will play in the slate of CEF activities. IEl is led by developing country interests with strong leadership from experts in the field of energy efficiency, but success will likely rest on IEl's ability to secure stable funding. CEEE is an American-led effort supported by a wide array of energy efficiency institutions, yet coalescing these broad interests may prove difficult. Each initiative has the unique potential to shape future development, but all are initiatory programs and their future impacts are much a function of conjecture.

An increasing number of institutions are involved in the promotion of energy efficiency to developing countries. The peripheral involvement of established institutions like the U.S. Agency for International Development and multilateral development banks is broadening, although supply-side interests continue to dominate funding patterns. The more targeted promotion of energy efficiency is provided by recently emo rged national and intergovernmental efficiency centers and by certain non-governmental organizations. Such efficiency centers may prove particularly critical for economies in transition, where efficiency may prove a key ingredient for economic integration into the competitive marketplace.

In the last two decades, energy efficiency has evolved from an isolated concern of a few energy experts to a general concern in both the industrialized and developing countries. Although concern has not yet catalyzed concerted action, we can expect more such efforts in the future. For example, emerging from Rio was the U.S.-sponsored ADEIT program (Assisting Deployment of Energy Practices and Technologies) whose mission is specifically to promote the wise selection of energy technologies in developing countries. Weare monitoring the progress of these new and ongering programs, and will update this report with information on their progress.

\section{Reference}

Monahan P. Sathaye J. Internatonul Eners.y

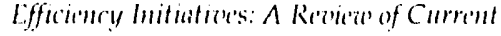
Actiritic's to Promote Enersy Effictency in Detidoping Countriess. Lawrence Berkeley Laboratory Report No. L.BL-3.31117, 1992.

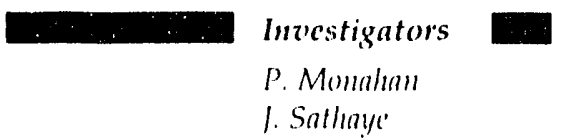




\section{Ilvinex, Mexico's Residential-Sector Lighting Efficiency Program: A Feasibility Study}

The llumex project aims to replace 1.5 to 2 millior, incandescent bulbs with compact fluorescent lamps (CFLs) over a two-vear period in homes in Guadalajara and Monterrey, Mexico. llumex will be carried out by Comision Federal de Electricidad (CFE, the Mexican electric utility). Program costs will be shared by CFE and !!le Global Environment Facility of the World Bank. The funds will become a revolving fund to expand the Ilum.ex program to the rest of Mexico's 15 million households.

The U.S. Agency for International Development sponsores $\mathrm{LBL}$ and the International Institute for Energy Conservation to prepare a feasibility study of Ilumex for CFE to submit to the World Bank. LBL was entrusted with designing and 1 anaging a household survey and performing the economic benefit-cost analysis. CFE provided crucial inf astructural support and input to the survey design and its implementation.

The household survey, conducted by the Centro de Estudios Energéticos under LBL guidance, was used to determine the technical potential for substitution of incandescent bulbs with compact fluorescent lamps. The survey also gathe red data on household electric appliances from about 900 homes in Guadalajara and Monterrey in July 1992. These data were analyzed to ob- tain daily lighting load curves for the residential customers in each city and to determine the technical potential of replacing incandescent lamps with CFLs. The analysis was done for three customer groups according to their monthly electric consumption.

Survey results show a large evening peak demand between 6 P.M. and 11 P.M., which is about six times larger than the residential lighting demand during the rest of the day. There also is a small peak betwern 5 A.M. and 7 A.M. whose magnitude is just $10 \%$ that of the evening peak. If Ilumex targets physically replaceable 40 to $100 \mathrm{~W}$ incandescents that are used at least two hours per day, the utility could defer about $300 \mathrm{MW}$ of capacity and save about $170 \mathrm{GWh}$ annually in Guadalajara and Monterrey.

The economic and financial analysis from national, utility, and customer perspectives shows that CFLs are economically feasible in Mexico for all actors involved as long as they last a certair: minimum number of hours. Due to subsidized residential electric tariffs (in particular to small users), it is also necessary for the utility company to share some of its benefits with the smallest users. Net present value of benefits to society were estimated at about 430 to 570 million dollars over the 7.6 years the CFLs would last.
Extrapolating the results to a Mexirs; wide program implies a technical potential of 50 million CFLs, equivalent to $4 \mathrm{GW}$ of capacity, 2.2 TWh annual generation savings, and a net national benefit of 1.1 billion dollars.

Future work will entail completing the analysis of survey data. Of particular interest will be the analysis of household appliance data for saturation and time-of-use. The appliance data will enable us to build daily time-of-use curves for the different electricity end uses in the homes of Guadalajara and Monterrey. We want to dissaggregate these results into three consumer classes according to their electric consumption levels, which will allow us to differentiate between customer classes and to propose electric efficiency programs that are particularly suited to each class. The spreadsheets developed will be used in the future to re-evaluate the economics of the llumex program, as field results start coming in and any assumptions that were imprecise are corrected.
Investigators

1. Sathaye

R. Friedmann

O. de Buen

A. Gadgil 
Projects described in this report were supported by the following sources:

- Assistant Secretary for Conservation and Renewable Energy, U.S. Department of Energy Deputy Assistant Secretary for Building Technologies, Office of Building Energy Research Deputy Assistant Secretary for Utilities Technologies, Office of Planning and Assessment Office of Codes and Standards

- Assistant Secretary for Fossil Energy, U.S. Department of Energy

Deputy Assistant Secretary for Coal Technology

- Assistant Secretary for Domestic and International Energy Policy, U.S. Department of Energy Associate Deputy Under Secretary for Policy Analysis, Office of Electricity/Coal/Nuclear, and Renewable Policy

Associate Deputy Under Secretary for Policy Analysis, Office of Environmental Analysis

- U.S. Environmental Protection Agency

Office of Policy, Planning, and Evaluation

Office of Policy Analysis, Division of Global Climate Change

- U.S. Agency for International Development, Office of Energy

- AB Volvo

- Bonneville Power Administration

- California Institute for Energy Efficiency

- Chevron

- Conocor

- Empire State Electric Energy Research Corporation

- Exxon USA

- LBL Laboratory-Directed R\&D Program

- New York State Energy Research and Development Authority

- Oak Ridge National Laboristory

- Pacific Gas \& Electric Company

- Rockefeller Family and Associates

- Shell Oil Company (Houston)

- Stockholm Environment Institute

- Swedish National Board for Industrial and Technical Development (NUTEK)

- Texas Governor's Energy Management Center through Texas A\&M University

This support was provided through the U.S. Department of Energy under Contract No. DE-AC03-76SF00098. 

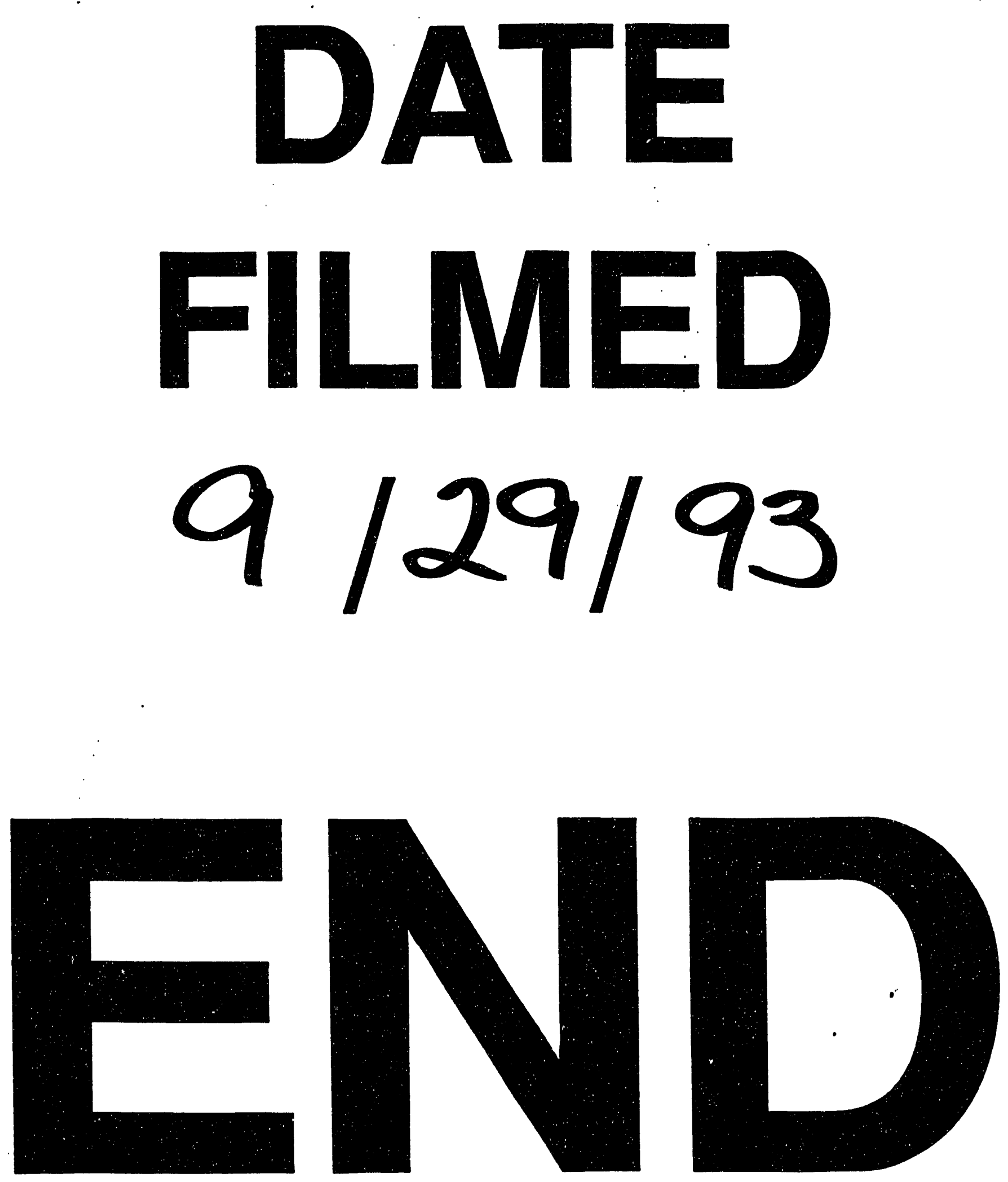
